\title{
Instituto Politécnico de Setúbal
}

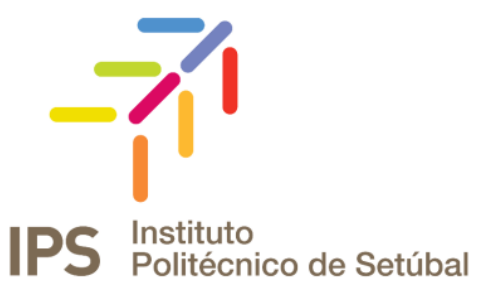

Escola Superior de Ciências Empresariais

\section{A Comunicação Interna na Guarda Nacional Republicana}

\author{
Fernando Carlos Rodrigues Pereira
}

Dissertação apresentada para cumprimento dos requisitos necessários à obtenção do grau de

MESTRE EM GESTÃO ESTRATÉGICA DE RECURSOS HUMANOS

Orientadora: Maria Odete de Almeida Pereira 

Aos meus queridos filhos Rodrigo e Patrícia e à minha extraordinária mulher Ana Paula...

...A todos os que acreditaram em mim...

...A eles dedico este trabalho. 


\section{Agradecimentos}

Quero agradecer às pessoas que de alguma forma contribuíram para a realização desta dissertação de mestrado, ao longo destes meses, assumindo desde logo, à partida, como de minha inteira responsabilidade quaisquer falhas ou omissões.

Em primeiro lugar quero agradecer especialmente à minha orientadora Professora Doutora Maria Odete de Almeida Pereira, pelas suas orientações, compreensão, motivação que me deu ao longo do trabalho e disponibilidade para orientar esta dissertação. Não posso deixar de referir, a sua extraordinária competência, as excelentes qualidades profissionais e o profundo conhecimento que tem, de áreas tão sensíveis, como o Comportamento Organizacional, Comunicação Interna e Recursos Humanos.

Um agradecimento muito especial ao Professor Doutor António José de Sousa Almeida, pelo incentivo, o apoio, o entusiasmo e a amizade manifestada durante a execução deste trabalho.

Agradeço também ao meu orientador da GNR, Gonçalo Nuno Silva Gonçalves de Carvalho, Major, Chefe da Divisão de Comunicação e Relações Públicas, pela disponibilidade e simpatia manifestada durante toda a prossecução da dissertação, bem como pelas sugestões e incentivos ao longo da sua elaboração.

Quero também aqui realçar, o meu profundo e sentido agradecimento à minha extraordinária amiga Rita Faroppa Silva e Sousa, de quem eu sinto um enorme orgulho por conhecer. Pela sua disponibilidade permanente, mesmo sacrificando o seu bemestar, pela sua generosidade, compreensão, motivação, entrega, paciência e força que sempre me deu para continuar. A ela, ser-humano perfeito, extremamente humilde e muito inteligente, agradeço do fundo do meu coração, pois sem ela, a entrega da dissertação não teria sido possível.

Igualmente uma palavra de apreço aos meus colegas de trabalho, especialmente à Dr. ${ }^{a}$ Maria João, da Divisão de Comunicação e Relações Públicas da Guarda Nacional Republicana, pela confiança que sempre me fizeram sentir. A todos os meus familiares e amigos, a certeza de que, apesar das minhas longas ausências e falta de atenção, nunca foram esquecidos.

Por fim, agradeço aos amores da minha vida, aos meus filhos Rodrigo (9 anos) e Patrícia (6 anos) e à minha mulher Ana Paula, pelo apoio que me deram nos bons e maus momentos e por terem suportado, durante todo o Mestrado, as minhas faltas de atenção para com eles. Reitero o agradecimento à minha extraordinária mulher, pelo amor, carinho e confiança que depositou em mim.

Pelas inúmeras dificuldades que encontrei, agradeço a DEUS, por me dar tanta força para continuar. 
"Cheio de Deus, não temo o que virá, Pois, venha o que vier, nunca será Maior do que a minha alma."

(Fernando Pessoa) 


\section{Resumo}

Num mundo cada vez mais complexo, caracterizado por incertezas, várias partes interessadas e conflitos entre os objetivos, as organizações têm necessidade de se adaptarem a novas realidades. Desta forma é necessário recorrer a vários meios, sendo a Comunicação Interna um ponto-chave para o sucesso organizacional, uma vez que, as organizações que apostam em bons sistemas de Comunicação Interna têm maior propensão em atingir melhores condições de planeamento estratégico, onde a informação flui com mais rapidez e facilidade.

Este trabalho consiste num diagnóstico da Comunicação Interna existente na Guarda Nacional Republicana, para a preparação de um eventual Plano de Comunicação Interna. Através da caracterização da perceção dos militares da Guarda sobre a Comunicação Interna, pretendeu-se apurar a importância da mesma, bem como a eficácia e utilização dos meios e instrumentos de comunicação na GNR.

Inicialmente foi efetuado um enquadramento teórico fundamentado em diversas obras bibliográficas e sítios da internet, no qual são descritos os aspetos de comunicação, comunicação organizacional e comunicação interna. A pesquisa de campo baseou-se na recolha de dados através da aplicação de questionários aos militares dos Comandos Territoriais da GNR, cujo tratamento dos dados obtidos foi efetuado com recurso às aplicações informáticas SPSS e Microsoft Excel, permitindo dar resposta à pergunta de partida formulada.

Baseados numa amostra de 241 inquiridos, os principais resultados obtidos a partir dessa amostra permitem concluir que os militares gostariam de obter mais informação sobre as mudanças na GNR, através de ações de formação. A comunicação mais valorizada é a que se estabelece entre colegas, verificando-se que os militares não se sentem muito à vontade para expressar as suas opiniões, sendo que os boatos são frequentes na instituição e de difícil desmistificação.

Assim, pretende-se que esta dissertação seja um precioso instrumento de trabalho, para ajudar a construir uma Comunicação Interna mais eficaz, tendo em conta as necessidades e os objetivos organizacionais da instituição.

Palavras-chave: Organização, Comunicação Interna, Informação e Eficácia. 


\begin{abstract}
In an increasingly complex world characterized by uncertainty, various stakeholders and conflicts between the goals, organizations need to adapt to new realities. Thus it is necessary to resort to various means, and the Internal Communication a key to organizational success, given that organizations that invest in good systems of internal communication are more likely to achieve better strategic planning, where information flows more quickly and easily.

This work consists of an analysis of existing Internal Communication in the National Guard, for the preparation of any Internal Communication Plan. Through the characterization of the perception of the military Guard on Internal Communication, was intended to determine the importance of it, as well as the effectiveness and use of media and communication tools in GNR.

Initially it was made a theoretical framework based on several bibliographical works and web sites, which are described in the aspects of communication, organizational communication and internal communication. The field research was based on data collected through questionnaires to the military territorial commands of the GNR, whose treatment of the data was performed using the SPSS software applications and Microsoft Excel, allowing you to answer the initial question asked.

Based on a sample of 241 respondents, the main results obtained from this sample can be concluded that the military would like to obtain more information about the changes in GNR, through training activities. Communication is the most valued established between peers, verifying that the military did not feel very comfortable expressing their opinions, and rumors are frequent in the institution and difficult demystification.

Thus, it is intended that this work is a valuable tool, to help build a more effective internal communication, taking into account the needs and organizational objectives of the institution.
\end{abstract}

Keywords: Organization, Internal Communication, Information and Effectiveness. 


\section{Índice Geral}

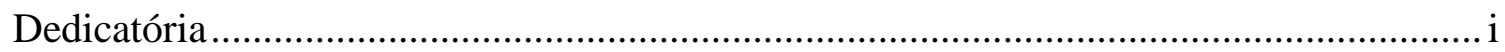

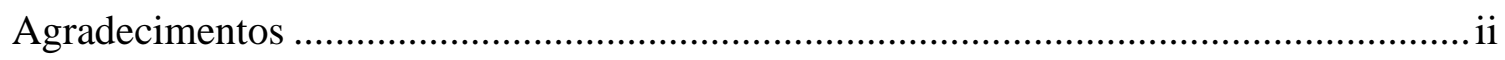

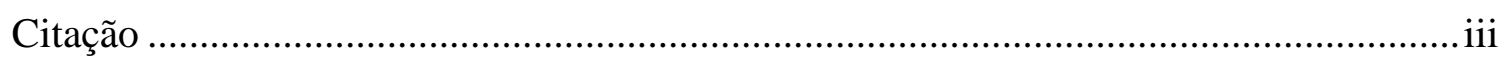

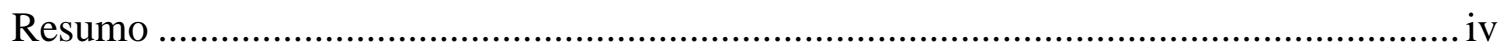

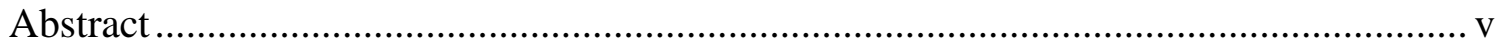

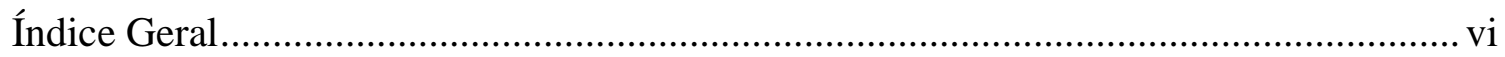

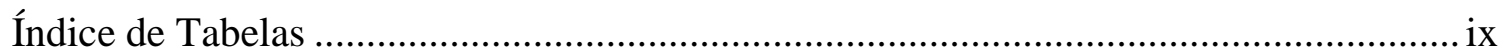

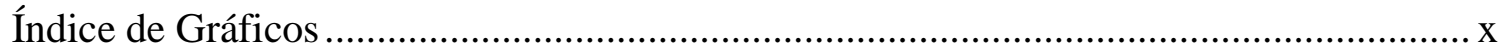

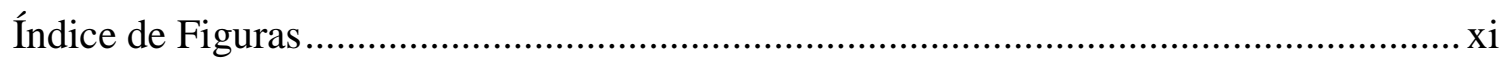

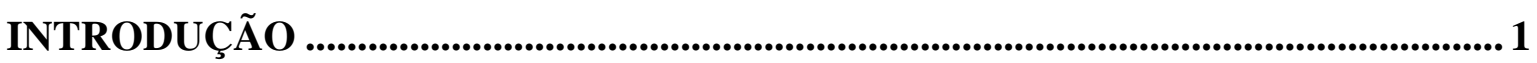

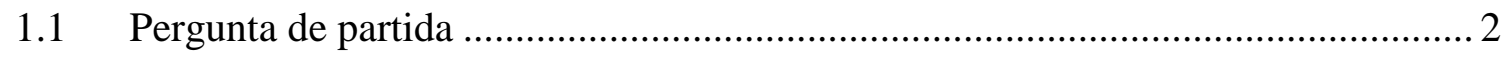

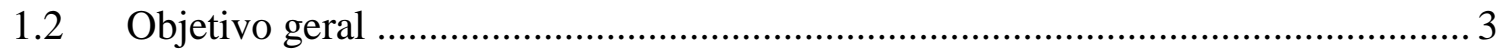

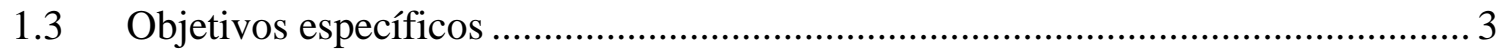

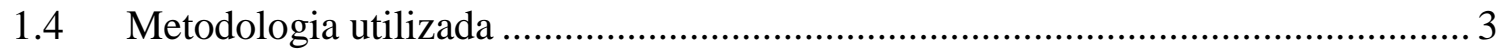

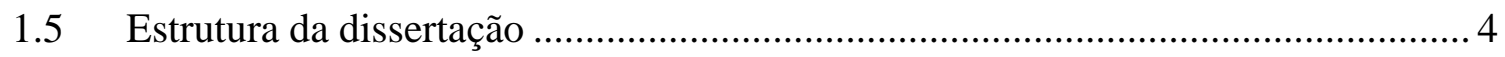

PARTE I - REVISÃO DA LITERATURA .......................................................................5 5

2.1 Comunicação Organizacional ........................................................................ 5

2.1.1 O papel da comunicação no contexto organizacional ................................... 5

2.1.2 A importância da Comunicação Organizacional ............................................ 6

2.1.3 A Comunicação nas Organizações ................................................................ 7

2.1.4 Funções da Comunicação na Organização ...................................................... 9

2.1.5 Tipos de Comunicação na Organização ....................................................... 11

2.1.6 Distinção entre comunicação e informação................................................ 12

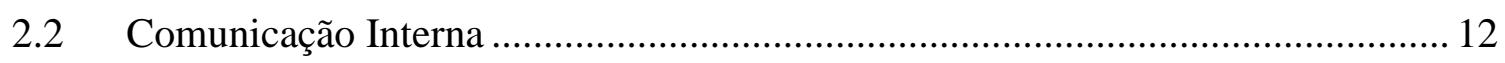

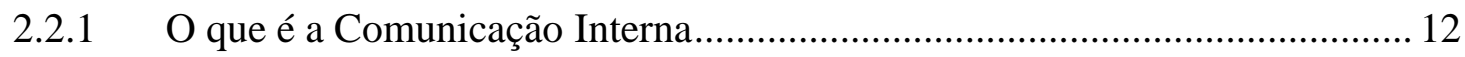

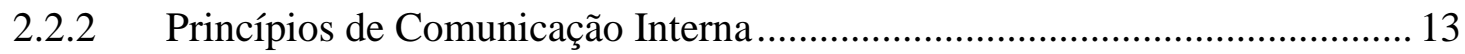

2.2.3 A importância da Comunicação Interna ......................................................... 15

2.2.4 Meios e instrumentos de Comunicação Interna............................................ 16

2.2.5 Fatores de Comunicação Interna ................................................................. 19

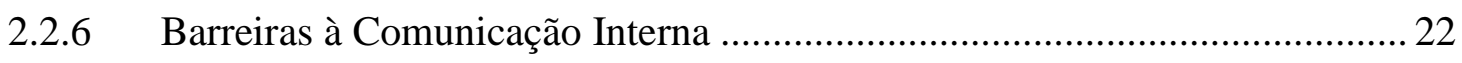


2.2.7 Comunicação interna como ferramenta estratégica no desempenho

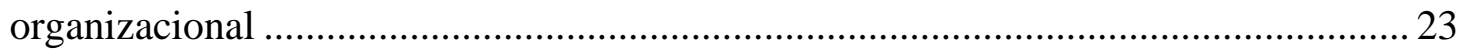

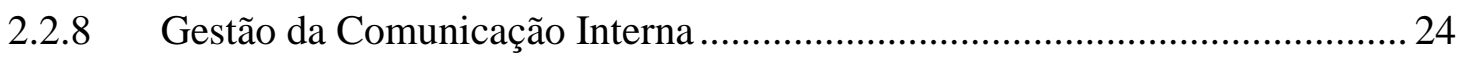

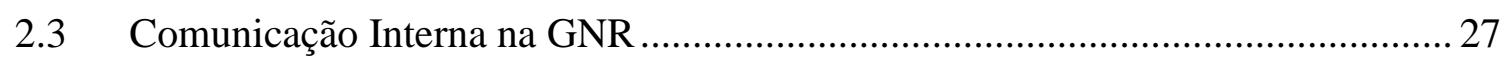

2.3.1 Meios e instrumentos de comunicação interna existentes na GNR ...............28

2.3.2 Análise SWOT à Comunicação Interna na GNR ………………................. 29

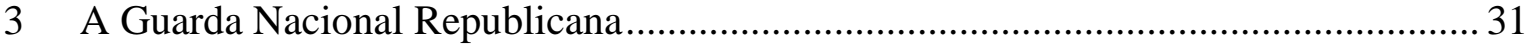

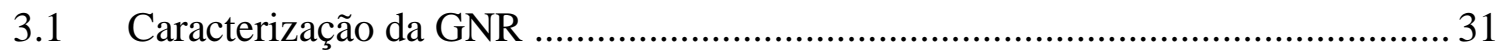

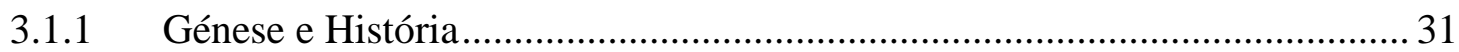

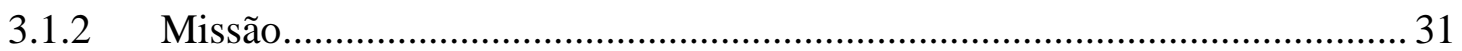

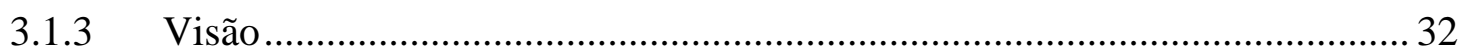

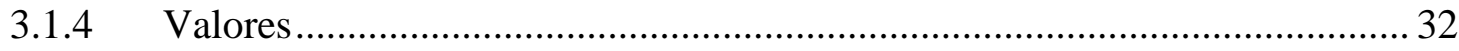

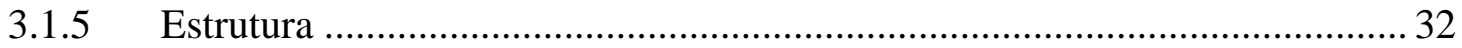

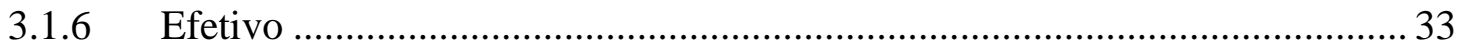

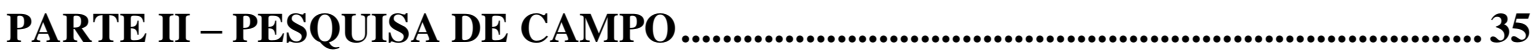

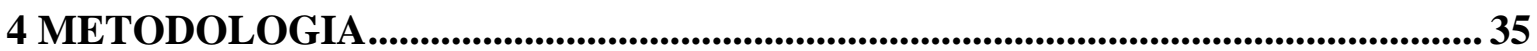

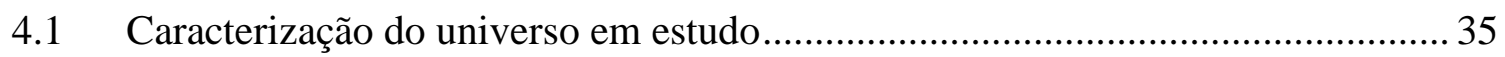

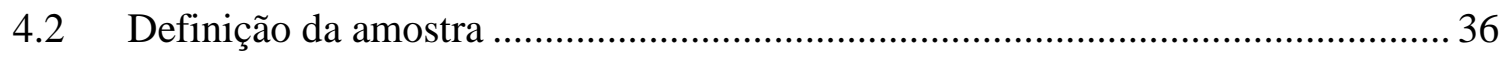

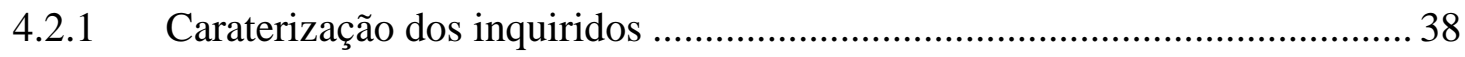

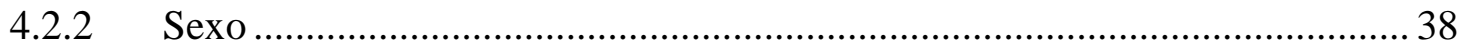

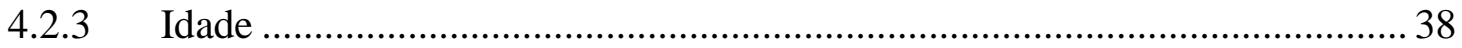

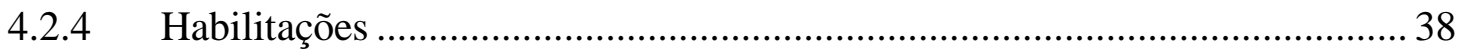

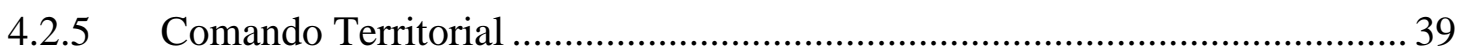

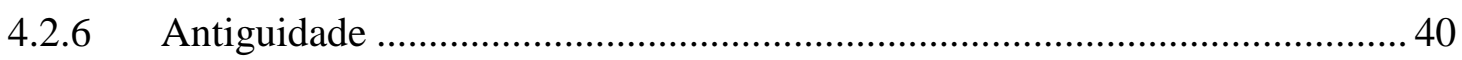

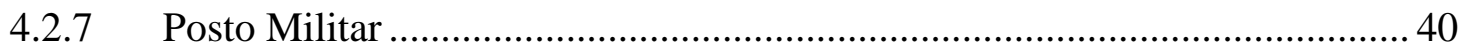

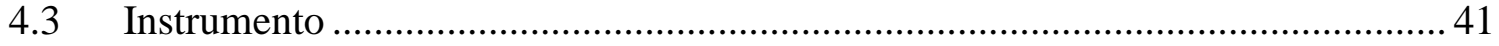

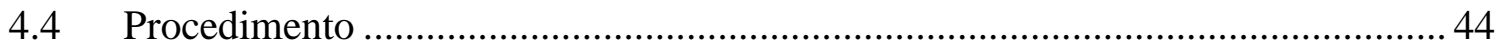

5 APRESENTAÇÃO E INTERPRETAÇÃO DOS RESULTADOS ............................... 45

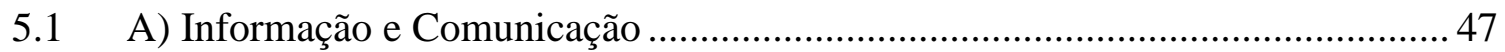

5.2 B) Meios e Instrumentos de Comunicação Interna................................................ 48

5.3 Influência das variáveis sociodemográficas nas dimensões de Comunicação e

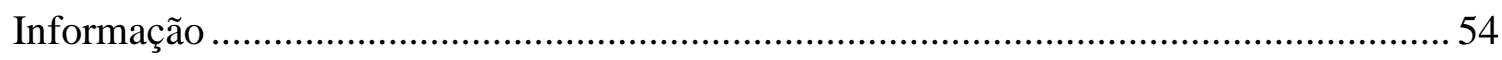


6 ANÁLISE E DISCUSSÃO DOS DADOS OBTIDOS ............................................ 62

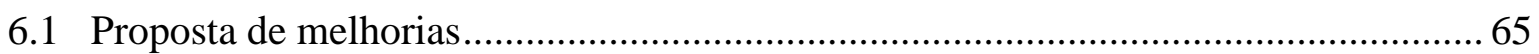

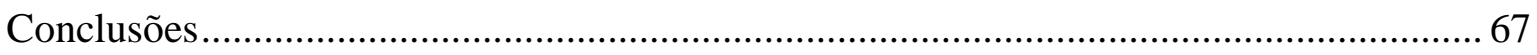

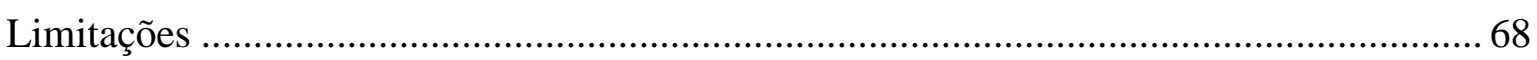

Referencias Bibliográficas .............................................................................................................. 70

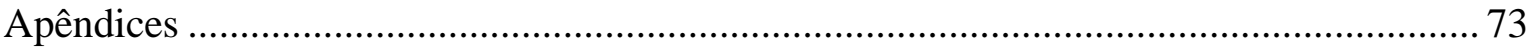

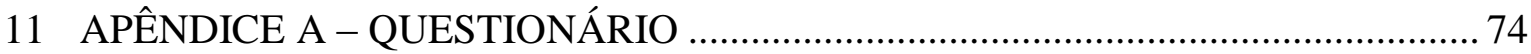

12 APÊNDICE B - Definição da Amostra - Caraterização dos inquiridos ..................... 81

13 APÊNDICE C - RESULTADOS - Médias e Desvios Padrão de cada dimensão ...... 87

14 APÊNDICE D - Resultados - Influência das Variáveis Sócio-demográficas nas

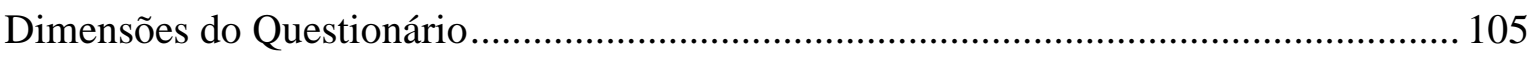

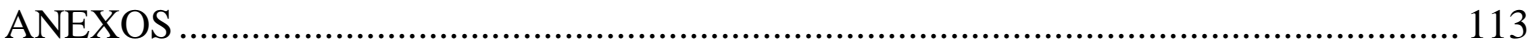

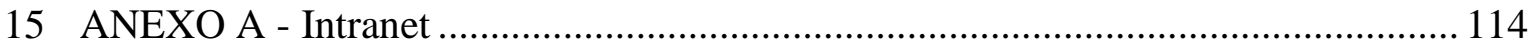

16 ANEXO B - Extratos da Lei Orgânica da Guarda Nacional Republicana................... 115

17 ANEXO C-Posição da Guarda Nacional Republicana no Sistema Nacional de

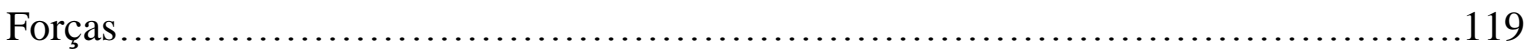

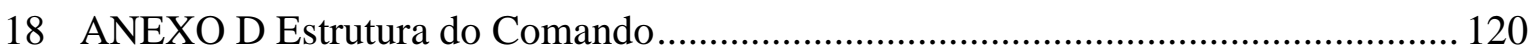

19 ANEXO E - Organograma Geral da GNR .......................................................... 121

20 Anexo F - Folheto de Informação Interna de 1974 .................................................... 122

21 ANEXO G - Dispersão e ocupação territorial dos postos da Guarda ......................... 123

22 Anexo H - Relação dos Comandos Territoriais e Postos da GNR estudados: ............ 124 


\section{Índice de Tabelas}

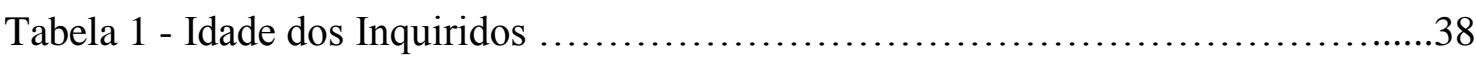

Tabela 2 - Estatísticas descritivas do Questionário de CI ...........................44

Tabela 3. Utilização dos Meios e Instrumentos de CI ..............................50

Tabela 4. Eficácia dos Meios e Instrumentos de CI .............................51

Tabela 5 - Diferenças de pontuações entre Sexos .................................55

Tabela 6 - Diferenças de pontuações entre Idades .................................55

Tabela 7 - Diferenças de médias entre idades .................................56

Tabela 8- Diferenças de pontuações entre níveis das Habilitações Literárias.............56

Tabela 9 - Diferenças de pontuações entre níveis de Comando Territorial ............ 57

Tabela 10 -Diferenças significativas entre níveis de Comando Territorial em três

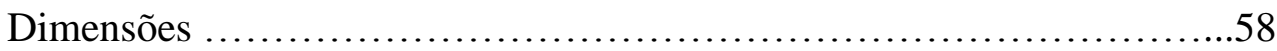

Tabela 11 - Diferenças de pontuações entre níveis de Antiguidade ...................59

Tabela 12 -Diferenças estatisticamente significativas entre a Antiguidade e o Clima de Comunicação ................................................60

Tabela 13 - Diferenças de pontuações entre o Posto Militar e as Dimensões ...........60

Tabela 14 - Diferenças estatisticamente significativas entre o Posto Militar e a Informação Geral na GNR ........................................61 


\section{Índice de Gráficos}

Gráfico 1 - Distribuição do efetivo militar pelas diferentes categorias profissionais .... 34

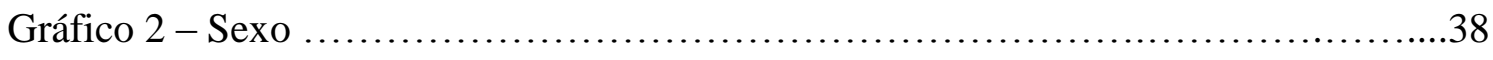

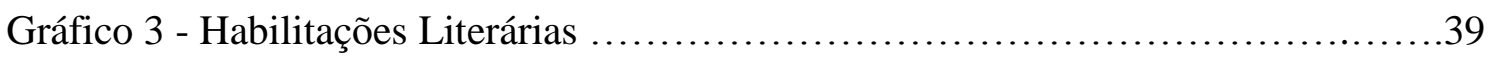

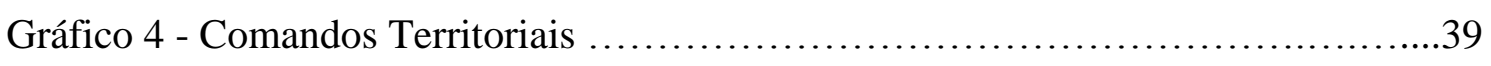

Gráfico 5 - Antiguidade dos militares da GNR ...............................40

Gráfico 6 - Posto Militar ..................................................... 41

Gráfico 7 - Médias e Desvios Padrão das respostas dos inquiridos .....................46

Gráfico 8. Meios de Comunicação Interna mais utilizados .......................... 49

Gráfico 9. Meios de Comunicação Interna mais eficazes ...........................51

Gráfico 10 - Meio mais adequado para a transmissão da Informação ..................52

Gráfico 11 - Assuntos a serem divulgados pela CI na GNR .......................53

Gráfico 12 - Conhecimento da existência de um serviço responsável pela CI na GNR.53 


\section{Índice de Figuras}

Figura 1 - Distintivos da categoria de Sargentos .................................. 36

Figura 2 - Distintivos da categoria de Guardas ................................. 36 


\section{INTRODUÇÃO}

No âmbito da estrutura curricular do Mestrado em Gestão Estratégica de Recursos Humanos, surge o presente trabalho de investigação, subordinado ao tema "Comunicação Interna na Guarda Nacional Republicana", para cumprimento dos requisitos necessários à obtenção do grau de Mestre em Gestão Estratégica de Recursos Humanos.

O Mestrado em Gestão Estratégica de Recursos Humanos visa contribuir para reforçar a profissionalização do campo da gestão de recursos humanos, através do desenvolvimento de conhecimentos e de competências em áreas estratégicas de ação procurando, simultaneamente, desenvolver a capacidade de participação na definição das estratégias organizacionais e na gestão autónoma de projetos e de equipas.

A escolha do tema "Comunicação Interna na Guarda Nacional Republicana" teve por base o local onde atualmente o investigador exerce funções, o Gabinete de Informação Interna da Guarda Nacional Republicana ${ }^{\mathbf{1}}$.

Os conhecimentos adquiridos e as competências desenvolvidas pelo investigador culminam na prossecução de um trabalho de investigação que poderá constituir-se como um instrumento útil de trabalho no contexto laboral do Gabinete de Informação Interna da GNR. Por conseguinte, esta dissertação afigura-se como uma mais-valia para a GNR, uma vez que poderá também contribuir para a perceção da visão e opinião dos militares da Guarda em relação à comunicação praticada no seio da Instituição.

A Comunicação Interna assume-se hoje como uma ferramenta cada vez mais importante para as organizações em geral e para a GNR em especial, onde a forma como a informação circula tem consequências a todos os níveis no funcionamento da instituição e na sua atividade operacional, condicionando a consecução dos objetivos organizacionais. A GNR exibe propriedades de uma organização formal, dirigida de acordo com normas estabelecidas de forma clara e rigidamente impostas, onde permanece a burocracia e o poder é distribuído numa hierarquia rígida, com nítidas linhas de autoridade. Por conseguinte, a comunicação descendente, dos superiores hierárquicos para os subordinados, é predominantemente específica e formalizada, através de objetivos e

1 Sediado na Divisão de Comunicação e Relações Públicas (DCRP) no Comando Geral da GNR, coordena a execução da informação pública e da comunicação interna. 
instruções, que por vezes originam necessidades e problemas que conduzem ao uso de feedback no âmbito da comunicação ascendente, a qual pode chegar aos escalões superiores (Ferreira et al., 2001).

Assim, para se compreender a importância da Comunicação Interna, na GNR, e para que esta flua de forma eficiente, no momento oportuno, de forma que seja atingido o objetivo pretendido, importa perceber quais as suas características.

Neste sentido, com este trabalho de investigação, pretende-se responder à pergunta de partida que formulamos no ponto seguinte, bem como à problemática dela decorrente.

\subsection{Pergunta de Partida}

A pergunta de partida inerente a este estudo e que constituiu o seu guia orientador foi: "Quais as características da Comunicação Interna na GNR."

No que diz respeito à problemática subsequente surgiram outras sub-questões, a que se procurou responder, nomeadamente:

- Quais as perceções dos militares acerca da Comunicação Interna na GNR;

- Quais as perceções dos militares sobre o papel das chefias e no que respeita à Comunicação Interna existente na GNR;

- Qual perceção dos militares sobre a importância da utilização dos meios de Comunicação Interna na GNR;

- Quais os meios e instrumentos de Comunicação Interna mais utilizados e por sua vez mais eficazes;

- Como é que as diferentes perceções, sobre a Informação que é transmitida internamente entre os militares da GNR, variam em função do Sexo, Idade, Habilitações Literárias, Comando a que pertence, Antiguidade ou Posto Militar (categoria); 


\subsection{Objetivo Geral}

A Comunicação Interna amplia a visão do trabalhador, dando-lhe um conhecimento sistémico do processo. As ações da instituição devem ter sentido para as pessoas, sendo necessário que encontrem no processo de comunicação as justificativas para o seu posicionamento e comprometimento.

Os trabalhadores devem ser considerados parceiros, e estarem sempre bem informados, pois assim estarão mais envolvidos com a organização e com a sua missão. Por conseguinte, o objetivo geral do trabalho é caracterizar a Comunicação Interna na GNR e tentar melhorar o processo de comunicação da corporação, através do uso de diferentes meios de comunicação, que mantenha os seus membros informados, integrados e motivados, de modo a contribuir com o seu trabalho, para o alcance dos objetivos organizacionais.

\subsection{Objetivos Específicos}

- Verificar a perceção que os militares da GNR têm sobre a importância da Comunicação Interna existente na GNR.

- Analisar se a Comunicação Interna satisfaz as necessidades do efetivo da instituição.

- Averiguar se os meios disponíveis são suficientes em número e em teor para manter o efetivo informado.

- Apurar quais os meios (tradicionais ou atuais) mais procurados para obtenção de informação.

- Compreender se a Comunicação Interna é um fator chave e estratégico que permite a integração e a motivação dos militares.

- Apresentar propostas de melhoria para a Comunicação Interna na GNR.

\subsection{Metodologia Utilizada}

A metodologia de pesquisa constitui a parte fundamental de qualquer trabalho científico, permitindo dar respostas às questões levantadas. Gil (1999) afirma que a pesquisa é um processo formal e sistemático de desenvolvimento do método científico. 
A metodologia de investigação seguida, em termos de procedimento técnico remete para um inquérito, através do levantamento de dados, com recurso a um questionário composto por oito dimensões de análise, aplicado a uma amostra de militares dos 20 Comandos Territoriais da Guarda Nacional Republicana.

A aplicação dos questionários foi efetuada através do Google Docs em que os inquiridos responderam através de um link. O último questionário aplicado, foi rececionado no final do mês de outubro de 2012.

Quanto à natureza, tipo de pesquisa e abordagem, a investigação é aplicada, descritiva e quantitativa.

A metodologia utilizada será caracterizada, em detalhe, na parte correspondente do trabalho.

\subsection{Estrutura da Dissertação}

A estrutura da dissertação, do ponto de vista formal, assenta em duas partes distintas:

$\mathrm{Na}$ primeira, a revisão de literatura sobre tema, onde são abordados e relacionados conceitos sobre comunicação, comunicação interna e sobre a instituição em estudo.

Na segunda, a realização do trabalho de campo efetuado através de uma investigação descritiva utilizando, conforme referimos, a análise quantitativa e a análise e discussão dos resultados obtidos. 


\section{PARTE I - REVISÃO DA LITERATURA}

\subsection{Comunicação Organizacional}

\subsubsection{O papel da comunicação no contexto organizacional}

A palavra Comunicação provém do latim "Comunicare" que significa "estar em contato com", todavia, o seu significado sofreu algumas alterações ao longo dos anos, estando atualmente mais ligado à transmissão, ou seja, significa difundir, transmitir, enviar ou fazer passar ideias de entidades para entidades (do emissor para o recetor), no espaço e no tempo (Almeida, 2003).

O mesmo autor, refere Charles Cooley (1991) para propor a definição de Comunicação, enquanto mecanismo pelo qual as relações humanas existem, contatam, percecionam, desenvolvem e criam significado.

Segundo Rego (2007:24), ”todos nós comunicamos, mesmo quando nada falamos ou escrevemos! Somos, por natureza, animais sociais, pelo que necessitamos de comunicar mesmo quando não temos nada de «relevante» a exprimir." Essa necessidade de comunicar é transposta naturalmente para as organizações, espaços onde desenvolvemos uma parte muito significativa das nossas vidas. Porque desejamos satisfazer necessidades pessoais e sociais, ou porque desejamos exercer as nossas funções organizacionais, comunicamos constantemente, falando, escrevendo, telefonando, reunindo, ouvindo, fazendo silêncios, adotando gestos, sorrindo ou vociferando, recebendo ou escrevendo mensagens eletrónicas, dando ordens ou escutando-as, reclamando ou mostrando satisfação, fazendo ou recebendo sugestões. Por conseguinte, a comunicação é, pois, uma condição sine qua non da vida social e da vida organizacional. Como refere Wiio citado por Rego (2007:25), “sem comunicação, não pode haver organização, gestão, cooperação, motivação, vendas, oferta ou procura, marketing ou processos de trabalho coordenados (...)", isto porque, uma organização humana é simplesmente uma rede comunicacional e se a comunicação falha, uma parte da estrutura organizacional também falha.

Os processos de comunicação e informação têm assumido um papel muito relevante no desenvolvimento das estratégias empresariais e na própria evolução das organizações. 
Vivemos na era da velocidade, a um ritmo acelerado com sucessivas mutações e contextos, onde as organizações precisam de pôr em prática novas lógicas de gestão para enfrentar a competitividade, numa tentativa de alcançar a melhoria contínua, a criatividade, a inovação, e a satisfação dos seus stakeholders ${ }^{2}$.

É através de uma comunicação clara, consistente, contínua e frequente, curta e rápida e completa que se estabelecem padrões de confiança.

A comunicação tem um papel fundamental nos ambientes organizacionais pois, é pelos processos comunicacionais que as organizações, como sistema social, realizam a sua autoconstrução. É pela comunicação que podemos conhecer a cultura e a identidade de uma organização (Luhmann, 2007).

\subsubsection{A importância da Comunicação Organizacional}

A importância de comunicar resulta da necessidade, que o ser humano tem, de recorrer à interação social para alcançar determinados fins. Neste sentido torna-se vital que a comunicação seja eficaz a todos os níveis de uma organização, assegurando assim que esta funcione eficazmente e atinja os seus objetivos. Segundo Cushway et. al. (1998) a comunicação tem os seguintes objetivos: Partilhar informação; Considerar ideias; Transmitir e trocar opiniões; Transmitir sentimentos.

Rego (1999), destaca algumas leis da comunicação que não se assumem como leis universais mas sim leis de orientação, suscetíveis de contribuírem para a eficácia organizacional. Segundo o autor estes princípios orientadores deverão ser os seguintes: o emissor deve ser congruente com a mensagem a transmitir, a comunicação é tanto mais eficaz, quanto mais importante e apropriado for o seu emissor para a transmissão da mensagem, e tão mais difícil, quanto maior for a quantidade de recetores e a sua heterogeneidade. Também as mensagens mais simples e mais vezes repetidas têm maior probabilidade de serem compreendidas e memorizadas.

O conteúdo de uma mensagem vai alterando à medida que esta é retransmitida de pessoa para pessoa. As pessoas têm tendência para memorizar mais facilmente as

2 Stakeholder - (parte interessada ou interveniente), é um termo usado em diversas áreas como administração e arquitetura de software referente às partes interessadas que devem estar de acordo com as práticas de gestão corporativa executadas pela empresa. Ou seja, compreende todos os envolvidos num processo, que pode ser de caráter temporário (como um projeto) ou duradouro (como o negócio de uma empresa ou a missão de uma organização. 
mensagens no início e no fim de um discurso organizacional. $\mathrm{O}$ recetor tem uma capacidade de perceção superior à do emissor e quando uma mensagem ou pessoa não agradam aos recetores estes podem rejeitar a mensagem (Rego, 1999).

Luiso (2003), considera que a sociedade não funcionaria adequadamente se não existisse comunicação, uma vez que, a interação entre o Homem e o que o rodeia subentende a mediação de informações que são comunicadas. Da mesma forma, uma organização só pode assegurar a sua sobrevivência utilizando a comunicação como forma privilegiada e cuidada de interação com a envolvente interna e externa.

Para Nelson (2003), “A dimensão da empresa não importa - a Comunicação tem de ser o seu alicerce". Fazendo uma analogia com o corpo humano, a Comunicação é o sangue que corre nas veias de qualquer organização, sendo função essencial dos gestores e elemento crucial para o crescimento e sobrevivência no mundo atual, cada vez mais globalizado. Nesta linha de raciocínio, a comunicação organizacional surge como uma necessidade para organizar a informação, de modo a questionar e mesmo, a desafiar, a estratégia de uma organização, contribuindo para um processo de autoavaliação e melhoria contínua. Assim, a informação tem de estar integrada e alinhada com a estratégia da organização (Drucker, 2008).

A Comunicação surge assim, como elemento essencial para garantir uma perceção favorável e em simultaneidade com os valores e realizações da organização. Como refere (Lindon et al., 2004:355), “A imagem de uma empresa é o resultado de múltiplas ações de comunicação e desempenha um papel fundamental no alcance dos seus objetivos”.

\subsubsection{A Comunicação nas Organizações}

Hoje em dia vivemos numa sociedade que, cada vez mais, é movida pela comunicação. Este fenómeno faz com que não baste apenas às empresas serem eficientes, tendo estas também que mostrar essa eficiência, uma vez que atuam num ambiente muito competitivo.

Neste sentido, a comunicação revela-se um indispensável instrumento de gestão. Ao nível interno, a comunicação coopera na gestão através da troca de informações, na determinação da estratégia e na tomada de decisões. Ao nível externo, a comunicação pode melhorar a imagem da empresa em duas vertentes: valorizar a imagem dos colaboradores 
que se sentirão motivados pelo orgulho de pertencer à organização e contribuir para aumentar a transparência da mesma (Almeida, 2003).

A comunicação empresarial tornou-se fundamental para a integração da empresa num contexto dominado pela heterogeneidade de opiniões de vários públicos. A integração é alcançada com o reconhecimento da necessidade de coerência entre todas as mensagens e as informações que são expedidas pelas empresas (Almeida, 2003).

A comunicação é o suporte das funções da gestão, isto é, os gestores das empresas carecem de informação para a realização dos seus planos, planos estes que têm de ser comunicados para serem realizados. Neste contexto, a comunicação motiva os trabalhadores, influência potenciais investidores, entidades oficiais e influência indiretamente a área das vendas de produtos ou serviços (Stoner, 1985).

O mesmo autor defende ainda que a sobrevivência das empresas depende intimamente da sua capacidade de comunicar, isto é, da notoriedade e da imagem que conseguem obter. Isto porque, a empresa não vende unicamente produtos, também cria uma identidade, uma alma no mercado face a públicos que esperam o desempenho de novas funções. A comunicação tem então a missão de posicionar a organização, dando-lhe uma identidade única. É também um instrumento de gestão, pois, serve para melhorar o desempenho organizacional, aumentando a eficiência e eficácia e promovendo o crescimento da empresa (Stoner, 1985).

Para Thévenet (1988) a comunicação na empresa é uma vontade, crença e uma necessidade. Os gestores das empresas expressam a vontade de ter uma política bem definida de comunicação interna, uma crença de que com essa política os problemas de comunicação serão resolutos, e uma necessidade da existência de comunicação para a coordenação das atividades e qualidade do clima organizacional.

Em suma, a comunicação é vital para o sucesso da organização, como referem (Hawabhay et al., 2009, p.4) "Communication that builds relationships of trust and accountability among people is vital to the success of an organization. For that matter, it is essential that management address the efficacy of its communication platform and allow communication managers to play a strategic role at the macro organizational level by interpreting strategic issues and providing strategic guidance with regards to stakeholder communication." 


\subsubsection{Funções da Comunicação na Organização}

Para os gestores e restantes membros das organizações, o exercício das suas funções não seria devidamente desenvolvido sem uma boa comunicação no seio destas. Vários autores sintetizam as funções da comunicação no seio das organizações, dos quais apresentaremos as funções consideradas por Brault (1992).

Para Bilhim, (1996), a importância da comunicação reside no facto de esta cumprir quatro grandes funções:

- Formal e informalmente, conduz o comportamento dos membros da organização;

- Esclarece os trabalhadores sobre o que estes devem fazer e ao dar-lhes feedback do grau da sua realização, acaba por motivá-los;

- Dá a informação imprescindível à tomada de decisão;

- Vai ao encontro das carências de afiliação que todo o ser humano tem.

De acordo com Rego (1999), a comunicação organizacional tem as seguintes proficuidades:

- Permitir aos gestores interagir com superiores, subordinados, colegas, sindicatos, fornecedores, clientes, entre outros;

- Facultar aos gestores a aquisição de informação junto dessas entidades (por exemplo, permite-lhes acompanhar as mudanças no ambiente externo);

- Permitir-lhes difundir as informações obtidas junto das entidades pertinentes (avisos, comunicados, ordens de serviço, planos e diretrizes de trabalho) e tomar decisões;

- Facilitar a coordenação do trabalho dos diversos membros organizacionais, e permitir-lhes estarem informados sobre os assuntos e orientações organizacionais;

- Permitir aos subordinados emitir as suas opiniões, propostas e reclamações, aos seus superiores;

- Possibilitar a realização de reuniões, sejam elas para tomar decisões, partilhar informações ou ouvir opiniões; 
- Incrementar o envolvimento das pessoas na organização;

- Funcionar como fator de interação e integração social.

Já Brault (1992), destaca as seguintes funções da comunicação:

A função informativa tem o objetivo de transmitir o conhecimento da organização. Esta função é fundamental, e a sua influência é importante para não conduzir a mal entendidos, provenientes de uma informação deficiente;

A função de integração tem como intuito introduzir e desenvolver nos trabalhadores da organização o sentimento de pertença a um grupo. É uma função indispensável que transmite os valores essenciais da empresa ao público interno e externo;

A função retroação possibilita o diálogo entre os trabalhadores dos vários níveis hierárquicos da organização, fazendo da comunicação uma relação de retorno. É através dela que o público interno expõe o seu descontentamento ou satisfação;

A função sinal dá a conhecer a imagem da organização através de logótipos, cores, discursos, palavras-chave, comportamentos, atitudes e valores. A ligação sólida destes elementos transmite a cultura de organização;

A função mudança proporciona a mudança de imagem, das mentalidades, das atitudes e das relações. No interior da organização, motiva os colaboradores, cria retroação e modifica as relações.

A função imagem tem o intuito de transmitir ao público interno e externo uma imagem favorável da organização.

Pode-se concluir que na proposição apresentada por Bilhim, (1996), a comunicação conduz ao comportamento dos membros da organização e leva à resolução de carências e problemas dos trabalhadores.

Na proposta de Rego (1999), a comunicação leva à coordenação do trabalho dos diversos membros organizacionais, desde os superiores aos subordinados, permitindo uma interação transversal a todas as categorias da organização.

Já para Brault (1992), a comunicação permite que os trabalhadores, através da informação que recebem, tenham mais possibilidades de tomarem decisões. Estas propostas são muito semelhantes, pois em todas elas, a partilha de informação e a interação entre todos os membros de uma organização conduz a uma boa Comunicação Interna. 


\subsubsection{Tipos de Comunicação na Organização}

A comunicação organizacional representa um conjunto de diferentes tipos de comunicação. Almeida (2003) refere que a comunicação comercial, a comunicação financeira, a comunicação institucional e a comunicação interna são instrumentos fundamentais de gestão global:

Comunicação Comercial: constituída pela Publicidade e Marketing;

Comunicação Financeira: representa a gestão da informação e as relações que estabelece com os seus públicos da área financeira;

Comunicação Institucional: define a legitimidade económica, social, política e cultural da organização. Tem como objetivo expressar os valores e a ideologia da organização, dandolhe uma orientação social;

Comunicação Interna: É o processo comunicativo através do qual, se cria, desenvolve e evolui a entidade da organização. Possibilita o esclarecimento de todos os trabalhadores e a criação de relações, entre eles, no interior da mesma, facilitando a produção, circulação e gestão da informação;

Segundo Lampreia (1992), a comunicação na organização é dividida em duas áreas distintas:

A comunicação de marketing, que comunica um produto, serviço ou marca;

A comunicação empresarial que comunica a empresa propriamente dita.

Estas duas áreas de comunicação utilizam os mesmos meios e técnicas, embora com objetivos diferentes e bem definidos. A comunicação de marketing tem o objetivo de disseminar e promover os produtos, serviços ou marcas e a comunicação empresarial pretende a divulgação da imagem da organização como entidade que integra um corpo social que tem direitos, deveres e obrigações.

O importante na comunicação organizacional é a própria imagem da organização que deve ser difundida através dos meios que esta dispõe. Apesar de, a comunicação de marketing influenciar a comunicação organizacional, o inverso acontece com mais regularidade, interferindo com todas as outras formas de comunicação. 


\subsubsection{Distinção entre comunicação e informação}

Comunicação e informação são dois conceitos muitas vezes confundidos numa perspetiva de Comunicação Interna, partindo-se do princípio que ao gerir a informação se gere a comunicação. Assim, é necessário distinguir os conceitos de informação e de comunicação. A informação assenta ao nível dos conteúdos no processo de comunicar, enquanto a comunicação consiste num conceito mais amplo que não está dependente da informação, ou seja, é o processo de transmissão. A falta de informação não significa necessariamente a falta de comunicação, mas, a falta de comunicação implica a não transmissão da informação (Almeida 2003).

Uma das grandes diferenças entre os conceitos, é que na presença de um processo de informação o emissor não recebe qualquer tipo de retorno, sendo que o destinatário não tem a possibilidade de fornecer feedback. Num processo de comunicação o feedback é uma constante, podendo o recetor tornar-se emissor e vice-versa num processo de interação contínua (Almeida 2003).

Em síntese, podemos dizer que "A comunicação é como um processo de transmissão, enquanto a informação é o objeto desse processo", e que, "A comunicação é um estado, enquanto a informação é, antes de tudo, um conteúdo" (Almeida 2003).

\subsection{Comunicação Interna}

\subsubsection{O que é a Comunicação Interna}

Num mundo cada vez mais globalizado, a importância dada ao conhecimento e à informação tem vindo a aumentar consideravelmente. O rápido crescimento das organizações fez com que estas desenvolvessem novas tecnologias de informação e comunicação para controlar os fluxos de dados e repensassem as suas estratégias e formas de gestão. Todas as mutações sociais, económicas e políticas originaram um novo relacionamento entre a administração e os trabalhadores. O bom relacionamento com os trabalhadores e a fluidez de comunicação passaram a ser encarados como fundamentais para o envolvimento, comprometimento e alcance dos objetivos organizacionais. Por conseguinte, a comunicação interna ganhou o seu espaço, ganhou valor e tornou-se o canal 
que liga diretamente a organização aos trabalhadores. A Comunicação Interna fomenta a participação e o envolvimento de todas as pessoas em todos os processos da organização.

Segundo Westphalen (1992), a Comunicação Interna abrange todos os atos de comunicação que têm origem na organização e que variam nas modalidades em que são utilizados, nos instrumentos de veiculação e nas funções que desempenham. Têm como objetivo principal estimular e manter informados os trabalhadores de uma organização.

Almeida (2003) define Comunicação Interna como um processo pelo qual se desenvolvem e se regulam as relações, não só entre pessoas do ponto de vista físico, mas essencialmente, entre as mesmas e a organização enquanto pessoa moral. Para o autor a Comunicação Interna, é antes de mais uma forma inteligente de administração. A organização é vista como uma identidade criadora de um discurso próprio, onde ela é emissora, recetora e objeto do seu próprio discurso.

Em suma, a Comunicação Interna é uma ferramenta estratégica para a harmonização dos interesses dos trabalhadores, através do incentivo ao diálogo, à troca de informações, de experiências e à participação de todos os níveis. O objetivo primordial da comunicação interna é fomentar a máxima integração entre os trabalhadores e a organização que representam (Kunsch 1995).

\subsubsection{Princípios de Comunicação Interna}

Uma organização deve reger-se por certos princípios para desenvolver as suas mudanças internas e alcançar os seus objetivos organizacionais. Esses princípios apareceram como resposta às dificuldades encontradas na realidade empresarial sendo a sua aplicação facilitadora do desenvolvimento da Comunicação Interna.

Dupuy (cit. por Ramos, 1997) apresenta doze princípios fundamentais para o desenvolvimento da Comunicação Interna:

Lucidez: Assenta na necessidade de adaptação a um público específico, aos seus valores e cultura. A empresa tem de se conhecer antes de se dar a conhecer e definir os seus fins;

Vontade: traduz-se em estabelecer um serviço de comunicação e o respetivo orçamento. A aplicação deste princípio atribui à comunicação um papel importante na gestão e na condução do negócio; 
Transparência: este princípio opõe-se ao hábito do secretismo para as informações em geral, exceto no caso de informações que podem ser usadas pela concorrência. Para se aplicar este princípio é preciso racionalizar em termos de análise de objetivos e resultados organizacionais. Toda a informação desfavorável à empresa deve ser imediatamente divulgada para evitar que apareçam rumores alarmistas. Assim, torna-se mais vantajoso a organização pôr um problema que escondê-lo;

Simplicidade: A comunicação deve permitir que todos os trabalhadores compreendam as mensagens de forma clara. As mensagens devem ser simples e acessíveis e os suportes devem ser adequados à mensagem a transmitir;

Rapidez: a rapidez de difusão da informação garante o interesse do recetor, evita a formação de rumores e evita que os trabalhadores sejam informados em primeiro lugar, pelos meios exteriores à organização, em vez de serem informados por ela;

Duração: A duração da comunicação numa organização deve apresentar uma certa permanência sem prejuízo dos resultados rápidos. A comunicação com os trabalhadores assenta num processo evolutivo e irreversível em que a organização e os seus membros se envolvem. Segundo este princípio, os suportes de Comunicação Interna devem evoluir para que os seus destinatários não os achem fastidiosos;

Tenacidade: este princípio pressupõe que uma mensagem, para ser compreendida, deve ser veiculada em todos os instrumentos de comunicação existentes na organização;

Realismo: A comunicação permite compreender melhor a organização, faz evoluir lentamente as atitudes, cabendo aos trabalhadores mudar o seu modo de relacionamento;

Adaptação: este princípio tem por base a cultura da empresa. Segundo este princípio, as publicações devem ser ajustadas às necessidades dos trabalhadores, tendo por base a cultura existente e não as estruturas estabelecidas;

Envolvimento: Baseia-se na escuta e na troca de impressões com os trabalhadores, na afirmação de uma transparência real, sem manipulações, traduzindo-se não só pela presença do discurso da direção em todos os suportes de comunicação mas, também, pela transmissão do discurso dos trabalhadores nos suportes de comunicação ascendente;

Sedução: A Comunicação Interna deve seduzir para poder chamar a atenção e estimular o interesse e persuadir. A organização deve aplicar este princípio na comunicação com os seus colaboradores, como aplica com os seus clientes na venda dos 
seus produtos, porque eles conhecem a comunicação que a organização estabelece com o grande público, da qual são também destinatários;

Antecipação: A organização tem de estar preparada em termos de comunicação, para poder responder prontamente aos possíveis acontecimentos, às mudanças que nela decorrem e às reações dos trabalhadores.

\subsubsection{A importância da Comunicação Interna}

Hoje em dia, dentro das organizações, não basta apenas ter um conjunto de grandes talentos altamente motivados. Se eles não estiverem bem informados e não se comunicarem adequadamente, não será possível potenciar a força humana da organização.

A Comunicação Interna nem sempre foi valorizada ou reconhecida como de vital importância para o desenvolvimento e sobrevivência das organizações. Todavia, na era da informação, quando a tecnologia é utilizada no processamento de dados e a transformação desses dados em informações prontas para serem usadas nas tomadas de decisões, representam uma oportunidade valiosa na melhoria do processo de comunicação, a Comunicação Interna eficiente, assume uma notável importância para a troca de informações.

Para Westphalen (1992), a aplicação da Comunicação Interna na prática diverge de organização para organização, mediante os valores, a tradição e própria política da empresa. A Comunicação Interna assume um papel de extrema importância, na medida em que são os trabalhadores que fomentam a organização. Por conseguinte, se os trabalhadores estiverem satisfeitos e identificados com a sua organização, irão trabalhar com mais eficiência, estarão mais motivados e, por isso, mais propensos a interiorizar e adotar como seus os princípios fundamentais da organização. Deste modo uma boa comunicação exerce um efeito positivo sobre o ambiente interno e, consequentemente, sobre a imagem global da organização. Para a construção de uma imagem coerente, a Comunicação Interna deve ser prioritária, ou seja, as mensagens que a organização quer difundir, devem ser dirigidas em primeiro lugar ao seu público interno. 


\subsubsection{Meios e instrumentos de Comunicação Interna}

As organizações devem desenvolver mecanismos de Comunicação Interna eficazes para manterem os trabalhadores bem informados sobre os assuntos que lhes dizem respeito e à empresa. Por conseguinte, uma Comunicação Interna eficaz implicará sempre meios eficazes e utilizados corretamente. Neste sentido, é importante ter em atenção os meios e instrumentos a utilizar na Comunicação Interna, conhecer as suas limitações e potencialidades. Para uma maior rentabilização desses meios e instrumentos da Comunicação Interna, deve saber-se o que comunicar, tendo em conta os objetivos que se pretendem atingir (Clampitt, 1991).

Para Almeida (2003), os meios de comunicação interna são: a Comunicação Oral, a Comunicação Escrita e Audiovisuais. Para além destes, existem ainda as Novas Tecnologias de Informação, cada vez mais importante para as empresas, como nova forma agregadora de outros meios e instrumentos.

\subsubsection{Comunicação oral}

A comunicação oral caracteriza-se por ser direta e económica, já que se destina a um número reduzido de pessoas. Esta comunicação privilegia o contato pessoal, aproximando fisicamente as pessoas. Contudo, é imprecisa, existindo o risco de deturpação da informação no momento em que a mensagem é transmitida, pelo que deve, na maioria dos casos, ser sempre acompanhada por um suporte escrito (Westphalen, 1992).

Este tipo de comunicação permite a partilha de conhecimentos e ideias de forma interativa e à elaboração de uma linguagem comum. Dentro das organizações esta comunicação pode encontrar-se na forma de informações de contato ou entrevistas individuais e coletivas ou conversas informais e formais, conferências, grupos de expressão, ações de formação, reuniões e brainstorming (Almeida, 2003).

Clampitt (1991) preconiza alguns instrumentos de comunicação oral que podem ser utilizados na Comunicação Interna:

Reunião: este instrumento estabelece a comunicação nos dois sentidos de uma ou mais mensagens e aproxima as chefias e subordinados;

Discurso: é um instrumento de comunicação oral descendente que permite para além de um contacto direto entre os intervenientes, o relacionamento pessoal entre estes; 
Face-a-face: é o meio de comunicação mais rico, pois engloba sugestões vocais, visuais, movimentos corporais, linguagem e cheiro. No entanto é também um meio suscetível a equívocos, pois transmite emoções e sentimentos;

Telefone: substitui a comunicação face-a-face, porém é menos rico, uma vez que não engloba a transmissão de informação visual.

\subsubsection{Comunicação Escrita}

A transmissão de ideias através da escrita vem de uma tradição latina que bem potencializada pode servir para transmitir ordens, publicar resultados, estabelecer contactos, motivar e até conhecer melhor os trabalhadores. Se este tipo de comunicação não for bem utilizado, poderá causar excessiva burocracia, gastos desnecessários, perdas de tempo e consequentemente desmotivação (Almeida, 2003).

Qualquer pessoa pode escrever, por isso, este modo de comunicação é "imediata", "tradicional" e é "rica", uma vez que, proporciona uma difusão rápida para um elevado número de pessoas. Este tipo de instrumento serve como prova do que foi transmitido. Porém, existem algumas desvantagens, pois a comunicação escrita pode ser "enganadora" e perigosa, considerando que poderá haver tendência para sobrecarregar os trabalhadores com informações escritas. No entanto, apesar destas desvantagens pode-se afirmar que esta forma de comunicar é muito positiva, visto que é menos dispendiosa, tem uma difusão ilimitada e pode ser utilizada por todas as organizações, seja qual for a sua dimensão. Todavia, deve ser usada com cautela, ou seja, sem excessos (Westphalen, 1992).

Segundo Crable \& Vibbert (cit. por Ramos, 1997), descrevem vários instrumentos de comunicação escrita, como:

Cartas: que têm como principal objetivo a explicação de situações e intenções, divulgação de projetos importantes para a organização;

Cartas de Integração: que têm a finalidade de envolver e integrar os trabalhadores nas atividades fazendo-os sentir parte da empresa;

Material de referência; Relatórios; Folhetos, Boletins e Brochuras: são uma forma de transmitir com celeridade pontos de vista da direção aos trabalhadores, como por exemplo: segurança, qualidade e campanhas temáticas; 
Quadro informativo (Placard): é muitas vezes utilizado para informações sobre direitos e deveres, saúde, segurança, tempos livres e desporto, sendo um dos meios mais tradicionais de comunicar com os trabalhadores.

Para Almeida, (2003), são entre outros, instrumentos deste meio de comunicação: a nota de serviço, o flash de informação, o placard no local de trabalho, o relatório reunião/atividade, o panfleto/atividade, o folheto de acolhimento, a carta ao pessoal, o inquérito de opinião, a caixa de sugestões, a revista ou jornal interno da organização e o correio interno.

\subsubsection{Audiovisuais}

Este tipo de meio de comunicação complementa o ditado popular "mais vale uma imagem do que mil palavras", pois conjuga palavras e imagens. É um instrumento cada vez mais utilizado pelas organizações, por exemplo em vídeos institucionais, onde é transmitida a Missão, a Visão e os Valores da organização, aos trabalhadores ou aos clientes/fornecedores. Neste sentido, a organização planeia criar e partilhar, vários vídeos discutindo dados financeiros, grandes ganhos, experiências de consumidores, anúncios e estratégias, reconhecimento de departamentos e/ou trabalhadores. Este nível de transparência permitirá que os trabalhadores estejam informados e motivados para realizarem o seu trabalho (Hood, 2009).

A comunicação audiovisual harmoniza o uso de imagens e sons para despertar os sentidos dos destinatários. Obriga a que os trabalhadores estimulem a imaginação e a construção de realidades, desenvolvendo capacidades de reação quer em termos físicos quer em termos de raciocínio. Assim, pode recorrer-se a filmes de informação, teleconferências ou jornal por telefone que representa um boletim de informação gravado e renovado periodicamente num aparelho de banda ou disco (Almeida, 2003).

\subsubsection{Novas Tecnologias de Informação}

Num mundo cada vez mais globalizado, as organizações recorrem frequentemente às novas tecnologias, para fazer face à gestão da infinidade de informação que têm disponível. O desenvolvimento tecnológico permitiu a criação de ferramentas capazes de combinar os diversos instrumentos de comunicação, potenciando as suas possibilidades através da combinação das técnicas informáticas, áudio, visuais e de telecomunicações. Estas ferramentas fazem com que as trocas de informação caracterizem as atividades em 
que os elementos de uma organização participam, proporcionando um aumento significativo da informação (Almeida, 2003).

Porém, segundo Penela (1999), é fundamental conhecer como é utilizada e interpretada essa informação, bem como equacionar a utilização dessas ferramentas em função do grau de aceitação dos seus utilizadores.

Almeida, (2003), refere como instrumentos de novas tecnologias de informação a intranet $^{\mathbf{3}}$, que é um meio de comunicação cada vez mais utilizado e que utiliza a mesma tecnologia que a internet. $\mathrm{O}$ acesso à intranet é restrito aos trabalhadores da organização. Esta rede tem inúmeras vantagens na sua utilização como: informação disponível de forma simples e acessível; sendo uma rede interna, também permite comunicar através da internet; como agrega sistemas operativos, toda a informação é atualizada em diferentes sistemas, sendo disponibilizada rapidamente a toda a organização; pode agregar correio eletrónico, automação de processos, gestão de informação e conversa on-line; ganha-se tempo e espaço; favorece e possibilita o espírito de trabalho em grupo; permite a circulação de impressos para requisições, inquéritos de opinião, boletins informativos, manuais técnicos, entre outros.

O mesmo autor refere ainda a videoconferência, que é uma forma de comunicar em tempo real através de imagens áudio e vídeo via satélite, que tem como vantagem poder transmitir uma mensagem simultaneamente a todos os trabalhadores. O correio eletrónico que, atualmente, já faz parte da vida da maioria dos trabalhadores e permite uma rápida transmissão de mensagens para diferentes níveis hierárquicos e as newsletters.

Em suma, a eficácia dos meios e instrumentos de Comunicação Interna depende da forma como são utilizados, dos conteúdos a divulgar ou da recetividade dos destinatários. Por conseguinte, é fundamental ter um conhecimento profundo dos meios e instrumentos de Comunicação Interna, bem como das necessidades e possibilidades da organização.

\subsubsection{Fatores de Comunicação Interna}

Ao analisarmos a Comunicação Interna temos que, necessariamente explanar os fatores aos quais está associada.

3 Ver anexo A 
Segundo Madureira, (1990) existem determinados fatores que estão associados à Comunicação Interna, designadamente, fluxo de informação, nível de complexidade, canal de comunicação e formalidade da comunicação.

\subsubsection{Fluxo de informação}

Dupuy, (1998) defende o fluxo de informação é influenciado pela estrutura da organização, que incrementa os seus circuitos e as relações comunicacionais, dividindo-se da seguinte forma:

- Comunicação descendente - efetua-se de cima para baixo, através dos níveis superiores hierárquicos até aos trabalhadores. A sua finalidade é de informar, instruir e dirigir;

- Comunicação ascendente - ocorre no sentido inverso da anterior, ou seja, de baixo para cima. Deriva dos subordinados para os seus superiores com o objetivo de fornecer informações aos níveis de topo. É através desta comunicação que é estabelecido o feedback entre os trabalhadores e os seus superiores;

- Comunicação horizontal ou lateral - efetua-se entre os elementos de um grupo de trabalho ou entre elementos de grupos de trabalho diferentes mas ao mesmo nível hierárquico;

- Comunicação em diagonal - ocorre entre uma chefia funcional e elementos de outro grupo de trabalho quando ela exerce autoridade funcional. Apresenta um maior dinamismo e assenta no fluxo de informação entre especialistas de diferentes áreas funcionais em diferentes níveis de gestão;

Em síntese, o fluxo ascendente é mais reduzido do que o descendente, havendo tendência para bloquear mais facilmente. Isto deve-se ao facto dos trabalhadores evitarem, o mais possível, transmitir informação desfavorável, nomeadamente reclamações ou colocar questões problemáticas, com receio de serem punidos. Outro motivo prende-se com o facto de os trabalhadores ao transmitirem aos seus superiores informação favorável, estão a exprimir os seus pontos de vista (Dupuy, 1998).

\subsubsection{Nível de complexidade}

Quanto ao nível de complexidade podemos considerar as seguintes formas de comunicação: 
- Comunicação interpessoal: troca de informação pessoal entre dois ou mais indivíduos com interação entre eles;

- Comunicação em grupo: ocorre entre elementos de um grupo, como por exemplo reuniões;

- Comunicação em toda a organização: ocorre quando a informação parte da gestão até todos os trabalhadores da organização. Tem como finalidade informações sobre os procedimentos e políticas da organização;

\subsubsection{Canal de Comunicação}

Neste fator, importa salientar a caraterização do padrão de comunicação estabelecido de acordo com os propósitos do grupo. A comunicação pode estabelecer-se através de várias redes de comunicação, que, segundo Wagner III (2002) podem ser centralizadas ${ }^{4}$ ou descentralizadas 5 .

\subsubsection{Formalidade da comunicação}

A comunicação interna pode fluir de duas maneiras completamente distintas: formal e informal.

Formal: é a comunicação que ocorre dentro da estrutura formal da cadeia de comando, assumindo normalmente a forma escrita;

Informal: ocorre independentemente da estrutura formal e assume, especialmente, a forma oral.

A comunicação formal assenta principalmente na estrutura funcional de onde provém um modelo formal de comunicações escritas e orais, enquanto a comunicação informal consiste num contacto pessoal e direto entre pares ou entre trabalhadores e superiores hierárquicos, possibilitando o esclarecimento de questões e contribuindo para a integração das pessoas.

A comunicação informal das organizações nasce das relações sociais dos seus membros, onde a criação de lideranças desempenha um papel muito importante. São vários, os meios de comunicação informal, entre os quais a conversa, o burburinho, os

4 Redes Centralizadas - O trabalhador está no centro da estrutura e pode controlar os fluxos de informação do grupo. A produtividade dos grupos que executam tarefas simples aumenta, enquanto, a satisfação dos seus membros reduz (Wagner III 2002).

5 Redes Descentralizadas - A capacidade dos trabalhadores para enviar e receber mensagens é igual. A produtividade do grupo que exerce tarefas complexas aumenta, aumentando também a satisfação de cada trabalhador (Wagner III 2002). 
rumores, os boatos, o diz que disse, e muitos outros tipos, dependendo da organização. Este tipo de comunicação deve ser aproveitada com vista ao crescimento e desenvolvimento da organização e não constituir um óbice (Kunsch 1995).

Segundo Buckley, (1992) o sistema informal é um poderoso canal de comunicação, especialmente quando os canais formais bloqueiam, fluindo apenas metade da informação necessária à gestão de topo. Porém, apesar das mensagens transmitidas por este meio serem frequentemente distorcidas, têm por vezes mais credibilidade e são mais rápidas do que as recebidas pelos canais formais. Por exemplo, o lançamento de um boato provoca uma reação instantânea, enquanto um memorando pode demorar três semanas a obter uma resposta.

Uma comunicação eficaz abrange os dois sistemas, formal e informal, que devem ser corretamente determinados e verificados na sua funcionalidade e utilização em todo o processo de transmissão de mensagens.

\subsubsection{Barreiras à Comunicação Interna}

Segundo Witinghausen (cit. por Ramos, 1997), a maior parte dos conflitos internos são devidos à ausência de informação e à falta de conhecimento sobre a organização, pois, esta ausência de informação provoca erros e cria falsas interpretações que podem prejudicar a empresa.

Outro autor salienta que existem barreiras à comunicação que têm origem na insistência da transmissão da informação através de canais formais, provocando complicações na livre circulação da informação. Refere ainda a preparação dos trabalhadores para lidar com os processos de Comunicação Interna da organização, que pode impedi-los de potenciar ao máximo a informação disponível (Gondrand, 1990).

Clampitt, (1991) refere que o aumento da quantidade de meios de comunicação não é proporcionalmente equivalente a um aumento do grau de informação das pessoas.

Brault, (1992) salienta que nem sempre o problema da comunicação é a falta dela mas, demasiada informação poderá também destruir a comunicação. Este autor refere também alguns problemas da falta de gestão da Comunicação Interna numa organização:

- O distanciamento entre os departamentos da organização;

- A disparidade entre trabalhadores motivados e eficazes e outros que levantam discussões constantemente; 
- Quadros que não cumprem as suas funções ao nível da Comunicação Interna.

Por último, Bland e Jackson, (1992) referem as mesmas barreiras, acrescentando ainda outras variáveis de uma comunicação deficiente:

- A falta de compreensão dos objetivos da organização;

- A incapacidade de realização de tarefas individuais com a máxima qualidade possível;

- A falta de perceção das exigências do cliente e dos desafios da concorrência;

- As relações deficientes com os superiores imediatos;

- As críticas e mal entendidos entre departamentos;

- A incapacidade de dar informações sinceras aos subordinados;

- A insuficiente apreciação da necessidade de qualidade e perfeição;

- A preferência pelo recurso rápido à ação empresarial em detrimento de um diálogo esclarecedor com vista a soluções harmoniosas;

- A queda geral da moral.

Podemos então verificar que as barreiras existentes relativas à Comunicação Interna devem-se à ausência de informação, à existência de diferentes necessidades e à qualidade e natureza da informação que os trabalhadores necessitam.

Para destruir estas barreiras, é importante ter uma Comunicação Interna eficaz e organizada, o que requer uma análise cuidada das necessidades, uma definição de objetivos e de ações coerentes.

\subsubsection{Comunicação interna como ferramenta estratégica no desempenho organizacional}

Num mundo cada vez mais globalizado, onde as novas tecnologias e a revolução digital fizeram emergir novas exigências de excelência em produtos e serviços, o público interno assumiu um papel de destaque no sucesso da organização. É através do público interno que são adquiridos novos conceitos e práticas que garantem o desempenho da organização. 
Hoje em dia, para que as organizações sejam competitivas é necessário que se atualizem constantemente, adaptando-se a processos e modelos de gestão com o intuito de reforçar a identidade da organização e os laços de pertença. Neste sentido, a Comunicação Interna será a combinação de ações que a organização coordena com o objetivo de ouvir, informar, mobilizar, educar e manter a coesão interna em torno de valores que necessitam de ser identificados e partilhados por todos. Desta forma, todos contribuem para a construção de uma boa imagem pública da organização (Zemor, P. 1995).

A Comunicação Interna é um processo de troca de informação e conhecimento dentro de uma organização, é responsável por circular a informação de forma vertical quando circula da liderança para os níveis subordinados e de forma horizontal, entre os colaboradores do mesmo nível hierárquico, com a finalidade de interação entre as várias áreas da organização.

A Comunicação Interna atua na organização como ferramenta estratégica, quando harmoniza a troca de conhecimento, na difusão de informações, de objetivos estratégicos e aspetos da cultura organizacional. Desta forma, surge uma linguagem única e inteligível, transversal a todos os níveis da organização, fomentando o debate num ambiente onde os colaboradores se sentem com liberdade para discutir questões pertinentes num espaço integrado. Nesta linha de raciocínio, a Comunicação Interna é uma ferramenta estratégica no desempenho organizacional, uma vez que atua em três áreas essenciais para o sucesso da organização: os resultados do negócio, o fator humanizador das relações de trabalho e a consolidação da identidade da organização junto aos seus públicos (Marchiori, 1995)

Em síntese, segundo Santo, (2008) "a comunicação interna é uma das ferramentas que faz parte das estratégias de modernização, ao permitir a melhor participação dos diversos agentes na partilha dos objetivos, de resultados e de metas atingidas. Sem a comunicação interna, a organização estagna e gera rotas ou percursos isolados, não estratégicos de desempenho, os quais são frágeis, desenquadrados e pontuais".

\subsubsection{Gestão da Comunicação Interna}

Efetuar uma boa gestão da Comunicação Interna, implica que sejam definidos objetivos claros, que sejam selecionados recursos humanos adequados às tarefas a serem executadas, que as pessoas sejam motivadas e que sejam encontradas as estratégias mais apropriadas para se poderem atingir os objetivos organizacionais. Concretizar tudo isto não 
é fácil, quando se trata de fazer a gestão da Comunicação Interna já que implica gerir pessoas e interesses diversificados.

Uma das dificuldades da gestão da Comunicação Interna prende-se com o facto de algumas organizações serem constituídas por grupos muito heterogéneos. Estes grupos dividem-se em vários segmentos com características e objetivos diferentes. Por conseguinte, existe uma grande diversidade de linguagem, de filosofia, de idades, de níveis de escolaridade, de competências e de valores. Por vezes, nessa multiplicidade residem os diversos entraves de relacionamento entre os níveis ascendente, descendente e horizontal.

Referimos ainda que, o modo de planear e administrar a Comunicação Interna está diretamente ligado ao lugar ocupado pela comunicação e pelos profissionais dessa área.

A generalidade das organizações tendem a assumir que as suas equipas sabem como comunicar, e, portanto, a comunicação não é um aspeto da vida organizacional que tenha merecido muita atenção. Esta conjetura falsa tem levado as organizações a concentrar os seus recursos humanos e financeiros noutras áreas que são consideradas fundamentais para o bom funcionamento da organização, tais como os aspetos financeiros e técnicos. Além disso, poucas organizações têm sido capazes de avaliar o impacto que a comunicação tem sobre a satisfação no trabalho, comprometimento organizacional, e eficiência e da produtividade do mesmo (Madrid, 1994)

Segundo Downs e Adrian, (2004) para se realizar a gestão da comunicação, são necessárias, algumas condições, tais como: Independência, Profissionalismo, Diagnóstico exaustivo, Competência de avaliação, Desenho à medida e Cumprimento de prazos.

Madrid, (1994) salienta que existem quatro componentes para a gestão da Comunicação Interna, que são os seguintes: Auditoria de Diagnóstico; Planeamento; Implementação e Controle.

Auditoria de Diagnóstico - Consiste num processo que tem como objetivo avaliar e melhorar os sistemas e práticas de Comunicação Interna e externa de uma organização a todos os seus níveis. As auditorias de diagnóstico permitem identificar os elementos responsáveis, conhecer a perceção que têm das suas tarefas, a sua imagem da organização, a perceção dos outros membros da organização e das partes interessadas, identificar e analisar as relações entre os grupos na organização, analisar o conteúdo e o formato das mensagens e avaliar os fluxos de recursos comunicacionais. 
Planeamento - Consiste nos seguintes componentes: objetivos gerais e específicos, metas e resultados, critérios políticos e estratégicos de ação, programação, quadros de correspondência, calendarização, avaliação do projeto, avaliação contínua e avaliação de resultados.

Implementação - Esta fase terá que ter em consideração o que foi identificado na fase de Auditoria de Diagnóstico, o que foi definido na fase de Planeamento, as Barreiras à Comunicação Interna e as estratégias para as eliminar ou atenuar.

Controle - Compreende um conjunto de procedimentos, métodos e atividades que são utilizados para determinar se o processo de Comunicação Interna se comporta na sua execução de acordo com a fase de planificação. Está intrinsecamente associado ao princípio de melhoria contínua. Envolve a constituição de uma equipa de controlo, atividades contínuas e avaliações pontuais.

O mesmo autor (Madrid, 1994) acrescenta que os sistemas e práticas de comunicação de uma organização, tal como todas as atividades humanas, são suscetíveis de deterioração. Por conseguinte, há necessidade de as diagnosticar e melhorar. Nesse sentido, surgem as auditorias de comunicação, enquanto atividade de avaliação dos sistemas e práticas da Comunicação Interna. Essa avaliação é, geralmente, efetuada através dos seguintes instrumentos de análise:

Questionários - Estes instrumentos devem recolher os elementos essenciais de acordo com os objetivos que foram previamente definidos. São os instrumentos mais utilizados na realização destas auditorias.

Entrevistas - A entrevista permite recolher informação mais detalhada, contudo, para ser eficaz é necessário planificá-la e realizá-la com competência.

Análise da transmissão de mensagens - Este instrumento tem como objetivo encontrar o processo de difusão de uma mensagem na organização, desde a sua origem até atingir os trabalhadores.

Análise de incidentes críticos de comunicação - Tem como objetivo identificar exemplos e experiências reais no trabalho.

Análise das redes de comunicação - Esta técnica permite analisar a estrutura da comunicação da organização e a sua eficácia, como por exemplo, identificar quais são grupos existentes na organização e quem são os trabalhadores que permanecem isolados. 
Entrevista grupal (focus group) - Esta entrevista avalia os desejos, necessidades e opiniões dos grupos alvo e recolhe informação sobre temas e aspetos prioritários.

Observação direta - Esta técnica permite ao auditor ter acesso a informação detalhada sobre os processos de comunicação, que são vitais para a organização, como por exemplo, o processo de tomada de decisões.

Análise dos produtos de comunicação - Este processo permite recolher e analisar produtos de comunicação, tais como, histórias, metáforas, símbolos, artefactos, documentos escritos e conversas.

Sociograma - É um diagrama que representa a relação das ligações individuais entre os diferentes membros de um grupo. Representa graficamente quem comunica com quem dentro do grupo.

Matrizes - Permitem avaliar a comunicação através de tabelas com linhas e colunas, permitindo recolher dados através de duas dimensões.

Análise SWOT - Permite fazer uma análise interna e externa à comunicação na organização, identificando as principais ameaças, oportunidades, pontos fracos e pontos fortes.

Diagrama de Ishikawa ou diagrama de causa efeito - É uma ferramenta gráfica, que permite estruturar hierarquicamente as causas potenciais de determinados problemas ou oportunidades de melhoria.

Em suma, fazer uma boa gestão da Comunicação Interna pressupõe um conjunto de políticas, ações e procedimentos, postos em prática, para influenciar os comportamentos individuais e coletivos através da comunicação.

\subsection{Comunicação Interna na GNR}

Atualmente, são muitas as empresas que reconhecem a importância da Comunicação Interna, porém nem todas sabem como planear ações de intervenção eficientes.

A Guarda Nacional Republicana há muito que se preocupa com a Comunicação Interna ${ }^{6}$, tendo vindo a desenvolver ações, meios, instrumentos e estratégias de Comunicação Interna, para que esta se encontre sempre em paralelo com a inovação.

6 - Ver anexo F um folheto de informação interna de 29/05/1974 dirigido aos militares da GNR. 
Segundo Almeida, (2003) o conhecimento e o domínio dos meios e instrumentos de Comunicação Interna são a base da ação, ou seja, a parte operacional da estratégia a implementar. Para este autor, como já referido anteriormente, os meios utilizados pela Comunicação Interna são a comunicação oral, escrita e audiovisual, sendo as novas tecnologias de informação uma técnica com muito potencial para a Comunicação Interna.

Para que a Comunicação Interna resulte, os meios e instrumentos que a compõem devem ser selecionados em função da informação que se pretende transmitir, tendo em conta as necessidades do emissor e do recetor, as características da mensagem e dos instrumentos a utilizar (Clampitt, 1991).

\subsubsection{Meios e instrumentos de comunicação interna existentes na GNR}

A Comunicação Interna deve ser definida a um nível conceptual e prático, tendo como motor os níveis de topo de uma organização. No entanto, a implementação e correto funcionamento compete a todos os elementos que a compõem. Por outro lado, as chefias intermédias desempenham um papel nevrálgico, uma vez que, têm a responsabilidade de promover uma cultura de informação, alinhada com as necessidades da organização e fomentar a utilização dos meios e instrumentos de Comunicação Interna mais eficazes (Penela, 1999).

Os meios e instrumentos, mais frequentemente usados na GNR, são:

Comunicação oral - Conversas informais, conversas formais, reuniões nos vários escalões de comando, encontros de convívio, cursos e ações de formação e conversas de grupo.

Comunicação escrita - Notas internas e mensagens, ordens de serviço, normas de execução permanente (NEP), relatórios de atividade, correio interno, folhetos, placares e revista da GNR “Pela Lei e pela Grei”.

Audiovisuais - Filmes, fotos e slides em (Powerpoint).

Novas Tecnologias de Informação - Site da GNR, intranet, correio eletrónico (e-mail), videoconferência, telemóveis de serviço, Sistema Integrado de Informações Operacionais Policiais (SIIOP) e o Sistema e Gestão de Operações (SGO). 


\subsubsection{Análise SWOT à Comunicação Interna na GNR}

De acordo com um estudo efetuado por Pereira (2006), através de uma Análise SWOT à organização, foram identificados pontos fortes e fracos da GNR em termos comunicacionais, bem como algumas ameaças e oportunidades. Apresentamos, de seguida os aspetos salientados:

\section{Pontos Fortes}

- Boa comunicação ao nível horizontal;

- Redes informais coesas, como as potenciais fontes de informação;

- Espírito de coesão, camaradagem e cooperação, essencialmente ao nível horizontal;

- Interesse dos militares em participar em projetos de Comunicação Interna.

\section{Pontos Fracos}

- Subaproveitamento das capacidades e conhecimentos dos militares;

- Fraca eficácia dos canais de comunicação ascendente e descendente;

- Insatisfação com a clareza, objetividade, precisão e timing das informações;

- Procura de redes informais para suprir as necessidades de informação operacional;

- Fraco conhecimento interno sobre as atividades e acontecimentos relevantes para a GNR;

- Excessiva burocracia interna e externa;

- Falta de meios materiais;

- Pouco reconhecimento da hierarquia, sobre o trabalho desenvolvido.

\section{Oportunidades}

- Reconhecimento e avaliação do desempenho como fator relevante para a progressão na carreira.

- Promoção da imagem GNR.

- Alargamento de funções e do âmbito de atuação da GNR.

- Benchmarking ${ }^{7}$ com Forças congéneres.

\section{Ameaças}

- Restrições políticas, jurídicas e orçamentais;

- Exploração excessiva pelos media das situações negativas ocorrentes na GNR;

\footnotetext{
7 - Processo contínuo e sistemático que permite a comparação das performances das organizações e respetivas funções ou processos face ao que é considerado "o melhor nível", visando não apenas a equiparação dos níveis de performance, mas também a sua ultrapassagem.
} 
- Forte pressão da sociedade para a resolução de situações não legais;

- Fusão das Forças e Serviços de Segurança;

- Alterações à Lei Interna do Ministério da Administração Interna e Segurança Interna.

A autora defende que, para atenuar os pontos fracos da organização, devem ser considerados vários aspetos, nomeadamente: estrutura organizacional; formação; participação e criatividade, reconhecimento; política de gestão do pessoal; condições físicas e materiais; e comunicação e imagem organizacional, de modo a contribuírem para a correta definição de uma estratégia de atuação, em termos de Comunicação Interna.

Porém, apesar de não existir ainda uma política de Comunicação Interna bem definida e estrategicamente implementada, a GNR apresenta vários pontos fortes, que podem potenciar a sua Comunicação Interna, sustentados no orgulho dos militares pertencerem à instituição, na coesão interna, pelo forte espírito de camaradagem e pela vontade de manter uma boa imagem da instituição. 


\section{A Guarda Nacional Republicana}

\subsection{Caraterização da GNR}

\subsubsection{Génese e História}

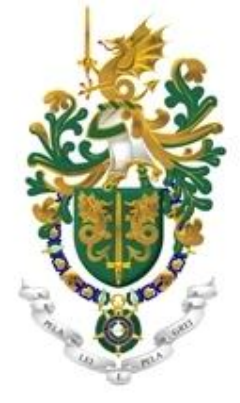

A origem da Guarda Nacional Republicana remonta a 1801, quando o Príncipe Regente D. João criou a Guarda Real da Polícia de Lisboa, inspirando-se no modelo da Gendarmerie Francesa de 1791. Em 1802 a Guarda junta-se ao Exército, como tropa de linha. O seu efetivo era composto por 642 homens e 227 cavalos.

A exemplo da Guarda Real da Polícia de Lisboa foi criada a Guarda Real da Polícia do Porto.

Em Maio de 1834, D. Pedro, dissolve as Guardas Reais da Polícia de Lisboa e Porto e cria a Guarda Municipal de Lisboa, com idênticas características. No ano seguinte surge a Guarda Municipal do Porto.

Com a chegada da República, as Guardas Municipais são extintas por Decreto do Governo, sendo criadas as Guardas Republicanas, em Lisboa e Porto.

No dia 3 de maio de 1911, foi criada a Guarda Nacional Republicana, «para zelar pela segurança pública, manutenção da ordem e proteção das propriedades públicas e particulares de todo o país», conforme se dispunha no artigo $1^{\circ}$ do decreto com força de lei, publicado no Diário do Governo do dia seguinte.

Atualmente a Lei Orgânica da GNR (LOGNR) ${ }^{8}$, no artigo $1^{\circ}$, define esta instituição como "uma força de segurança de natureza militar, constituída por militares organizados num corpo especial de tropas e dotada de autonomia administrativa".

\subsubsection{Missão}

Tem por missão, no âmbito dos sistemas nacionais de segurança e proteção, assegurar a legalidade democrática, garantir a segurança interna e os direitos dos cidadãos, bem como colaborar na execução da política de defesa nacional, nos termos da Constituição e da Lei.

8 - Anexo B - Lei n. 63/2007, de 6 de Novembro, e Declaração de Retificação n.. 1 1-A/2008, de 4 de Janeiro 
Pela sua natureza e polivalência, a GNR encontra o seu posicionamento ${ }^{9}$ institucional no conjunto das forças militares e das forças e serviços de segurança, sendo a única força de segurança com natureza e organização militares, pelo que se considera mais correto designá-la por Força Militar de Segurança.

\subsubsection{Visão}

Alcançar os mais elevados padrões de segurança e de tranquilidade pública na sociedade portuguesa, afirmando-se como uma instituição de referência no conjunto das forças militares e das forças e serviços de segurança.

\subsubsection{Valores}

O alinhamento dos valores corporativos com a missão e com a visão da Guarda é um fator determinante para o fortalecimento e desenvolvimento de uma nova cultura organizacional em busca da excelência.

Os valores de Honra e Dever, Disciplina, Camaradagem e Espírito de Corpo, Lealdade, Deontologia Militar, Código de Honra do Militar da Guarda, têm como pressuposto fundamental a condição militar, que representa uma entrega total, pelo que encerra uma exigência constante de disponibilidade, de frequente renúncia a comodismos, de sacrifícios sem conta e, muitas vezes, com enormes incompreensões, a que se associa a prossecução de um ideal de servir.

Existem valores éticos e restrições voluntariamente assumidas que não têm paralelo em qualquer outra instituição, de que o juramento de doação da vida pela Pátria e a disponibilidade permanente, sem restrições, são aspetos únicos da condição militar ${ }^{\mathbf{1 0}}$.

\subsubsection{Estrutura}

A GNR, desde 2007, sofreu uma profunda reestruturação decorrente da Lei n. ${ }^{\circ}$ 63/2007, de 6 de Novembro, que aprovou a nova Orgânica da Guarda. Esta Lei determinou várias alterações à estrutura ${ }^{11}$ orgânica da instituição, designadamente a substituição do Estado-Maior do Comando-Geral por três Comandos Funcionais (para as áreas operacional, administração de recursos internos e doutrina e formação), extinguindo um

9 - Ver Anexo C - Posicionamento da Guarda Nacional Republicana

10 - Fonte: GNR - Plano de Atividades de 2011. 11 - Ver estrutura de comando Anexo D e organograma Anexo E 
escalão de comando, a Brigada Territorial. Por conseguinte, foram criados os Comandos Territoriais de âmbito Distrital e regiões autónomas (Madeira e Açores), as Unidades Especializadas (Unidade Nacional de Trânsito, Unidade de Ação Fiscal e Unidade de Controlo Costeiro), a Unidade de Representação (Unidade de Segurança e Honras de Estado), a Unidade de Intervenção e Reserva (Unidade de Intervenção) e o Estabelecimento de Ensino (Escola da Guarda). Assim, a Guarda passa a compreender a Estrutura de Comando, as Unidades e o Estabelecimento de Ensino.

Os novos Comandos Territoriais articulam-se em serviços e em subunidades operacionais, designadas por Destacamentos Territoriais, em que a sua área de ação representa um conjunto de concelhos. Por sua vez, os Destacamentos Territoriais articulam-se localmente em Subdestacamentos ou Postos Territoriais, que representam um conjunto de Freguesias, contando a GNR com quatrocentos e noventa e dois em todo o País.

Os Comandos Territoriais são comandados por oficiais superiores: Coronéis ou Tenentes-Coronéis. O Destacamento é comandado por majores ou capitães, o subdestacamento por oficiais subalternos e os Postos Territoriais por sargentos.

De salientar, que na Guarda Nacional Republicana a conduta que se espera dos seus militares está claramente prevista em normas e regulamentos da organização, formalizados por escrito. A função atribuída a militares com cargos específicos e rigidamente hierarquizados, a sua estrutura piramidal, a centralização das decisões e um total controlo pelos superiores hierárquicos, leva-nos a definir que a organização em estudo possui um caráter burocrático e mecanicista.

\subsubsection{Efetivo}

A Guarda Nacional Republicana em 30 de Setembro de 2012 tinha em exercício de funções 22249 militares e 1929 civis, perfazendo um total geral de $\mathbf{2 4} \mathbf{1 7 8}^{\mathbf{1 2}}$ distribuídos pelas diversas categorias (Oficiais, Sargentos e Guardas), que se encontram distribuídos funcional e geograficamente pelas diversas unidades, órgãos e serviços.

A distribuição pelas três categorias é a seguinte: os Oficiais representam 3\% do efetivo militar, os Sargentos $12 \%$ e os Guardas $85 \%$, tal como representa o gráfico 1.

12 Fonte - mapa geral de efetivo presente, da divisão de planeamento e obtenção de recursos humanos do Comando da Administração dos Recursos Internos da GNR (CARI). 
Gráfico 1 - Distribuição do efetivo militar pelas diferentes categorias profissionais.

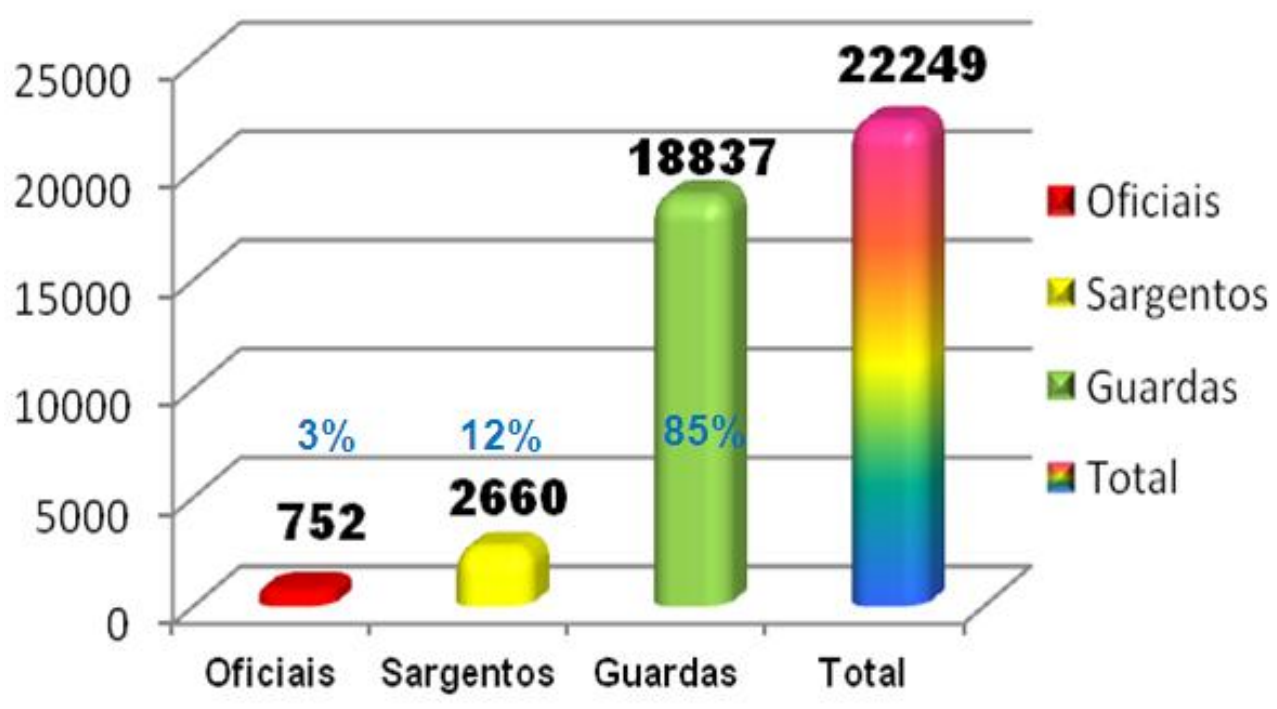




\section{PARTE II - PESQUISA DE CAMPO}

\section{METODOLOGIA}

A investigação teve início com uma fase exploratória, onde foi analisada a temática de Comunicação Interna. Depois de analisada toda a informação, foi efetuada uma seleção dos dados obtidos através da leitura das diversas obras bibliográficas e sítios da internet, no sentido de se obter e selecionar os conteúdos mais relevantes para a investigação. A pesquisa bibliográfica teve a sua maior incidência em obras relacionadas com a comunicação organizacional e, de modo mais marcado, com a Comunicação Interna.

Concluído o enquadramento teórico do tema e para dar continuidade aos objetivos pré-definidos, segue-se a pesquisa de campo, tendo em conta a aplicação e verificação dos conceitos teóricos desenvolvidos na Parte I. Na pesquisa de campo, recorreu-se à investigação descritiva ${ }^{13}$ utilizando a análise quantitativa $^{14}$, recorrendo-se fundamentalmente à análise estatística dos dados recolhidos.

\subsection{Caracterização do universo em estudo}

O universo da GNR é composto por 24178 militares distribuídos pelas diferentes categorias profissionais distribuídos pelo território nacional.

Dos 24178 militares, cerca de 11500 desempenham atividades de serviço operacional nos Comandos Territoriais. São estes 11500 militares que constituem o grupo relevante para a análise do objeto de estudo da presente investigação.

Este grupo interno compreende duas categorias profissionais: Sargentos e Guardas.

\footnotetext{
13 Neste tipo de investigação, o investigador procura conhecer e interpretar os factos, sem interferir nos mesmos. Podemos caracterizar como um estudo que procura determinar opiniões ou projeções futuras nas respostas obtidas. Tem como objetivo explicar o fenómeno em estudo, especificar os conceitos decorrentes do mesmo e elaborar um quadro conceptual que, para além de definir a perspetiva do estudo, serve de ligação entre os conceitos e a sua descrição (Carmo e Ferreira, 1998).

14 Este método de investigação considera que todos os dados podem ser quantificáveis, o que significa traduzi-los em números, opiniões e informações para os classificar e analisar. É baseado na observação de factos, de acontecimentos ou de fenómenos. A sua finalidade é contribuir para o desenvolvimento e validação dos conhecimentos e ainda para a possibilidade de generalizar resultados. A abordagem quantitativa permite efetuar um estudo com grandes amostras representativas e os dados são recolhidos a partir dos inquiridos, através de questionários (Carmo e Ferreira, 1998).
} 
Os Sargentos (sargento-mor, sargento-chefe, sargento-ajudante, primeiro-sargento, segundo-sargento e furriel, figura 1) desempenham essencialmente, de acordo com os respetivos quadros e postos, funções de chefia, comando operacional (postos territoriais) e de natureza executiva (secretarias, secções).

Figura 1 - Distintivos da categoria de Sargentos

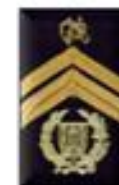

SARGENT0-M0R

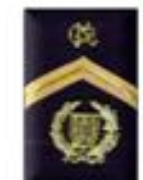

SARGENT0-CHEFE

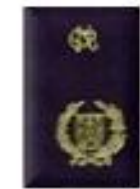

SARGENT0-AJUDANTE

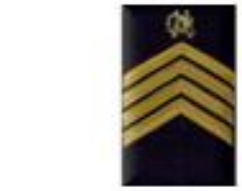

PRIMEIR0-SARGENT0

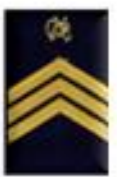

SEGIND0-SARGENT0

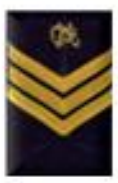

FURRIEL

Os Guardas (cabo-mor, cabo-chefe, cabo, guarda principal e guarda, figura 2) desempenham, fundamentalmente, funções de natureza executiva, são os que estão na linha da frente, têm o maior contato com a população, sendo esse contato responsável pela imagem positiva ou negativa da Guarda.

Figura 2 - Distintivos da categoria de Guardas

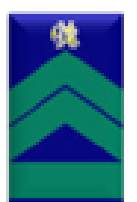

CABO MOR

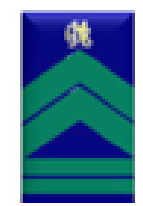

CAB0-CHEFE

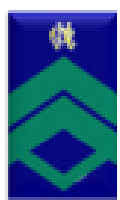

CABO

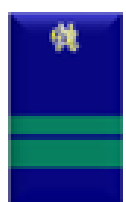

GUARDA PRINCIPAL

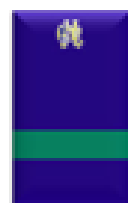

GUARDA

\subsection{Definição da amostra}

A escolha de uma amostra deve ser adequada às características do universo de análise, tendo em conta a finalidade e os objetivos do trabalho. Assim, a amostra irá ser definida segundo o método de amostragem por conveniência ${ }^{15}$ que se caracteriza por se

15 Ou por acessibilidade, em que se selecionam “... elementos a que se tem acesso, admitindo que estes possam de alguma forma representar o universo" (Gil, cit in Pereira, 2006:107). 
recorrer a um grupo de Militares da GNR disponíveis, distribuídos por 20 Comandos Territoriais, com características semelhantes às do universo (Carmo e Ferreira, 1998).

Os 11500 militares, na sua maioria da categoria de Guardas, exercem funções operacionais e estão distribuídos pelos 492 postos territoriais, existentes na Guarda Nacional Republicana.

Considerando que, são os Guardas que estão na base da hierarquia, a localização geográfica dos Postos Territoriais e a dispersão do efetivo pelo território nacional, decidimos selecionar aleatoriamente, 60 Postos Territoriais (três de cada Comando Territorial) atingindo um total de 1414 militares.

Para efeitos da definição da amostra, desses 60 Postos Territoriais foram selecionados aleatoriamente 10 militares, da categoria de Guardas, de cada Posto Territorial, para serem inquiridos, perfazendo um total de 600 militares. Dos 600 militares inquiridos, apenas 241 responderam ao inquérito.

Este modelo de amostra é especialmente utilizado nos estudos de carácter exploratório $^{16}$, cujos resultados não podem ser generalizados à totalidade do universo, mas dos quais pode ocorrer informação pertinente, se devidamente utilizada (Carmo e Ferreira, 1998).

A amostra não será representativa do universo devido às limitações de recursos existentes, dado a dimensão da população que constitui o universo de análise ser muito extensa. Para além deste critério delimitador do processo de amostragem, existe ainda o facto do efetivo, dos 20 Comandos Territoriais, se encontrar disperso nos 18 distritos do país (Anexo G), nos Açores e na Madeira, o que dificulta a recolha de dados de forma representativa.

Todavia, o carácter científico do estudo mantém-se, até porque “... não deve confundir-se cientificidade com representatividade"17 (Quivy, e Campenhoudt, 2005).

16 O objetivo de um estudo exploratório é "proceder ao reconhecimento de uma dada realidade pouco ou deficientemente estudada e levantar hipóteses de entendimento dessa realidade" (Carmo e Ferreira, 1998).

17 No mesmo sentido, Ghiglione e Matalon (2001) entendem que “ ... uma amostra representativa da população em estudo pode ser pouco prática, porque (...) Querer a qualquer preço uma amostra representativa, é impor uma condição difícil de satisfazer e, muitas vezes inútil." 


\subsubsection{Caraterização dos inquiridos}

Seguidamente serão descritos os dados sociodemográficos que constituem a amostra do presente estudo. Para uma análise mais pormenorizada, deve-se consultar o apêndice B, que é constituído pelos Outputs das variáveis em análise.

\subsubsection{Sexo}

A amostra é constituída por 241 militares (Gráfico 2), dos Postos Territoriais, dos quais 223 são indivíduos do sexo masculino, correspondendo a $93 \%$ e os restantes 18 são do sexo feminino e correspondem a $7 \%$.

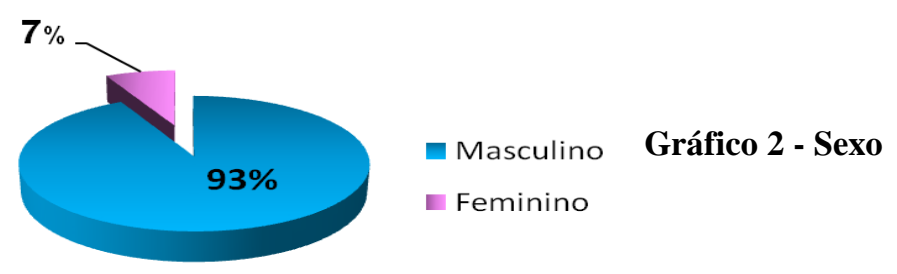

\subsubsection{Idade}

As idades oscilam entre os 21 e os 52 anos, sendo a média de idades dos inquiridos de 35 anos (tabela 1)

Tabela 1 - Idade dos Inquiridos

\begin{tabular}{lr} 
Média & 34,58 \\
Mínimo & 21 \\
Máximo & 52 \\
Total & 241 \\
\hline \hline
\end{tabular}

\subsubsection{Habilitações}

No que respeita à habilitação escolar, pode observar-se no gráfico 3, que a habilitação predominante é o ensino secundário, com 131 indivíduos, representando 54,4\%, seguindose o $3 .^{\circ}$ ciclo (9. ${ }^{\circ}$ ano) com 88 indivíduos, representando $36,5 \%$ dos inquiridos. Podemos verificar que a parte menos representativa da amostra corresponde ao ensino superior (Licenciatura) com 5 indivíduos, representando 2,1\% e Mestrado com 1 indivíduo, representando $0,4 \%$, sendo esta inferior ao ensino primário com 16 indivíduos, representando $6,6 \%$ dos inquiridos. 
Gráfico 3 - Habilitações Literárias

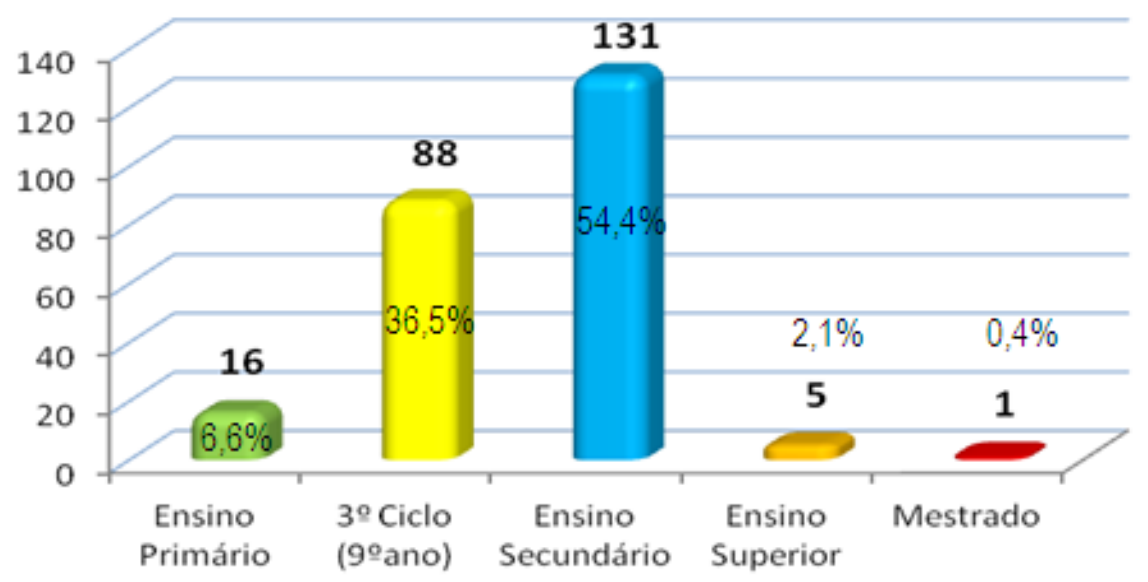

\subsubsection{Comando Territorial}

A análise desta variável (gráfico 4) permite constatar que a maioria dos respondentes pertence ao Comando Territorial de Viana do Castelo, com 48 questionários respondidos $(19,9 \%)$, seguindo-se o Comando de Viseu com 22 questionários $(9,1 \%)$ e Comando de Évora com 20 questionários respondidos (8,3\%). Os Comandos Territoriais, onde os militares menos responderam ao questionário, foram nos Comandos Territoriais de Beja e Santarém, ambos com apenas 1 questionário respondido, representando 0,4\% da amostra.

De salientar que não foram recebidos quaisquer questionários do Comando Territorial de Vila Real, pelo que não é considerado esse Comando.

\section{Gráfico 4 - Comandos Territoriais}

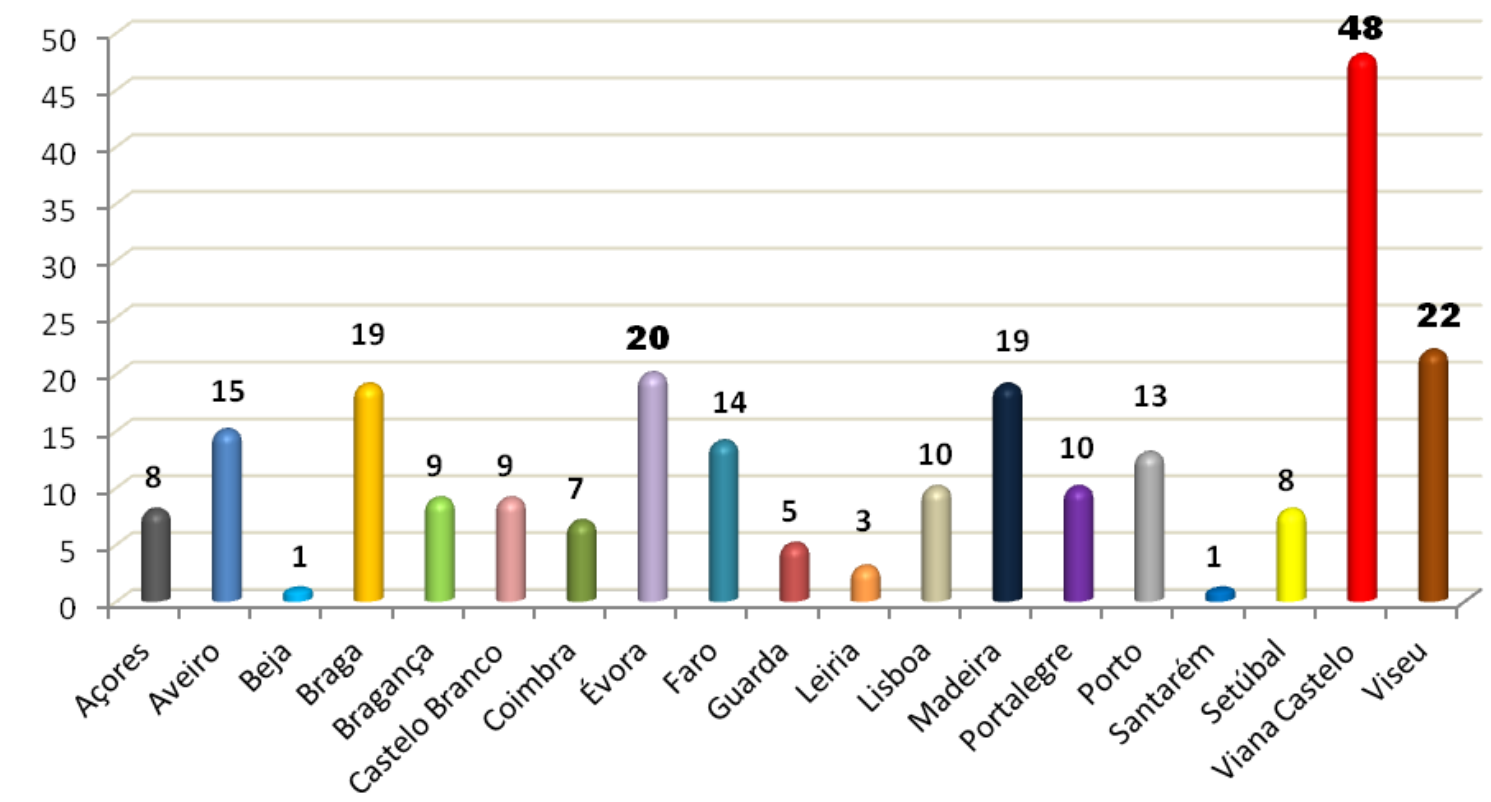




\subsubsection{Antiguidade}

A análise dos escalões de antiguidade dos militares, da Guarda Nacional Republicana (gráfico 5) indica que, existem três grupos mais representativos na amostra, totalizando os três grupos 70,9\%. O grupo mais significativo corresponde a 59 militares com antiguidade entre 1 a 5 anos, representando 24,4\%, seguindo-se 57 militares com 11 a 15 anos de serviço, representando $23,6 \%$ e 55 militares com 6 a 10 anos representando 22,8\%. Seguidamente verifica-se que 38 militares têm entre 16 a 20 anos de serviço $(15,7 \%)$ e 20 militares têm entre 21 a 25 anos de serviço, representando 8,3\%. O grupo com menor representatividade da amostra é constituído por 12 militares, representando 4,9\%. Podemos então concluir que a maior parte dos militares respondentes tem menos de 15 anos de serviço na GNR.

\section{Gráfico 5 - Antiguidade dos militares da GNR}

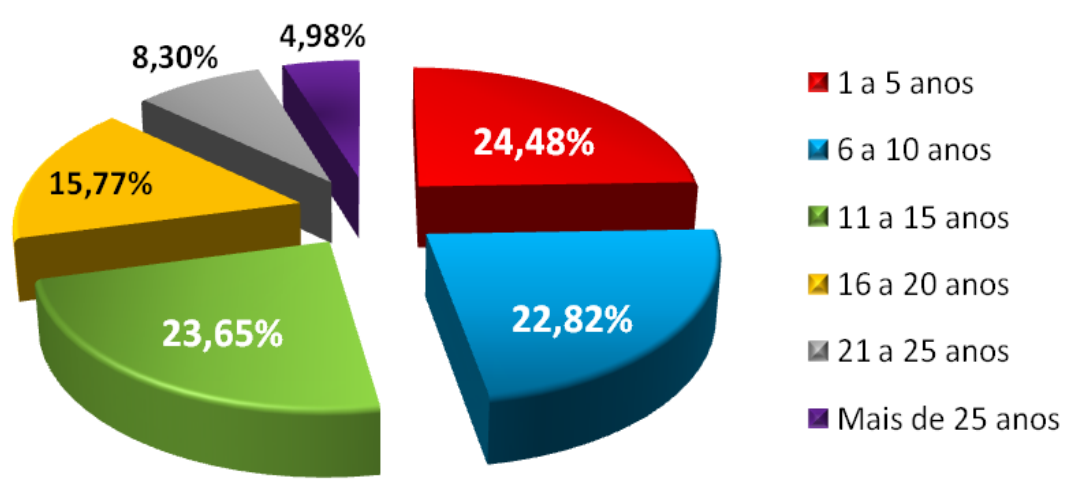

\subsubsection{Posto Militar}

Relativamente ao posto militar (categoria), podemos observar (gráfico 6) que o posto militar de Guarda, com 155 respondentes, foi a categoria mais representativa da amostra, representando 64,3\%. Em segundo lugar, a categoria de Cabo, foi a que mais se destacou com 74 respondentes, representando $30,7 \%$ do total. As três categorias que menos responderam foram as categorias de Cabo-Chefe e Guarda-Principal com 5 respondentes cada, representando cada uma $(2,1 \%)$ e a categoria de Cabo-Mor com 2 respondentes, representando $0,8 \%$ da amostra. 


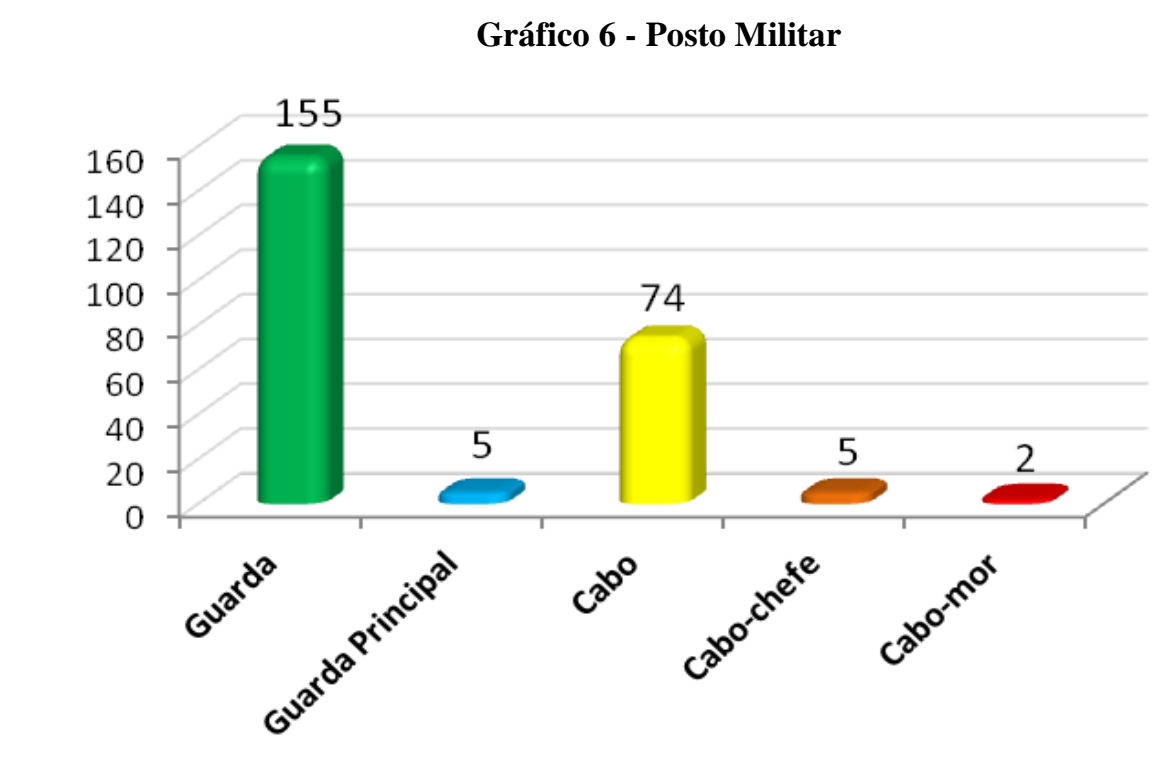

\subsection{Instrumento}

O instrumento de recolha de dados utilizado foi o inquérito por questionário construído para o efeito, aplicado através de uma plataforma informática, no Google Docs, permitindo aos inquiridos responder on-line. Este facto facilitou não só as respostas dos inquiridos como também a recolha dos dados. Conforme referido anteriormente, o questionário foi aplicado aleatoriamente a 600 militares, a exercerem funções nos Postos Territoriais, dos quais apenas 241 foram devolvidos e analisados.

O questionário ${ }^{18}$, utilizado neste estudo, é constituído por um conjunto de 74 perguntas fechadas e 1 pergunta aberta. Este instrumento é constituído por oito dimensões, sendo estas subdivididas em duas partes, a parte A remete para a Informação e Comunicação que inclui as dimensões de Informação Geral sobre a GNR, Informação Fornecida no local de trabalho, Comunicação com a Chefia, Clima de Comunicação, Comunicação entre Colegas e Boatos e Conflitos. A parte B remete para os Meios e Instrumentos de CI que inclui as dimensões de utilização e eficácia dos mesmos. Cada item da parte A é composto por uma escala de Likert com 5 proposições de concordância, variando de 1 ("Completamente de acordo"); 2 ("Concordo"); 3 ("Nem concordo nem discordo"); 4 (“ Discordo"); 5 (“Completamente em desacordo"), devendo o inquirido, de acordo com a sua opinião, indicar uma das cinco posições. No entanto, em cada item da parte B é utilizada uma escala de Likert com 4 proposições de concordância, no que respeita à utilização dos meios e instrumentos de CI, as proposições variam de 1 ("Não uso

18 Ver Apêndice A - Inquérito por questionário. 
nem consulto") a 4 ("Uso muito/consulto muito"), relativamente à eficácia dos meios de CI, variam de 1 (“Completamente Ineficaz) a 4 ("Completamente eficaz”), em que o inquirido escolhe apenas uma.

Relativamente aos itens que compõem a parte A, cerca de metade foram formulados pela negativa, para evitar problemas de aquiescência dos inquiridos. A especificidade do conteúdo dos itens da parte B permitiu uma formulação apenas numa direção.

As respostas dos inquiridos foram sujeitas a um conjunto de análises estatísticas de tipo descritivo e indutivo. No quadro das análises realizadas procurámos acautelar a determinação da consistência interna de cada uma das dimensões através do coeficiente Alpha $(\alpha)$ de Cronbach. Relativamente à validade do questionário, houve preocupações ao nível da composição das dimensões de análise e respetiva descrição dos itens, de modo a que estes estivessem articulados com a literatura da especialidade e com os conteúdos de outros instrumentos similares.

Passamos de seguida a descrever o conteúdo de cada uma das dimensões que compõem o respetivo questionário:

\section{A - INFORMAÇÃO E COMUNICAÇÃO}

Informação geral sobre a GNR: A dimensão informação geral sobre a GNR é composta por 4 itens, está associada ao modo como os militares da Guarda recebem a informação sobre as políticas, objetivos, orientações de gestão, mudanças e sucessos ou fracassos da instituição.

Informação fornecida no local de trabalho: Esta dimensão é composta por 5 itens e remete para o modo como a informação oral e escrita chega aos militares, no seu local de trabalho. Se a informação é clara, incompleta, suficiente, insuficiente ou demasiada e se por vezes a sua celeridade está associada à retenção nos escalões superiores.

Comunicação com a chefia: Esta dimensão é composta por 5 itens e está relacionada com o modo como os militares informam as suas chefias. Se informam as chefias de todas as informações, independentemente de serem ou não negativas, se existe obrigatoriedade de informar as chefias, mesmo que daí advenham consequências negativas e se as informações negativas são atenuadas antes de serem apresentadas às chefias.

Clima de comunicação: Esta dimensão é constituída por 5 itens e está associada à forma como se comunica dentro da instituição. Refere a forma como as pessoas comunicam umas 
com as outras, como elas se sentem para transmitirem as suas opiniões e se o modo como comunicam é saudável.

Comunicação entre colegas: Esta dimensão é composta por 4 itens e está relacionada com o modo como funciona a comunicação entre os colegas. Se a mesma é precisa, se a informação circula bem entre colegas.

Boatos e Conflitos: Esta dimensão é composta por 8 itens e está associada à forma como os boatos poderão provocar mal entendidos, entre os militares, e a forma como os conflitos são geridos.

\section{B - MEIOS E INSTRUMENTOS DE CI}

Utilização dos meios e instrumentos de comunicação: Esta dimensão é composta por 21 itens e está subdividida em Oral, Escrita e TIC com 5, 8 e 8 itens respetivamente. Pretende verificar quais os meios mais utilizados.

Eficácia dos meios e instrumentos de comunicação: Esta dimensão é composta por 20 itens e está subdividida em Oral, Escrita e TIC com 4, 8 e 8 itens respetivamente. Pretende verificar quais os meios mais eficazes.

Por fim, a última parte do questionário é composta por dados sócio demográficos do respondente, designadamente: Sexo, Idade, Habilitações Literárias, Comando a que pertence, Antiguidade no local de trabalho e Posto Militar.

A análise dos dados foi feita com recurso ao programa Statistical Package for the Social Sciences (SPSS) e ao Microsoft Excel.

\section{Síntese psicométrica}

Uma síntese das características do Questionário de Avaliação da Comunicação Interna na GNR (Apêndice A) pode ser analisada na tabela 2. Aí se indica para cada dimensão a respetiva média, variância, o $\alpha$ de Cronbach, o total de itens, bem como os itens com formulação positiva e negativa.

De salientar que, na primeira análise, verificou-se que o Alpha de Cronbach, de algumas dimensões, apresentava um valor pouco aceitável, $(<0,5)$. Por conseguinte, foi necessário retirar os itens correspondentes a cada dimensão, por forma a obter um valor de 
$\alpha$ de Cronbach aceitável $(\geq 0,6)$. Neste contexto, na dimensão Informação Geral sobre a GNR, retirou-se o item 4; na dimensão Comunicação com a Chefia retiraram-se os itens 12, 13 e 14; na dimensão Comunicação entre Colegas retirou-se o item 22 e na dimensão Boatos e Conflitos foi retirado o item 31.

Tabela 2 - Estatísticas descritivas do Questionário de CI

\begin{tabular}{|c|c|c|c|c|c|c|}
\hline Dimensões & $\begin{array}{c}\text { N. }{ }^{\circ} \text { itens com } \\
\text { formulação } \\
\text { positiva }\end{array}$ & $\begin{array}{c}\text { N. }{ }^{\circ} \text { itens com } \\
\text { formulação } \\
\text { negativa }\end{array}$ & $\begin{array}{c}\text { Total de } \\
\text { itens }\end{array}$ & $\begin{array}{c}\text { Média das } \\
\text { respostas }\end{array}$ & Variância & $\begin{array}{c}\text { Alfa de } \\
\text { Cronbach }\end{array}$ \\
\hline \multicolumn{7}{|l|}{ " A - INFORMAÇÃO E COMUNICAÇÃO } \\
\hline Informação geral sobre a GNR & 3 & 0 & 3 & 2,94 & 1,41 & 0,789 \\
\hline Informação fornecida no local de trabalho & 0 & 5 & 5 & 3,83 & 1,13 & 0,664 \\
\hline Comunicação com a chefia & 0 & 2 & 2 & 3,12 & 1,40 & 0,667 \\
\hline Clima de comunicação & 3 & 2 & 5 & 3,25 & 1,27 & 0,769 \\
\hline Comunicação entre colegas & 2 & 1 & 3 & 2,39 & 1,11 & 0,631 \\
\hline Boatos e conflitos & 2 & 5 & 7 & 3,82 & 1,02 & 0,785 \\
\hline Total & 10 & 15 & 25 & & & \\
\hline \multicolumn{7}{|l|}{ B - MEIOS E INSTRUMENTOS DE CI } \\
\hline Utilização dos meios & 21 & 0 & 21 & 2,15 & 0.74 & 0,821 \\
\hline Eficácia dos meios & 20 & 0 & 20 & 2,38 & 0,72 & 0,878 \\
\hline TOTAL & 41 & $\mathbf{0}$ & 41 & & & \\
\hline
\end{tabular}

\subsection{Procedimento}

Previamente foi solicitada, formalmente, autorização ao Exmo. Sr. Major-General Comandante do Comando da Doutrina e Formação da Guarda Nacional Republicana, para a realização deste estudo. Após aprovação, foi elaborada uma nota interna aos respetivos comandantes dos Comandos Territoriais existentes, onde o estudo se iria realizar, de modo a conhecer-se o conteúdo do mesmo e os objetivos a atingir.

Seguidamente comunicou-se aos Comandantes dos Postos Territoriais ${ }^{19}$ que iria ser distribuído este instrumento, solicitando a colaboração de todos os intervenientes no seu preenchimento.

O Questionário foi aplicado no período compreendido entre 1 de setembro a 31 de outubro de 2012. O processo de distribuição dos questionários foi, como já referido, uma plataforma informática denominada Google Docs. O questionário foi enviado através de

19 - Ver Anexo H com a relação dos Postos Territoriais selecionados para o estudo 
um Link, para a caixa de correio eletrónico institucional de cada militar a exercer funções nos Postos Territoriais. Cada militar acedeu ao Link, preencheu o questionário e no final clicou em submeter, sendo o questionário enviado automaticamente para a plataforma Google do investigador.

\section{APRESENTAÇÃO E INTERPRETAÇÃO DOS RESULTADOS}

Com vista a atingir os objetivos propostos no presente trabalho foi efetuada inicialmente uma comparação das médias e dos desvios padrão das respostas dos inquiridos ao conjunto das seis dimensões compreendidas na parte A que compõem o questionário. Os dados obtidos podem observar-se no gráfico 7 , onde se analisa a média $(\bar{X})$ e o desvio padrão $(\sigma)$ de cada uma das dimensões, estes dados podem ser consultados de forma mais detalhada no apêndice C. De salientar que as respostas dadas nos itens que constituem a parte A do questionário apresentam-se com proposições de concordância que variam de 1 ("Completamente de acordo"); a 5 ("Completamente em desacordo") sendo que este facto irá condicionar a análise subjacente na medida em que os valores mais baixos das variáveis correspondem a níveis da escala mais positivos, para contornar esta situação, na análise que se segue, subtraiu-se o nível mais alto de concordância (5) aos valores das médias dos itens das dimensões que compõem o questionário, fazendo assim com que a valores mais elevados nas médias correspondam a valores de concordância mais elevada com o conteúdo da dimensão em análise. No entanto, a análise dos outputs apresentados no apêndice $\mathrm{C}$ esse ajustamento não está presente.

Passamos, de seguida, à análise efetuada das dimensões que constituem a parte $\mathrm{A}$, e posteriormente, à descrição dos dados relativos aos Meios e Instrumentos de CI. 
Gráfico 7 - Médias e Desvios Padrão das respostas dos inquiridos

(Parte A - Informação e Comunicação)

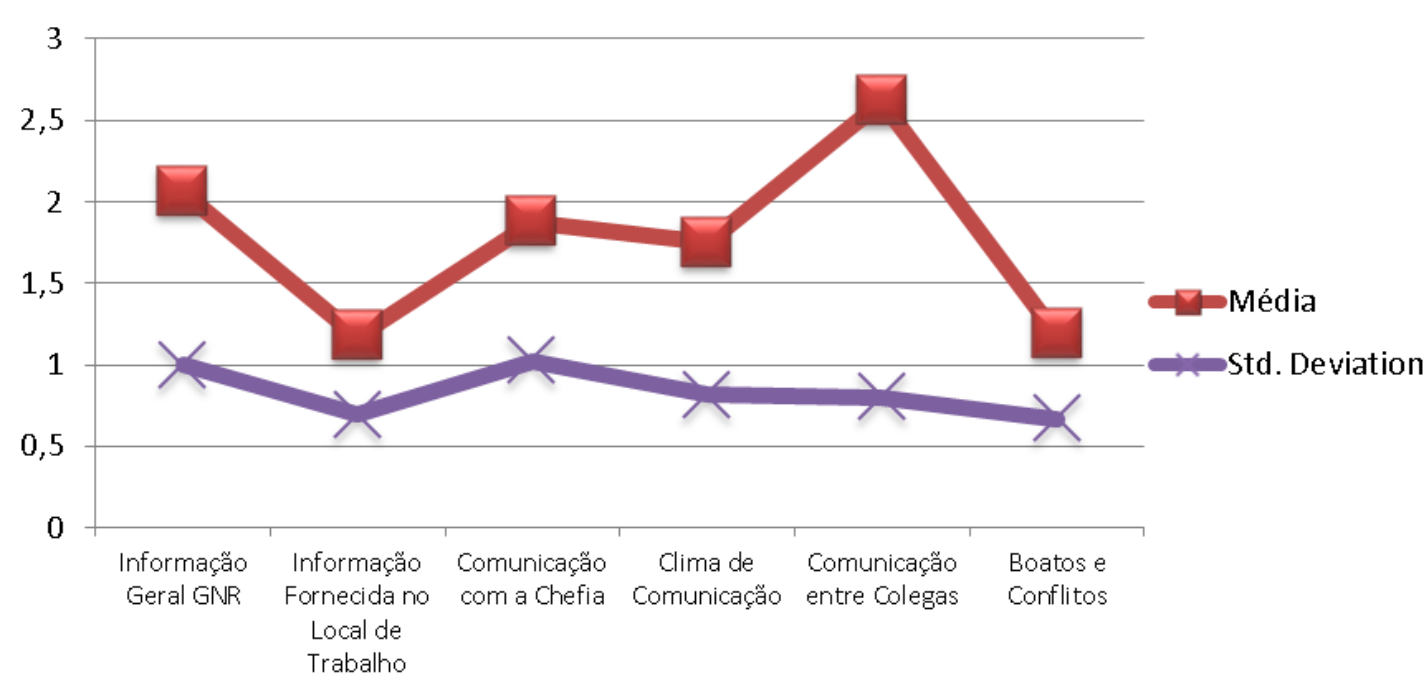

No gráfico acima apresentado podemos observar que a média obtida nas diferentes dimensões esteve compreendida entre os 1.17 e os 2.61 ; o desvio padrão oscilou entre 0,67 e 1,03. A dimensão com a média mais elevada é a Comunicação entre colegas ( $\bar{X}=2.61)$ o que traduz numa avaliação, bastante, positiva uma vez que revela a existência de camaradagem entre os militares da GNR. A dimensão com a média mais baixa foi a dimensão de Informação Fornecida no Local de Trabalho ( $\bar{X}=1.17)$ o que traduz, em termos de média, uma apreciação, negativa desta dimensão. Complementarmente, observamos que a dimensão Boatos e Conflitos foi a que originou um maior grau de convergência de opiniões entre os inquiridos tendo em consideração o valor do desviopadrão das respostas $(\sigma=0,67)$. Em contrapartida a dimensão Comunicação com a Chefia foi a que motivou um maior grau de divergência opiniões entre os inquiridos tendo em consideração o valor da dispersão $(\sigma=1,03)$.

De acordo com os dados obtidos, iremos ordenar as dimensões por ordem decrescente, mediante as respetivas médias de pontuação, relativamente à Informação e Comunicação:

A) Informação e Comunicação: $1^{\mathrm{a}}$ Comunicação entre Colegas; $2^{\mathrm{a}}$ Informação Geral sobre a GNR; $3^{\text {a }}$ Comunicação com a Chefia; $4^{\text {a }}$ Clima de Comunicação; $5^{\text {a }}$ Boatos e Conflitos; $6^{\mathrm{a}}$ Informação fornecida no Local de Trabalho. 
No que respeita à parte dos Meios e Instrumentos de CI não foi procedida a esta ordenação dado que o conteúdo dos itens, não aconselha o mesmo tratamento.

Seguidamente na descrição dos dados obtidos (Apêndice C), iremos dar relevo aos itens que obtiveram maiores e menores pontuações, com o objetivo de apresentar sugestões, que fundamentem melhorias que possam ser introduzidas. De referir que foi necessário inverter as pontuações dos itens formulados pela negativa, desta forma a apresentação do conteúdo desses itens será também invertida de modo a obter coerência com as novas pontuações e assim tornar mais inteligível os dados apresentados.

\subsection{A) Informação e Comunicação}

\section{Comunicacão entre Colegas}

Esta dimensão foi a mais pontuada no conjunto do questionário $(\bar{X}=2.61 ; \sigma=0,80)$ sendo o item 21 "Sinto que a informação entre colegas é precisa e de facil circulação" o mais pontuado. O item 20 "Agrada-me o modo como a comunicação entre colegas funciona na instituição." foi o menos pontuado. Sendo que a percentagem de opiniões dos inquiridos recai sobre o nível de concordância em ambos os itens.

\section{Informacão Geral sobre a GNR}

Esta dimensão foi a segunda mais pontuada no conjunto do questionário ( $\bar{X}=2,06$; $\sigma=0,99)$ sendo o item 1 "A informação sobre as politicas e objetivos da instituição que recebo é suficiente" o mais pontuado, O item 2 "A informação que recebo sobre as mudanças na GNR é suficiente" e o item 3 "A informação sobre as orientações da gestão da GNR que recebo é adequada" são os menos pontuados. Sendo que no item 1 a percentagem de opiniões dos inquiridos recai sobre o nível de concordância e nos itens 2 e 3 a percentagem de opiniões aponta para o nível de discordância.

\section{Comunicacão com a chefia}

Esta dimensão foi a terceira mais pontuada no conjunto do questionário ( $\bar{X}=1,88 ; \sigma=1,03$ ) sendo o item 11 "Quando comunico informações ruins à minha chefia tendo a apresentá- 
las mais atenuadas" o mais pontuado, O item 10 "Tendo a evitar dar informações ruins à minha chefia" foi o menos pontuado. Sendo que a percentagem de opiniões dos inquiridos recai sobre o nível de concordância em ambos os itens.

\section{Clima de Comunicacão}

Esta dimensão foi a quarta mais pontuada no conjunto do questionário $(\bar{X}=1,75 ; \sigma=0,81)$ sendo o item 18 "Nesta instituição as pessoas sentem-se à vontade para expressar livremente a suas opiniões" o mais pontuado, $\mathrm{O}$ item 16 "A comunicação nesta instituição incentiva-me a alcançar os meus objetivos" foi o menos pontuado. Sendo que a percentagem de opiniões dos inquiridos recai sobre o nível de concordância em ambos os itens.

\section{Boatos e conflitos existentes na GNR}

Esta dimensão foi a quinta mais pontuada no conjunto do questionário ( $\bar{X}=1,18 ; \sigma=0,67$ ) sendo o item 28 "Na GNR os boatos são muito frequentes" o mais pontuado, O item 29 "Nesta instituição os boatos são rapidamente desmistificados" foi o menos pontuado. Sendo que a percentagem de opiniões dos inquiridos recai sobre o nível de concordância em ambos os itens, de realçar que o item 28 apresentou uma percentagem muito elevada $(72 \%)$.

\section{Informacão fornecida no Local de Trabalho}

Esta dimensão foi a menos pontuada no conjunto do questionário $(\bar{X}=1,17 ; \sigma=0,69)$ sendo o item 8 "A informação oral é insuficiente" o mais pontuado, o item 9 "A informação escrita é demasiada" foi o menos pontuado. Sendo que a percentagem de opiniões dos inquiridos recai sobre o nível de concordância em ambos os itens.

\subsection{B) Meios e Instrumentos de Comunicação Interna}

De seguida passamos a apresentar os dados relativos aos Meios e Instrumentos de CI, para uma consulta mais detalhada deverá consultar-se o Apêndice C. 


\section{Utilizacão dos Meios e Instrumentos de CI}

$\mathrm{Na}$ análise dos Meios e Instrumentos de CI mais utilizados (gráfico 8) pode observar-se que a média desta dimensão está compreendida entre 1.17 e 2.82 , sendo que os inquiridos consideram que o meio mais utilizado entre os militares da GNR é o correio eletrónico ( $\bar{X}=2.82)$ e o meio considerado como menos utilizado é a videoconferência $(\bar{X}=1.17)$.

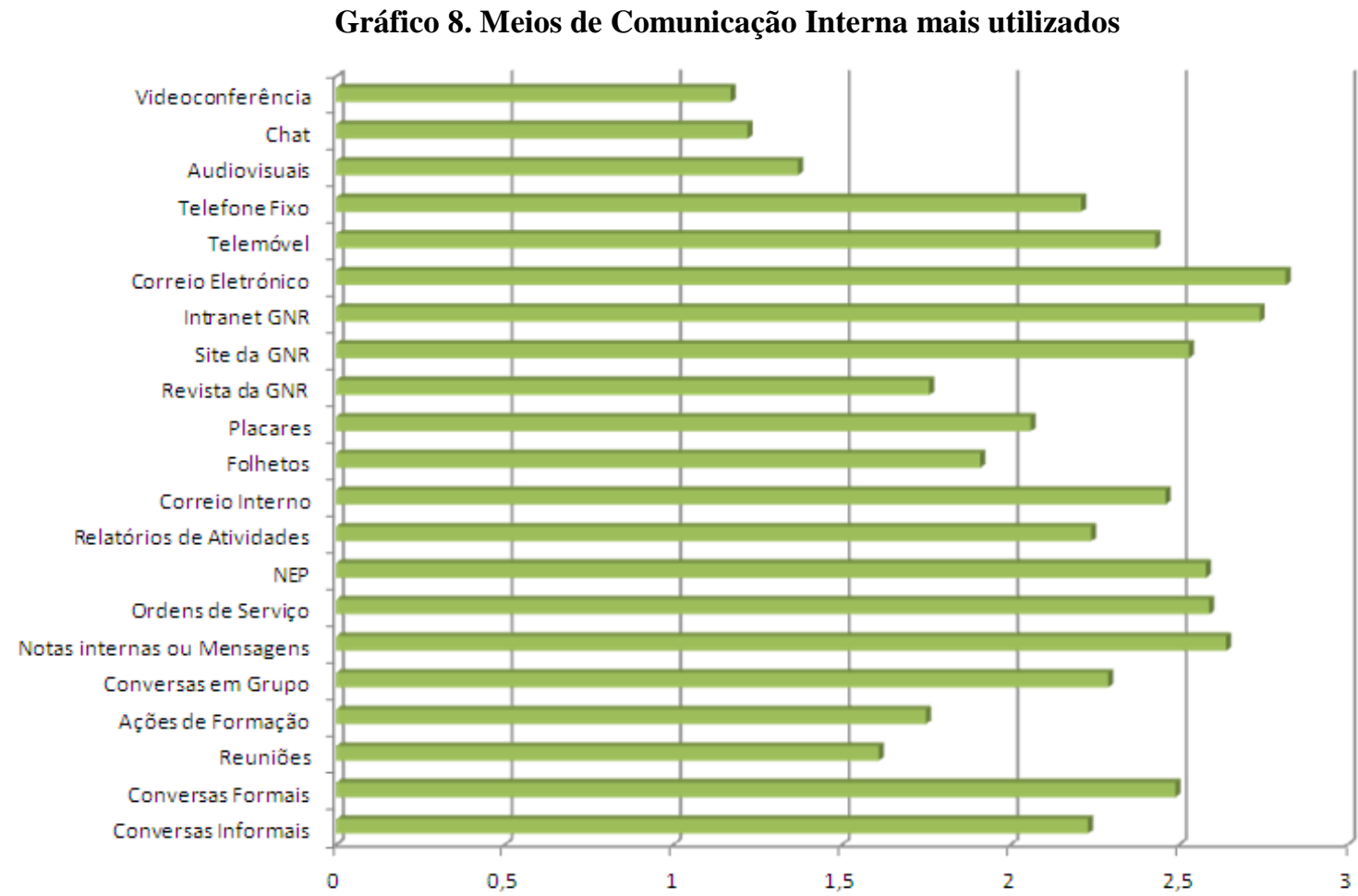

Seguidamente na descrição dos dados obtidos (consultar apêndice C), irá realçar-se a percentagem de inquiridos que evidenciam respostas de sentido favorável ou desfavorável relativamente aos meios de comunicação acima referidos, com o objetivo de apresentar sugestões, que fundamentem melhorias que possam ser introduzidas. Os meios e instrumentos de Comunicação Interna apresentados seguidamente encontram-se ordenados de acordo com as médias obtidas em função do que é considerado pelos inquiridos o mais utilizado para o menos utilizado. 
Tabela 3. Utilização dos Meios e Instrumentos de CI

\begin{tabular}{lccc}
\hline \multicolumn{1}{c}{ Meios e Instrumentos de Cl } & $\bar{X}$ & $\begin{array}{c}\text { \% de inquiridos que não } \\
\text { usa nem consulta }\end{array}$ & $\begin{array}{c}\text { \% de Utilização / } \\
\text { Consulta }\end{array}$ \\
\hline Correio Eletrónico & 2.82 & $9 \%$ & $91 \%$ \\
\hline Intranet na GNR & 2.74 & $13 \%$ & $87 \%$ \\
\hline Notas Internas ou Mensagens & 2.64 & $18 \%$ & $82 \%$ \\
\hline Ordens de Serviço & 2.59 & $20 \%$ & $80 \%$ \\
\hline NEP & 2.58 & $21 \%$ & $79 \%$ \\
Site da GNR & 2.53 & $24 \%$ & $76 \%$ \\
Conversas Formais & 2.49 & $25 \%$ & $75 \%$ \\
\hline Correio Interno & 2.46 & $27 \%$ & $73 \%$ \\
\hline Telemóvel & 2.43 & $29 \%$ & $71 \%$ \\
\hline Conversas em Grupo & 2.29 & $35 \%$ & $65 \%$ \\
Relatório de Atividades & 2.24 & $38 \%$ & $62 \%$ \\
Conversas Informais & 2.23 & $39 \%$ & $61 \%$ \\
\hline Telefone Fixo & 2.21 & $39 \%$ & $61 \%$ \\
\hline Placares & 2.06 & $47 \%$ & $53 \%$ \\
\hline Folhetos & 1.91 & $54 \%$ & $46 \%$ \\
\hline Revista da GNR & 1.76 & $62 \%$ & $38 \%$ \\
\hline Ações de Formação & 1.75 & $63 \%$ & $37 \%$ \\
\hline Reuniões & 1.61 & $70 \%$ & $30 \%$ \\
\hline Audiovisuais & 1.37 & $81 \%$ & 19 \\
\hline Chat & 1.22 & $89 \%$ & $11 \%$ \\
\hline Videoconferência & 1.17 & $92 \%$ & $8 \%$ \\
\hline
\end{tabular}

Observando a tabela 3 pode verificar-se que o Correio Eletrónico é o meio de CI considerado pelos inquiridos como o mais utilizado ( $\bar{X}=2.82$ ), mas ao qual está associada uma percentagem de $9 \%$ de inquiridos que evidenciou não utilizar este meio e $91 \%$ de respostas que traduzem a utilização do correio eletrónico por parte dos inquiridos. Analisase ainda que a Videoconferência é o meio de CI considerado pelos inquiridos como menos utilizado ( $\bar{X}=1.17$ ), ao qual está associada uma percentagem de $92 \%$ de inquiridos que evidenciou não utilizar este meio e $8 \%$ de respostas que traduzem a utilização de videoconferência por parte dos inquiridos.

\section{B) Meios e Instrumentos de Comunicação Interna}

De seguida passamos a apresentar os dados relativos aos Meios e Instrumentos de CI, para uma consulta mais detalhada deve consultar-se o Apêndice C. 


\section{Eficácia dos Meios e Instrumentos de Comunicação Interna}

$\mathrm{Na}$ análise dos Meios e Instrumentos de Comunicação Interna mais eficazes (gráfico 9) pode observar-se que a média desta dimensão está compreendida entre 1.57 e 2.84 , sendo que os inquiridos consideram que o meio mais eficaz entre os militares da GNR é o correio eletrónico ( $\bar{X}=2.84)$ e o meio considerado menos eficaz é o Chat ( $\bar{X}=1.57)$.

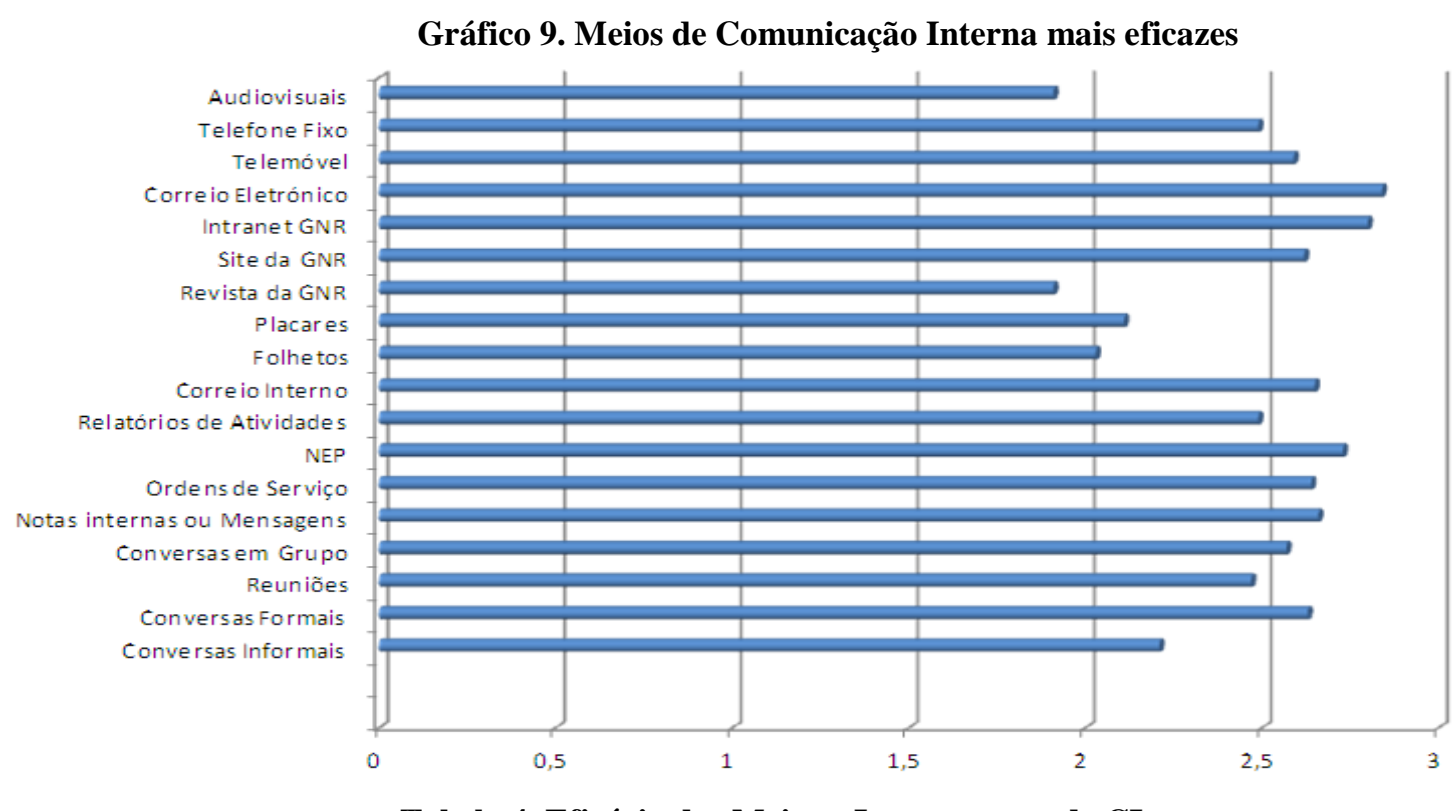

Tabela 4. Eficácia dos Meios e Instrumentos de CI

\begin{tabular}{|c|c|c|c|}
\hline Meios e Instrumentos de CI & $\bar{X}$ & \% de ineficácia & \% de eficácia \\
\hline Correio Eletrónico & 2,84 & $8 \%$ & $92 \%$ \\
\hline Intranet na GNR & 2,80 & $10 \%$ & $90 \%$ \\
\hline NEP & 2.73 & $13 \%$ & $87 \%$ \\
\hline Notas Internas ou Mensagens & 2,66 & $17 \%$ & $83 \%$ \\
\hline Correio Interno & 2,65 & $17 \%$ & $83 \%$ \\
\hline Ordens de Serviço & 2,64 & $18 \%$ & $82 \%$ \\
\hline Conversas Formais & 2,63 & $19 \%$ & $81 \%$ \\
\hline Site da GNR & 2.62 & $19 \%$ & $81 \%$ \\
\hline Telemóvel & 2,59 & $20 \%$ & $80 \%$ \\
\hline Conversas em Grupo & 2,57 & $22 \%$ & $78 \%$ \\
\hline Relatório de Atividades & 2,49 & $25 \%$ & $75 \%$ \\
\hline Telefone Fixo & 2,49 & $25 \%$ & $75 \%$ \\
\hline Reuniões & 2,47 & $27 \%$ & $73 \%$ \\
\hline Conversas Informais & 2,21 & $39 \%$ & $61 \%$ \\
\hline Placares & 2,11 & $44 \%$ & $56 \%$ \\
\hline Folhetos & 2,03 & $49 \%$ & $51 \%$ \\
\hline Revista da GNR & 1,91 & $54 \%$ & $46 \%$ \\
\hline Audiovisuais & 1,91 & $54 \%$ & $46 \%$ \\
\hline Videoconferência & 1,59 & $71 \%$ & $29 \%$ \\
\hline Chat & 1,57 & 71\% & $29 \%$ \\
\hline
\end{tabular}


Observando a tabela 4 pode verificar-se que o Correio Eletrónico é o meio de Comunicação Interna considerado pelos inquiridos como o mais eficaz ( $\bar{X}=2,84)$, ao qual está associada uma percentagem de $8 \%$ que consideram este meio como ineficaz e $92 \%$ de respostas traduzem a eficácia do correio eletrónico por parte dos inquiridos. Analisa-se ainda que o Chat é o meio de Comunicação Interna considerado pelos inquiridos como o menos eficaz ( $\bar{X}=1.57$ ), ao qual está associada uma percentagem de $71 \%$ que considera este meio como ineficaz e $29 \%$ de respostas que traduzem a utilização do chat por parte dos inquiridos.

De seguida irá proceder-se à descrição dos dados obtidos (consultar apêndice C) de 3 perguntas, em que as respostas não têm níveis de concordância. Neste sentido, iremos dar relevo ao meio que os inquiridos consideram como sendo o mais adequado na transmissão da informação (gráfico 10), aos assuntos mais relevantes que os inquiridos gostariam que fossem divulgados com vista a melhorar a Comunicação Interna na GNR (gráfico 11), bem como será verificado o conhecimento que os inquiridos têm acerca da existência de um serviço responsável pela CI na GNR (gráfico 12).

\section{Gráfico 10 - Meio mais adequado para a transmissão da Informação}

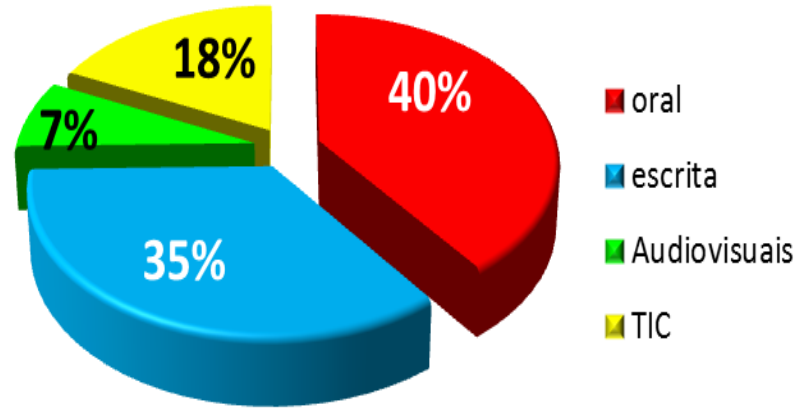

No gráfico 10 pode-se observar que os inquiridos consideram o meio de comunicação oral como sendo o mais adequado para a transmissão da informação (40\%) sendo o meio de audiovisuais o meio considerado como o menos adequado na transmissão de informação (7\%). 


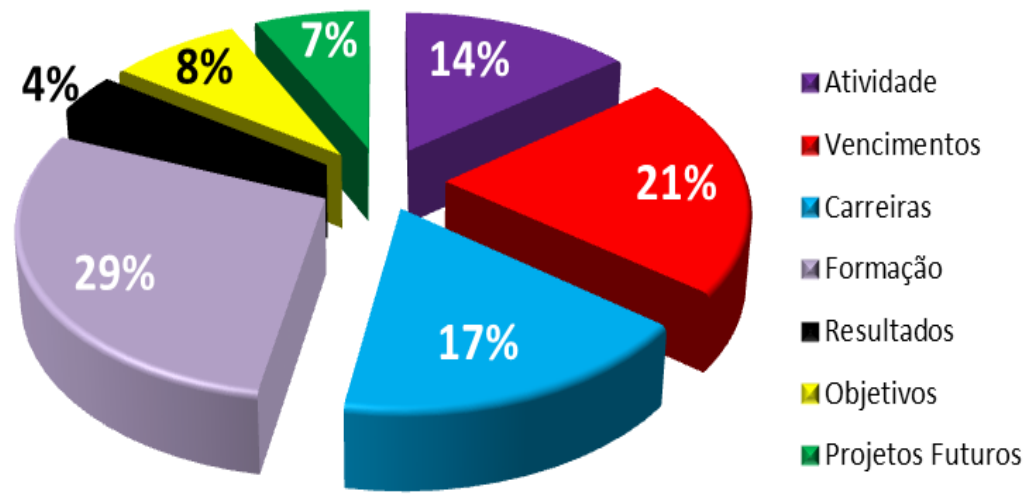

Os dados apresentados no gráfico 11 correspondem aos assuntos que deveriam ser divulgados para melhorar a CI na GNR, de salientar que 129 inquiridos não responderam a esta questão. Verificando-se que a Formação é o assunto principal a ser desenvolvido de forma a contribuir na melhoria da CI na GNR apresentando $29 \%$ das respostas dadas e os Resultados do trabalho é o assunto que os inquiridos consideram como sendo o de menor importância para melhorar a CI na GNR, com 4\% das respostas.

Gráfico 12 - Conhecimento da existência de um serviço responsável pela CI na GNR

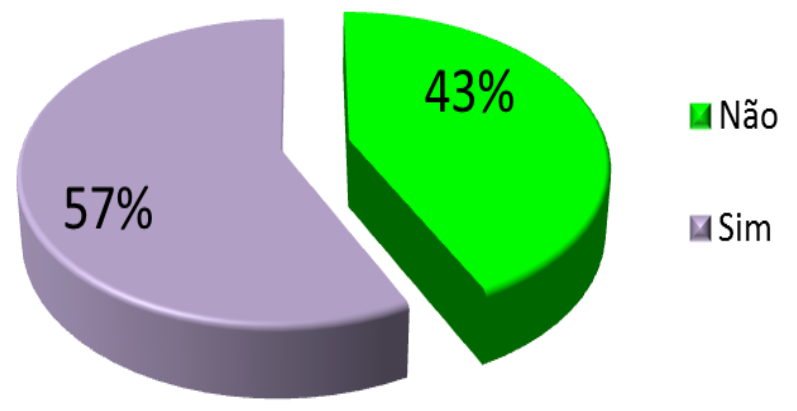

Observando o gráfico 12 verifica-se que 43\% dos inquiridos afirma não ter conhecimento da existência de um serviço responsável pela comunicação interna na GNR. 


\subsection{Influência das variáveis sociodemográficas nas dimensões de Comunicação e Informação}

Como já referido anteriormente, a presente investigação tem como finalidade caracterizar a Comunicação Interna na Guarda Nacional Republicana e tentar melhorar o processo de comunicação da GNR, através do uso de diferentes meios de comunicação, que os mantenha informados, integrados e motivados, de modo a contribuir com o seu trabalho, para o alcance dos objetivos organizacionais, desta forma irá analisar-se de que modo, as características Sociodemográficas têm ou não influência na visão sobre a comunicação e informação na GNR.

Foi realizada uma comparação da média das dimensões relativamente às variáveis sociodemográficas, designadamente: Sexo; Idade; Habilitações Literárias; Comando Territorial; Antiguidade e Posto Militar. Para tal foi utilizado o teste ANOVA (Apêndice D).

Conforme sabemos, através deste teste, pretende-se testar se existem diferenças significativas no modo como os diferentes níveis das variáveis sociodemográficas pontuam as dimensões objeto de análise.

\section{Formulação de hipóteses}

Ho: não há diferenças significativas entre os grupos

H1: há diferenças significativas entre os grupos

Rejeita-se a hipótese nula quando o $p$-value é inferior ao nível de significância do teste $(\alpha)$.

Lembramos que nas tabelas seguintes, em virtude das pontuações atribuídas a cada uma das alternativas de resposta, valores mais baixos significam opiniões mais positivas, relativamente ao conteúdo da dimensão.

\section{$\underline{\text { Sexo }}$}

A tabela 5 permite verificar se existem diferenças significativas entre o Sexo e as dimensões que constituem a parte A do questionário (Comunicação e Informação). 
Tabela 5 - Diferenças de pontuações entre Sexos

\begin{tabular}{|c|c|c|}
\hline \multicolumn{3}{|c|}{ ANOVA } \\
\hline & $\mathrm{F}$ & Sig. \\
\hline Informação Geral GNR & ,055 & ,815 \\
\hline Informação Fornecida no Local de &, 001 & ,978 \\
\hline \multicolumn{3}{|l|}{ Trabalho } \\
\hline Comunicação com a Chefia & ,088 & ,768 \\
\hline Clima de Comunicação & ,003 & ,959 \\
\hline Comunicação entre Colegas & ,243 & ,622 \\
\hline Boatos e Conflitos & 1,193 & ,276 \\
\hline
\end{tabular}

Analisando a tabela 5 podemos verificar que todas as dimensões apresentam um $p$ value superior a qualquer nível de significância aceitável, logo aceita-se a hipótese nula, concluindo que não existem diferenças significativas entre os Sexos no modo como pontuam as dimensões do questionário em análise.

\section{Idade}

Observemos agora a tabela seguinte:

Tabela 6 - Diferenças de pontuações entre Idades

\begin{tabular}{|c|c|c|}
\hline \multicolumn{3}{|l|}{ ANOVA } \\
\hline & $\mathrm{F}$ & Sig. \\
\hline Informação Geral GNR & 2,934 & ,034 \\
\hline Informação Fornecida no Local de Trabalho & 918 & ,433 \\
\hline Comunicação com a Chefia & 1,787 &, 150 \\
\hline Clima de Comunicação & 2,919 & ,035 \\
\hline Comunicação entre Colegas &, 536 & ,658 \\
\hline Boatos e Conflitos & ,921 & 431 \\
\hline
\end{tabular}

Analisando a tabela 6 podemos observar que a maioria das dimensões apresentam um p-value superior a qualquer nível de significância aceitável, logo aceita-se hipótese nula nestes casos, concluindo que não há diferenças estatisticamente significativas no modo como são pontuadas a maior parte das dimensões de Comunicação e Informação em função da Idade para um nível de significância de referência $(\leq 0.05)$.

Contudo, há que salientar duas exceções, que se referem à dimensão de Informação Geral na GNR e Clima de Comunicação em que observamos um p-value= 0.034 e 0.035 
respetivamente, sendo inferiores ao nível de significância de 0.05 teremos de rejeitar a hipótese nula e portanto concluir que existem diferenças significativas no modo como cada sexo pontua estas dimensões.

Tabela 7 - Diferenças de médias entre idades

\begin{tabular}{|c|c|c|c|c|c|}
\hline \multirow{6}{*}{ Informação Geral GNR } & & 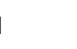 & Mean & Std. Deviation & Std. Error \\
\hline & $20-30$ & 79 & 2,9409 & ,88797 & ,09990 \\
\hline & $31-40$ & 98 & 3,1020 & 1,10545 & ,11167 \\
\hline & $41-50$ & 62 & 2,7312 & ,89897 & ,11417 \\
\hline & $51-60$ & 2 & 1,6667 & ,00000 &, 00000 \\
\hline & Total & 241 & 2,9419 & ,99552 &, 06413 \\
\hline \multirow[t]{5}{*}{ Clima de Comunicação } & $20-30$ & 79 & 3,4506 & ,83111 &, 09351 \\
\hline & $31-40$ & 98 & 3,2204 & ,88072 & ,08897 \\
\hline & $41-50$ & 62 & 3,0710 & ,62526 & 07941 \\
\hline & $51-60$ & 2 & 2,8000 & ,28284 & ,20000 \\
\hline & Total & 241 & 3,2539 & ,81317 & 05238 \\
\hline
\end{tabular}

No seguimento da análise feita anteriormente a tabela 7 demonstra que na dimensão de Informação Geral na GNR, os inquiridos do grupo etário de 51-60 percecionam uma opinião mais positiva do conteúdo desta dimensão $(\bar{X}=1.67)$ do que os inquiridos do grupo etário de 31-40 anos $(\bar{X}=3.10)$ Na dimensão de Clima de Comunicação os inquiridos do grupo etário 51-60 refletem uma opinião mais positiva do conteúdo desta dimensão ( $\bar{X}=2.80$ ) do que os inquiridos do grupo etário de 20-30 anos $(\bar{X}=3.45)$. Talvez porque os militares mais velhos têm uma comunicação mais privilegiada.

\section{Habilitacões Literárias}

Atenda-se agora à tabela seguinte:

Tabela 8 - Diferenças de pontuações entre níveis das Habilitações Literárias

\begin{tabular}{llr}
\hline \hline \multicolumn{1}{c}{ ANOVA } & F & Sig. \\
Informação Geral GNR & 1,717 &, 147 \\
Informação Fornecida no Local de Trabalho & 1,779 &, 134 \\
Comunicação com a Chefia & 1,821 &, 126 \\
Clima de Comunicação & 1,451 &, 218 \\
Comunicação entre Colegas &, 667 &, 615 \\
Boatos e Conflitos &, 209 &, 933 \\
\hline \hline
\end{tabular}


Analisando a tabela 8 podemos verificar que todas as dimensões apresentam um $p$ value superior a qualquer nível de significância, logo aceita-se hipótese nula, concluindo que não existem diferenças significativas entre as habilitações literárias e as dimensões que compõem o questionário.

\section{Comando Territorial}

Atenda-se agora à tabela seguinte:

Tabela 9 - Diferenças de pontuações entre níveis de Comando Territorial

\begin{tabular}{lcr}
\hline \multicolumn{1}{c}{ ANOVA } & & \\
& \multicolumn{1}{c}{ Sig. } \\
& &, 007 \\
Informação Geral GNR & 2,100 &, 169 \\
Informação Fornecida no Local & 1,333 & \\
de Trabalho & &, 705 \\
Comunicação com a Chefia &, 795 &, 050 \\
Clima de Comunicação & 1,649 &, 070 \\
Comunicação entre Colegas & 1,567 &, 014 \\
Boatos e Conflitos & 1,944 & \\
\hline \hline
\end{tabular}

Analisando a tabela 9 podemos observar que as dimensões "Informação Geral GNR", "Clima de Comunicação" e "Boatos e Conflitos apresentam um p-value inferior ou igual a qualquer nível de significância, logo rejeita-se a hipótese nula, concluindo que existem diferenças significativas entre o modo como diferentes Comandos Territoriais pontuam as dimensões mencionadas. 
Tabela 10 - Diferenças significativas entre níveis de Comando Territorial em três Dimensões

\begin{tabular}{|c|c|c|c|c|c|c|c|c|}
\hline Dimensão & $\begin{array}{l}\text { Comando } \\
\text { Territorial }\end{array}$ & Médias & Dimensão & $\begin{array}{l}\text { Comando } \\
\text { Territorial }\end{array}$ & Médias & Dimensão & $\begin{array}{l}\text { Comando } \\
\text { Territorial }\end{array}$ & Médias \\
\hline \multirow{20}{*}{ 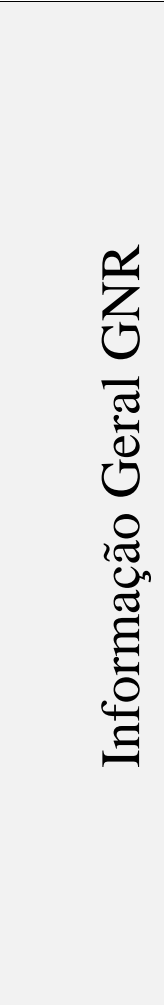 } & Bragança & 2,3333 & \multirow{20}{*}{ 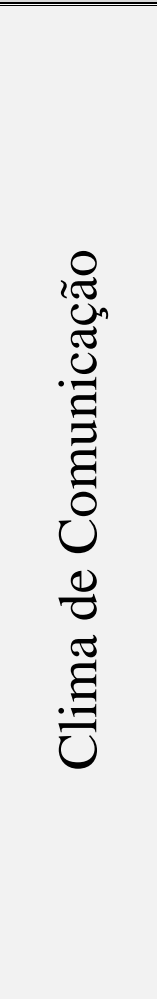 } & Santarém & 2,6 & \multirow{20}{*}{ 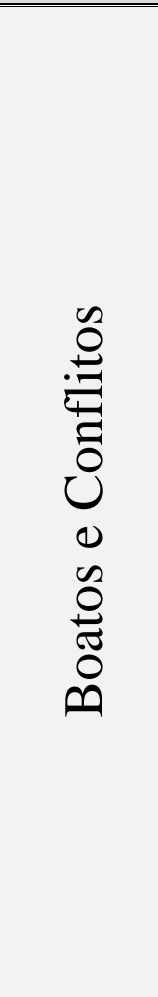 } & Madeira & 3,3459 \\
\hline & Évora & 2,5333 & & Madeira & 2,8947 & & V. Castelo & 3,5595 \\
\hline & V. Castelo & 2,6389 & & Açores & 2,9 & & Bragança & 3,6984 \\
\hline & Faro & 2,7143 & & Bragança & 2,9556 & & Portalegre & 3,7143 \\
\hline & Madeira & 2,7895 & & Guarda & 3 & & Leiria & 3,7619 \\
\hline & Aveiro & 2,9111 & & V.Castelo & 3,025 & & Açores & 3,7857 \\
\hline & Total & 2,9419 & & Faro & 3,1429 & & Total & 3,8156 \\
\hline & Braga & 2,9649 & & Aveiro & 3,1867 & & Beja & 3,8571 \\
\hline & Leiria & 3 & & Évora & 3,24 & & Évora & 3,8571 \\
\hline & Portalegre & 3 & & Total & 3,2539 & & Viseu & 3,8701 \\
\hline & Santarém & 3 & & Leiria & 3,2667 & & C. Branco & 3,8889 \\
\hline & Viseu & 3 & & Setúbal & 3,35 & & Porto & 3,9011 \\
\hline & Setúbal & 3,0833 & & Portalegre & 3,36 & & Guarda & 3,9143 \\
\hline & Açores & 3,1667 & & Beja & 3,4 & & Aveiro & 3,9333 \\
\hline & Coimbra & 3,1905 & & Coimbra & 3,4 & & Setúbal & 3,9643 \\
\hline & Porto & 3,4615 & & Viseu & 3,4 & & Coimbra & 3,9796 \\
\hline & Beja & 3,6667 & & Lisboa & 3,52 & & Faro & 4,0612 \\
\hline & C. Branco & 3,6667 & & Porto & 3,5846 & & Braga & 4,1128 \\
\hline & Guarda & 3,6667 & & C. Branco & 3,7111 & & Santarém & 4,1429 \\
\hline & Lisboa & 3,9333 & & Braga & 3,8211 & & Lisboa & 4,4 \\
\hline
\end{tabular}

No seguimento da análise feita anteriormente a tabela 10 demonstra que na dimensão de Informação Geral na GNR, os inquiridos do Comando Territorial de Bragança revelam uma opinião mais positiva do conteúdo desta dimensão $(\bar{X}=2,33)$ do que os inquiridos do Comando Territorial de Lisboa $(\bar{X}=3,93)$. Na dimensão de Clima de Comunicação os inquiridos do Comando Territorial de Santarém, percecionam uma opinião mais positiva do conteúdo desta dimensão $(\bar{X}=2,6)$ do que os inquiridos do Comando Territorial de Braga ( $\bar{X}=3,82)$. Na dimensão Boatos e Conflitos os inquiridos do Comando Territorial da Madeira percecionam uma opinião mais positiva do conteúdo desta dimensão $(\bar{X}=3,34)$ do que os inquiridos do Comando Territorial de Lisboa $(\bar{X}=4,44)$ 


\section{$\underline{\text { Antiguidade }}$}

Consideremos agora a tabela seguinte:

Tabela 11 - Diferenças de pontuações entre níveis de Antiguidade

\begin{tabular}{|c|c|c|c|c|c|c|}
\hline \multicolumn{7}{|c|}{ ANOVA } \\
\hline & & Sum of Squares & df & Mean Square & $\mathrm{F}$ & Sig. \\
\hline Informação Geral GNR & $\begin{array}{l}\text { Between Groups } \\
\text { Within Groups } \\
\text { Total }\end{array}$ & $\begin{array}{r}8,216 \\
229,638 \\
237,853 \\
\end{array}$ & $\begin{array}{r}5 \\
235 \\
240 \\
\end{array}$ & $\begin{array}{r}1,643 \\
, 977\end{array}$ & 1,682 &, 140 \\
\hline $\begin{array}{l}\text { Informação Fornecida no } \\
\text { Local de Trabalho }\end{array}$ & $\begin{array}{l}\text { Between Groups } \\
\text { Within Groups } \\
\text { Total }\end{array}$ & $\begin{array}{r}2,676 \\
112,034 \\
114,710 \\
\end{array}$ & $\begin{array}{r}5 \\
235 \\
240 \\
\end{array}$ & $\begin{array}{l}, 535 \\
, 477\end{array}$ & 1,122 & ,349 \\
\hline Comunicação com a Chefia & $\begin{array}{l}\text { Between Groups } \\
\text { Within Groups } \\
\text { Total }\end{array}$ & $\begin{array}{r}3,409 \\
248,856 \\
252,266 \\
\end{array}$ & $\begin{array}{r}5 \\
235 \\
240 \\
\end{array}$ & $\begin{array}{r}, 682 \\
1,059\end{array}$ & ,644 & ,666 \\
\hline Clima de Comunicação & $\begin{array}{l}\text { Between Groups } \\
\text { Within Groups } \\
\text { Total }\end{array}$ & $\begin{array}{r}7,221 \\
151,477 \\
158,699 \\
\end{array}$ & $\begin{array}{r}5 \\
235 \\
240 \\
\end{array}$ & $\begin{array}{r}1,444 \\
, 645\end{array}$ & 2,241 &, 051 \\
\hline Comunicação entre Colegas & $\begin{array}{l}\text { Between Groups } \\
\text { Within Groups } \\
\text { Total }\end{array}$ & $\begin{array}{r}1,343 \\
152,214 \\
153,556 \\
\end{array}$ & $\begin{array}{r}5 \\
235 \\
240 \\
\end{array}$ & $\begin{array}{l}, 269 \\
, 648\end{array}$ & ,415 & ,838 \\
\hline Boatos e Conflitos & $\begin{array}{l}\text { Between Groups } \\
\text { Within Groups } \\
\text { Total }\end{array}$ & $\begin{array}{r}2,681 \\
103,761 \\
106,442 \\
\end{array}$ & $\begin{array}{r}5 \\
235 \\
240 \\
\end{array}$ & $\begin{array}{l}, 536 \\
, 442\end{array}$ & 1,214 & ,303 \\
\hline
\end{tabular}

Analisando a tabela 11 podemos observar que a dimensão "Clima de Comunicação" apresenta um p-value inferior ou igual a qualquer nível de significância, logo rejeita-se a hipótese nula, concluindo que existem diferenças significativas entre a Antiguidade e a dimensão mencionada. 
Tabela 12 - Diferenças estatisticamente significativas entre a Antiguidade e o Clima de Comunicação

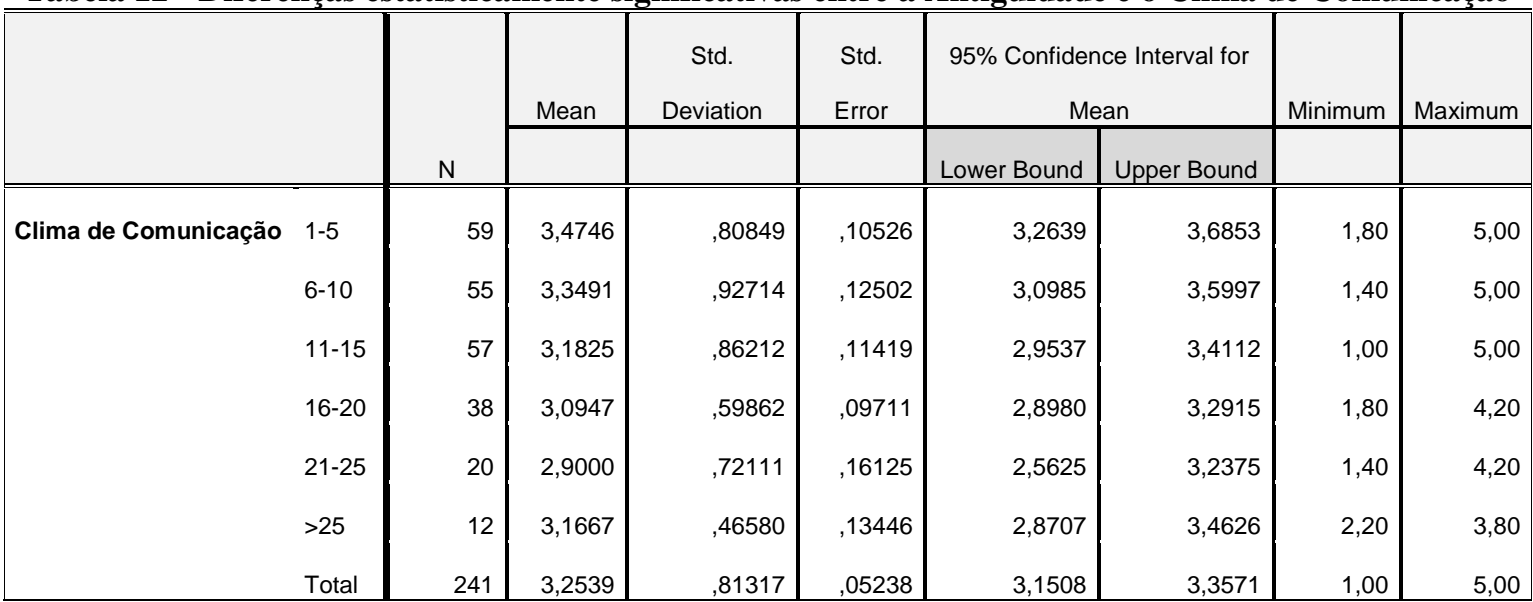

No seguimento da análise feita anteriormente a tabela 12 demonstra que na dimensão de Clima de Comunicação os inquiridos com uma Antiguidade de 21 a 25 anos, evidenciam uma opinião mais positiva do conteúdo desta dimensão $(\bar{X}=2,90)$ do que os inquiridos com uma Antiguidade de 1 a 5 anos $(\bar{X}=3,47)$.

\section{Posto Militar}

Observemos agora a tabela seguinte:

Tabela 13 - Diferenças de pontuações entre o Posto Militar e as Dimensões

\begin{tabular}{|c|c|c|c|c|c|c|}
\hline \multicolumn{7}{|c|}{ ANOVA } \\
\hline & & $\begin{array}{l}\text { Sum of } \\
\text { Squares }\end{array}$ & $\mathrm{df}$ & Mean Square & $\mathrm{F}$ & Sig. \\
\hline \multirow[t]{3}{*}{ Informação Geral GNR } & Between Groups & 12,283 & 4 & 3,071 & 3,213 & ,014 \\
\hline & Within Groups & 225,570 & 236 & ,956 & & \\
\hline & Total & 237,853 & 240 & & & \\
\hline \multirow{3}{*}{$\begin{array}{l}\text { Informação Fornecida } \\
\text { no Local de Trabalho }\end{array}$} & Between Groups & 1,288 & 4 &, 322 & ,670 & ,613 \\
\hline & Within Groups & 113,422 & 236 & ,481 & & \\
\hline & Total & 114,710 & 240 & & & \\
\hline \multirow{3}{*}{$\begin{array}{l}\text { Comunicação com a } \\
\text { Chefia }\end{array}$} & Between Groups & 7,137 & 4 & 1,784 & 1,718 &, 147 \\
\hline & Within Groups & 245,129 & 236 & 1,039 & & \\
\hline & Total & 252,266 & 240 & & & \\
\hline \multirow[t]{3}{*}{ Clima de Comunicação } & Between Groups & 4,806 & 4 & 1,202 & 1,843 & ,121 \\
\hline & Within Groups & 153,892 & 236 & ,652 & & \\
\hline & Total & 158,699 & 240 & & & \\
\hline Comunicação entre & Between Groups & 3,342 & 4 &, 836 & 1,313 & ,266 \\
\hline
\end{tabular}




\begin{tabular}{|ll|r|r|r|r|r|}
\hline Colegas & Within Groups & 150,214 & 236 &, 637 & & \\
& Total & 153,556 & 240 & & & \\
\hline Boatos e Conflitos & Between Groups & 2,269 & 4 &, 567 & 1,285 &, 277 \\
& Within Groups & 104,173 & 236 &, 441 & & \\
& Total & 106,442 & 240 & & & \\
\hline
\end{tabular}

Analisando a tabela 13 podemos observar que a maioria das dimensões apresentam um p-value superior a qualquer nível de significância, logo aceita-se hipótese nula para a maior parte das dimensões, concluindo que não há diferenças estatisticamente significativas entre as pontuações da maioria das dimensões de Comunicação e Informação em função do Posto Militar para um nível de significância de referência $(\leq 0.05)$.

Contudo, é de salientar a exceção que se refere à dimensão de Informação Geral na GNR em que observamos um p-value $=0.014$, sendo inferior ao nível de significância de 0.05 teremos de rejeitar a hipótese nula e portanto concluir que existem diferenças significativas no modo como é pontuada esta dimensão em função do posto militar (Tabela 12).

Tabela 14 - Diferenças estatisticamente significativas entre o Posto Militar e a Informação Geral na GNR.

\begin{tabular}{|c|c|c|c|c|c|c|c|c|c|}
\hline & & \multirow[b]{2}{*}{$\mathrm{N}$} & \multirow[b]{2}{*}{ Mean } & \multirow[b]{2}{*}{$\begin{array}{c}\text { Std. } \\
\text { Deviation }\end{array}$} & \multirow[b]{2}{*}{$\begin{array}{l}\text { Std. } \\
\text { Error }\end{array}$} & \multicolumn{2}{|c|}{$\begin{array}{l}\text { 95\% Confidence Interval } \\
\text { for Mean }\end{array}$} & \multirow[b]{2}{*}{ Minimum } & \multirow[b]{2}{*}{ Maximum } \\
\hline & & & & & & $\begin{array}{l}\text { Lower } \\
\text { Bound }\end{array}$ & $\begin{array}{l}\text { Upper } \\
\text { Bound }\end{array}$ & & \\
\hline \multirow[t]{3}{*}{ Geral GNR } & Guarda Principal & 5 & 3,5333 & 1,44530 & ,64636 & 1,7388 & 5,3279 & 1,67 & 5,00 \\
\hline & Cabo & 74 & 2,7207 & 87590 &, 10182 & 2,5178 & 2,9237 & 1,00 & 5,00 \\
\hline & Cabo-chefe & 5 & 3,0000 & 1,05409 &, 47140 & 1,6912 & 4,3088 & 1,67 & 4,33 \\
\hline
\end{tabular}

De acordo com a análise feita anteriormente a tabela 14 demonstra que na dimensão de Informação Geral na GNR, os inquiridos do posto militar Cabo-mor revelam uma opinião mais positiva do conteúdo desta dimensão $(\bar{X}=1.33)$ do que os inquiridos do posto militar de Guarda Principal ( $\bar{X}=3.53$ ). Esta análise pode dever-se ao facto de os militares Cabo Mor possuírem mais informação do que as restantes categorias. 


\section{ANÁLISE E DISCUSSÃO DOS DADOS OBTIDOS}

Relativamente aos dados obtidos, observamos que em articulação com os objetivos previamente definidos, que os militares apontam para uma maior aproximação no relacionamento entre colegas. O facto de esta dimensão ser a mais pontuada, poderá estar relacionado com a cultura militar existente na GNR, onde os militares possuem uma elevada camaradagem e espirito de corpo, tal como foi identificado no estudo de Pereira (2006), através de uma análise SWOT, onde um dos pontos fortes da GNR em termos comunicacionais prende-se com o espirito de coesão, camaradagem e cooperação elevados, essencialmente ao nível horizontal. Essa camaradagem consiste numa estreita união entre todos os militares, que os ajuda a ultrapassar com mais facilidade as adversidades encontradas no quotidiano.

Relativamente à informação geral sobre a GNR, podemos aferir que os militares recebem informação suficiente sobre as políticas e objetivos da instituição, contudo, sentem necessidade de informação quando se trata de alguma mudança na GNR. Esta análise permite concluir que a conduta dos militares está claramente prevista em normas e regulamentos da organização e formalizada por escrito, no entanto, toda a informação não contemplada nestas normas e regulamentos, é definida a um nível interno, designadamente, nos níveis de topo da instituição, não chegando atempadamente ao nível inferior. Pelo que os militares consideram que a informação que recebem sobre as mudanças na GNR, não é suficiente.

No que concerne à comunicação com a chefia, os militares tendem a atenuar as informações negativas que transmitem às suas chefias. Esta situação poderá estar relacionada com o facto da maioria dos militares que participaram no presente estudo, pertencerem ao posto militar de Guardas, e se encontrarem no início da sua carreira, evitando assim, transmitir informações menos agradáveis às suas chefias, por terem algum receio de serem prejudicados. Esta análise vai ao encontro da teoria defendida por Dupuy, (1998), que define a comunicação em dois sentidos, descendente e ascendente, sendo a comunicação ascendente a mais suscetível de ser bloqueada, o autor justifica esta situação devido aos trabalhadores evitarem transmitir informação desfavorável, nomeadamente reclamações ou colocar questões problemáticas, com receio de serem punidos 
Complementarmente, Cushway et. al. (1998) defende que a comunicação tem como principais objetivos: partilhar informação, considerar ideias, transmitir e trocar opiniões e sentimentos, no entanto, observámos que, em termos gerais os militares não se sentem muito à vontade para expressar as suas opiniões, devido, designadamente, ao facto do clima de comunicação assumir uma gestão verticalizada. O relacionamento entre os militares varia em função da posição que ocupam na cadeia hierárquica, sendo que, os militares dirigem-se ao seu superior como "meu comandante", podendo este tipo de tratamento constituir uma barreira, à livre expressão de opiniões dos militares. Desta forma, os militares assumem comportamentos passivos, devido ao receio de serem punidos.

Observámos ainda que os boatos são frequentes na instituição e de difícil desmistificação. Apesar de a GNR apresentar um caráter burocrático e mecanicista, encontra grandes dificuldades em lidar com os seus ambientes internos, o que à partida parece elementar, revela-se numa grande complexidade. A GNR com mais de 24000 militares pode sofrer enormes abalos como consequência da instabilidade na perceção dos seus funcionários em relação ao funcionamento da instituição e seus objetivos. Nestas circunstâncias, a comunicação torna-se um dos elementos primordiais para que as estratégias organizacionais atinjam os resultados esperados. A falta de uma política de comunicação esclarecedora e estruturada que permeie o relacionamento entre a instituição e o militar pode gerar o surgimento de boatos internos, que se não forem bem diagnosticados e rapidamente desmistificados podem causar danos irreversíveis à instituição. Neste sentido, os níveis superiores devem adotar medidas que atenuem os efeitos dos boatos, procurando evitar que a informação, direcionada aos escalões inferiores, fique retida.

Relativamente à informação que é fornecida no seu local de trabalho, os militares entendem que a informação oral é insuficiente, indo ao encontro do que Westphalen, (1992), enfatiza, em que a comunicação oral é, frequentemente, imprecisa e pode ser deturpada no momento da transmissão da mensagem, devendo ser sempre acompanhada por um suporte escrito. Os resultados obtidos revelam que os militares nem sempre se consideram devidamente informados, o que, poderá condicionar o desempenho das suas funções. A falta de informação poderá estar relacionada com a retenção nos escalões superiores, que origina desmotivação e potencia a existência de boatos, que como vimos 
anteriormente, poderá ter consequências muito graves para a instituição. Poderá ainda, estar relacionada com a fraca utilização e eficácia dos meios de comunicação oral, designadamente as conversas formais e informais, as reuniões, refletindo a tendência dos militares para privilegiarem a utilização e eficácia do modo escrito, designadamente o correio eletrónico e a intranet.

No que respeita à transmissão da informação, a maioria dos militares considera que o meio mais adequado, para que esta seja completamente percetível e absorvida, é o meio oral. Nesta linha de raciocínio, uma vez que esta dimensão apresenta a média mais baixa, poder-se-ia investir mais em reuniões, conversas informais e ações de formação, uma vez que estes meios apresentam uma percentagem de utilização baixa.

Relativamente aos assuntos que os militares gostariam que fossem divulgados para melhorar a Comunicação Interna, verificou-se que a formação é a componente principal que gostariam de ver desenvolvida, seguindo-se os vencimentos e a carreira profissional. Este facto poderá estar relacionado com a área de atuação, extremamente complexa, a que estão sujeitos os militares que desempenham funções nos Postos Territoriais. Por conseguinte, a formação é, claramente, decisiva e de grande importância para a avaliação da eficácia operacional.

Segundo Clampitt, (1991) é essencial conhecer os meios e instrumentos de CI, as suas limitações e potencialidades. Da análise geral efetuada aos resultados relativos à utilização dos meios e instrumentos de comunicação interna, conclui-se que o meio mais utilizado é o correio eletrónico, seguido da intranet. Como refere Almeida, (2003), a intranet, é um dos meios de comunicação cada vez mais utilizado tendo como vantagem agregar o correio eletrónico. A utilização destes meios, onde predomina a comunicação escrita, é uma das características de uma organização mecanicista weberiana como é a GNR. A perceção e utilização do correio eletrónico pode ser reflexo das mudanças efetuadas no ano de 2009, decorrentes da reestruturação da instituição. Podemos também concluir que a utilização deste meio pode ser um indicador de que a instituição está a modernizar-se e a consolidar a sua presença numa Sociedade da Informação, cada vez mais exigente. O meio considerado menos utilizado, é a videoconferência, talvez devido ao seu custo de instalação em todo o dispositivo operacional da Guarda Nacional Republicana.

Relativamente ao meio e instrumento de comunicação interna, mais eficaz, verificámos que, mais uma vez, o correio eletrónico é o mais eficaz, seguindo-se a intranet 
e as Normas de Execução Permanente (NEP) e o meio menos eficaz foi o chat. Podemos concluir que o correio eletrónico é o meio mais utilizado e o mais eficaz, para que os militares tenham acesso à informação. De realçar que as NEP's também foram consideradas como um meio bastante eficaz, talvez por serem um documento com informação muito precisa e adaptada ao destinatário, emitidas pelas chefias para fornecer diretivas ou explicações.

No que concerne à influência das variáveis sociodemográficas nas dimensões de Comunicação e Informação, verificámos que os militares pertencentes ao grupo etário 5160 anos, revelam uma opinião mais positiva sobre a Informação Geral sobre a GNR, e sobre o Clima de Comunicação. Na dimensão Informação Geral sobre a GNR, verificamos que os Cabos-mor revelam uma opinião mais positiva do que os Guardas Principais. Esta análise pode dever-se ao facto de os Cabos-Mor possuírem mais informação em quantidade e qualidade do que as restantes categorias, em virtude do posto de Cabo-mor pertencer ao nível mais elevado da categoria de Guardas.

\subsection{Proposta de melhorias}

Com base nas reflexões e conclusões apresentadas e, considerando que a melhoria da comunicação interna depende, essencialmente, da definição e implementação de uma política e de um plano de comunicação interna na GNR, propõem-se as seguintes medidas:

- Aumentar as reuniões, conversas informais e ações de formação em quantidade e qualidade;

- Valorizar o trabalho dos militares, definindo periodicamente novos objetivos, individuais e coletivos, bem como reconhecer os seus resultados;

- Uniformizar procedimentos em todo o dispositivo;

- Elaboração de um Plano de Comunicação Interna;

- Criar uma apresentação institucional dinâmica, atrativa e simplificada da GNR que permita demonstrar em breves minutos a estrutura e a atividade operacional;

- Elaborar um Manual de Acolhimento, onde todos os elementos que iniciam funções na GNR deverão ficar a ser conhecedores da Instituição. Este Manual, criado de forma simples, deverá elucidar os iniciados sobre a Missão, Visão e 
Valores, estrutura organizacional e hierárquica (decomposta até ao último nível), e outros temas que se considerem ser pertinentes para quem entra de novo para a Instituição;

- A elaboração de uma Newslleter com o objetivo de informar sobre potenciais assuntos que realcem e valorizem as características pessoais e profissionais de todos os elementos da GNR. Considera-se que, desta forma, se possa contribuir para aumentar a auto estima interna, valorizando a instituição, promover uma competição saudável e informar, em tempo útil, de algumas ações que possam ser desenvolvidas internamente. Com uma periodicidade quinzenal poderá ser visualizada no perfil pessoal do Portal Social ou, ainda, enviada para o endereço eletrónico pessoal, através de inscrição prévia em lista de contactos criada para o envio da newsletter. Será feito um apelo para que todos possam contribuir para o sucesso desta publicação através das histórias que sejam do seu conhecimento;

- A criação de um Open Day Famílias, pretendendo-se mostrar às famílias o quotidiano do militar da Guarda através de um maior contacto com o espaço físico e inter-relacional. Desta forma, abrindo "portas" dos quartéis à família sociedade - permitir-se-á dar a conhecer uma realidade que, para muitas famílias, ainda desconhecida.

- Efetuar um estudo de Avaliação que permita analisar os fatores críticos de sucesso, das medidas implementadas, e gerar novas apostas para a dinamização e motivação do público interno;

- Implementar mais e melhores meios de comunicação interna, designadamente as tecnologias de comunicação e informação;

- Promover mais convívios que envolva todos os escalões hierárquicos;

- Criação de uma política de comunicação esclarecedora e estruturada que permeie o relacionamento entre a instituição e o militar. 


\section{Conclusões}

Esta dissertação, teve por base o estudo e caracterização da Comunicação Interna existente na Guarda Nacional Republicana e procurou, de alguma forma, contribuir para a análise e interpretação das perceções e dinâmicas relacionadas com a Comunicação Interna, de modo a, auxiliar a conceção futura de um Plano de Comunicação Interna.

O objetivo geral deste trabalho foi estudar e caracterizar a Comunicação Interna na GNR de modo a tentar contribuir para melhorar o processo de comunicação na instituição, através do uso de diferentes meios de comunicação.

Decorrente do objetivo geral, foram definidos outros objetivos específicos complementares, que pretenderam nomeadamente: Verificar a perceção que os militares da GNR têm sobre a importância da comunicação interna existente na GNR; Analisar se a comunicação interna satisfaz as necessidades do efetivo da instituição; Averiguar se os meios disponíveis são suficientes em número e em teor para manter o efetivo informado; Apurar quais os meios e instrumentos de CI mais procurados para obtenção de informação.

Este trabalho envolveu a revisão de literatura sobre o tema, em estudo, a caracterização sucinta da organização, bem como o trabalho de campo e respetiva fundamentação metodológica, apresentação dos dados obtidos, reflexão sobre os mesmos e propostas de melhoria.

No que concerne, especificamente, à metodologia de investigação esta teve por base o recurso a um questionário, aplicado a uma amostra de 241 militares. Este trabalho constitui uma investigação aplicada e transversal que teve como objetivo adquirir novos conhecimentos orientados para a solução de problemas reais.

A análise dos dados foi realizada com recurso ao SPSS (Versão IBM SPSS Statistics19), o que supõe uma abordagem quantitativa, a qual pretendeu quantificar as opiniões e informações fornecidas pela amostra, a qual corresponde a inquiridos inseridos em diferentes Comandos e Postos Territoriais da Guarda Nacional Republicana.

Tal como referimos anteriormente, a comunicação é, cada vez mais, essencial na definição de estratégias para a constituição de uma organização flexível, onde a aprendizagem desta deve ser constante. A comunicação pode assumir um papel vital no seu funcionamento, na medida em que é constituída por valores individuais e de grupo, atitudes e crenças, bem como padrões de comportamento que determinam o compromisso, 
competência e estilo de gestão, pelo que a implementação de um sistema de comunicação eficaz permite contribuir para um ambiente saudável.

Nos dados obtidos, observamos, designadamente, que:

Os militares apontam para um bom relacionamento interpessoal entre colegas. Consideram que recebem informação suficiente sobre as políticas e objetivos da instituição, contudo, sentem necessidade de mais informação quando se trata de alguma mudança na GNR. No que concerne à comunicação com as chefias, tendem a atenuar as informações negativas que transmitem às suas chefias. Em termos gerais, evidenciam que não se sentem muito à vontade para expressar as suas opiniões junto das chefias e os boatos são frequentes na instituição e de difícil desmistificação.

Em relação à informação que lhes é fornecida, no seu local de trabalho, entendem que a informação oral é insuficiente. Sendo o meio apontado como mais adequado para a transmissão da informação o meio oral.

A formação é o componente principal que gostariam de ver desenvolvido, seguindose os vencimentos e a carreira profissional.

Relativamente à utilização dos meios e instrumentos de comunicação interna, conclui-se que o meio mais utilizado é o correio eletrónico, seguido da intranet, notas internas e ordens de serviço. Relativamente ao meio e instrumento de comunicação interna, mais eficaz salienta-se o correio eletrónico, seguindo-se a intranet e as Normas de Execução Permanente (NEP) e o meio menos eficaz o chat. No que respeita à influência das variáveis sociodemográficas nas dimensões de Comunicação e Informação, verificámos que os militares pertencentes ao grupo etário 51-60 anos, revelam uma opinião mais positiva sobre a Informação Geral sobre a GNR, e sobre o Clima de Comunicação. Na dimensão Informação Geral sobre a GNR, verificamos que os militares do posto militar de Cabo-mor revelam uma opinião mais positiva do que os militares do posto de Guarda Principal.

\section{Limitações}

Uma das grandes limitações deste estudo encontra-se na distribuição do questionário, que foi distribuído através de um link por e-mail, uma vez que, uma parte considerável dos sessenta Postos Territoriais selecionados não possuem internet. 
Outra das limitações deste estudo encontra-se na sua reduzida amostra: 241 militares. Desta forma, as conclusões deste trabalho aplicam-se apenas a essa mesma população, tratando-se por isso de um estudo exploratório.

Por outro lado, a amostra deste trabalho engloba apenas militares dos Postos Territoriais, pelo que os resultados observados podem ter sido influenciados pelas circunstâncias organizativas do serviço operacional.

Assim sendo, não podemos generalizar os resultados obtidos a outros militares da GNR. No entanto, estas limitações não constituíram impedimento para validar os resultados do estudo efetuado e as conclusões que se retiradas a partir da análise dos mesmos. 


\section{Referências Bibliográficas}

ALMEIDA, V (2003); A Comunicação Interna na Empresa; Áreas Editoras, Lisboa.

ANDRADE, N. (2011); 100 anos Guarda Nacional Republicana (1911-2011), Editora Guerra \& Paz S.A.

BILHIM, J. (1996); Teoria Organizacional - Estruturas e Pessoas; Lisboa, Instituto Superior de Ciências Sociais e Políticas.

BLAND, M.; JACKSON, P. (1992) A Comunicação na Empresa, Lisboa, Editorial Presença

BRAULT, L. (1992). A Comunicação da Empresa para além do Modelo Publicitário. Portugal: Edições Cetop.

BUCKLEY, A. The Essence of Effective Communication, $1^{\text {a }} \mathrm{ed}$. Inglaterra, Prentice Hall, 1992

CARMO, H; FERREIRA, M. (1998) Metodologia da Investigação - Guia para AutoAprendizagem, Lisboa, Universidade Aberta

CLAMPITT, P. (1991). Communicating for Managerial Effectiveness. Inglaterra: Sage.

CUSHWAY, B. (1998); Organizações, Planeamento e Comportamento: Estrutura Cargos e Funções; Comunicação - Motivação; Lisboa; Clássica.

DOWNS, C., ADRIAN, A. (2004). Assessing organizational communication. New York: Guilford Press.

DRUCKER, P. (2008), O essencial de Drucker - Uma selecção das melhores teorias do pai da Gestão, Actual Editora, 29, 41-42, 121, 126, 283-284.

DUPUY, G. (1998) Emmanuel et al, La communication Interne - Vers l'Entreprise Transparente, Paris, Les Éditions d'Organisation, 1988, pp.31-54.

SANTO, P. (2008), Revista Interface Administração Pública, Algébrica Edição Electrónia de 17 de Outubro 2008.

FERREIRA J., NEVES, J., CAETANO, A. (2001), Manual de Psicossociologia das Organizações, McGraw-Hill, Lisboa.

GHIGliOne, R., MATAlON, B. (2001), O Inquérito: Teoria e Prática (C. Pires Trad.) Celta editora, Oeiras.

GIL, A. (1999). Métodos e técnicas de pesquisa social. São Paulo: Editora Atlas. 
GONDRAND, F. (1990) L' Information dans les Entreprises et les Organizations, Paris, Editions d' Organizations.

HAWABHAY, B., Abratt, R., \& Peters, M. (2009). Academic Research. The Role of Corporate Communications in Developing a Corporate Brand Image and Reputation in Mauritius.

HOOD, R. (2009). The New Era of Corporate Communications. Streaming Media Magazine .

KUNSCH, M. (1995) A comunicação integrada nas organizações modernas: avanços e perspetivas no Brasil, São Paulo, Edicom

LAMPREIA, J. (1992). Comunicação Empresarial. Lisboa: Texto Editora.

LUHMANN, N. (2007), La sociedad de la sociedad. México: Herder.

LINDON, D. et al. (2004), Mercator XXI - Teoria e Prática do Marketing, Dom Quixote, 165-188, 297-318, 354-355, 448-453.

LUISO, E. (2003), Gestão de Sistemas de Informação Aplicado às ONGD, Dissertação para obtenção do grau de Mestre, ISCTE, 22-28.

MADRID, V. (1994) Las auditorias de la comunicacion organizacional desde una perspectiva académica estadounidense. I Seminario-Taller Latinoiamericano.

MADUREIRA, M., Introdução à Gestão, 1ª ed., Lisboa, Publicações D. Quixote, 1990, p.316.

NELSON, P. (2003), Gestão para Tótós (2a edição), Porto Editora, 14-15, 164-165.

MARCHIORI, M. (1999) Comunicação é cultura e cultura é comunicação, Rio de Janeiro, Comunicação Empresarial.

PENELA, A. (1999), Imagem Interna, um fator estratégico nas organizações. Perspetivas para o Século XXI., Tese de Mestrado em Comunicação, Cultura e Tecnologias de Informação, Instituto Superior de Ciências de Ciências do Trabalho e da Empresa, Lisboa.

PEREIRA, C. (2006), Estudo de Caso: Guarda Nacional Republicana - Marketing Interno como instrumento para a melhoria do atendimento na atividade operacional, Tese de Mestrado em Ciências da Comunicação, Faculdade de Ciências Humanas da Universidade católica Portuguesa, Lisboa.

QUIVY, R., CAMPENHOUT, L. (2005) Manual de Investigação em Ciências Sociais, (J. Marques, M. Mendes, M. Carvalho, Trad.), Lisboa, Gravida.

RAMOS, H. (1997). A Comunicação Interna, Estudo de caso no C.E.T. 
REGO, A. (1999); Comunicação nas Organizações; $1^{a}$ Edição, Lisboa, Sílabo.

REGO, A. (2007); Comunicação Pessoal e Organizacional. Teoria e Prática; $1^{\text {a }}$ Edição, Lisboa, Sílabo.

STONER, J. (1985). Administração. Brasil: Prentice Hall do Brasil.

THEVENET, M. (1988). La Communication Interne ou la Recherche dún Problématique. Révue Française du Marketing, p. n²0.

WAGNER III, J. (2002) Comportamento organizacional: criando vantagem competitiva, Tradução Cid Moreira. São Paulo, Saraiva.

WESTPHALEN , M. (1992). A Comunicação na Empresa. Porto, Rés Editora.

ZEMOR, P. (1995), La communication publique. Paris, PUF. 


\section{Apêndices}




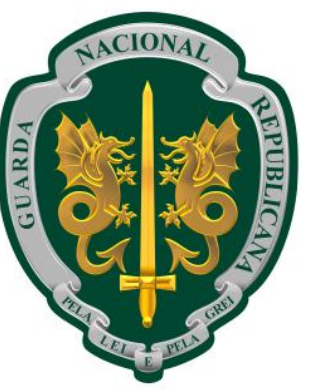

\section{Apêndice A - QUESTIONÁRIO}

\section{A Comunicação Interna na}

\section{Guarda Nacional Republicana QUESTIONÁRIO}

O questionário que lhe apresentamos insere-se numa investigação, para a elaboração de uma dissertação de mestrado, sobre a Comunicação Interna na Guarda Nacional Republicana.

Trata-se de um trabalho académico realizado no âmbito do Mestrado em Gestão Estratégica de Recursos Humanos, mas que pretende ser útil para a melhoria da Comunicação Interna na GNR, pelo que o seu contributo e colaboração são essenciais. As conclusões deste estudo serão disponibilizadas ao Gabinete de Informação Interna da Divisão de Comunicação e Relações Públicas da Guarda Nacional Republicana, que as poderá utilizar para implementar medidas que visem melhorar a Comunicação Interna.

O questionário será aplicado nos vinte Comandos Territoriais da Guarda Nacional Republicana.

Por razões éticas e deontológicas garantimos, em absoluto, que as informações que fornecer permanecerão totalmente confidenciais e anónimas. Este questionário é de natureza confidencial, garantindo-se que o tratamento de dados estatísticos é efetuado de uma forma global, não sendo sujeito a uma análise individualizada, o que significa que é respeitado o anonimato dos inquiridos. Por motivo algum serão reveladas informações acerca de pessoas ou opiniões. Não haverá qualquer ligação entre dados que possam vir a identificar pessoas.

É de toda a conveniência que a colaboração dos inquiridos seja espontânea. O rigor e a honestidade da resposta serão fundamentais para a obtenção de informação realistas que possa vir a ser usada de forma credível na fundamentação da tomada de decisão e opções que afetam a esta temática.

Para responder ao questionário que se segue, pede-se que avalie o seu grau de concordância com as seguintes afirmações relativas à comunicação interna na GNR. 
Por favor responda a todas as questões marcando na resposta que melhor descreve a sua opinião. Para que os resultados possam ser benéficos para todos, é indispensável que responda com honestidade.

Muito obrigado.

\section{QUESTÕES:}

\begin{tabular}{|c|c|c|c|c|c|}
\hline $\begin{array}{l}\text { Até que ponto concorda com as seguintes afirmações relacionadas com a } \\
\text { Informação Geral sobre a GNR que lhe é fornecida? }\end{array}$ & 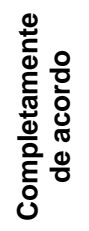 & $\begin{array}{l}\text { 움 } \\
\text { ¿े } \\
\text { 잉 }\end{array}$ & 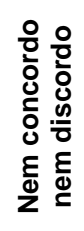 & $\begin{array}{l}\text { 음 } \\
\text { 음 } \\
\stackrel{\mathscr{0}}{0}\end{array}$ & 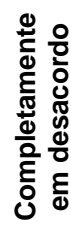 \\
\hline $\begin{array}{l}\text { 1. A informação sobre as políticas e objetivos da instituição que } \\
\text { recebo é suficiente }\end{array}$ & 1 & 2 & 3 & 4 & 5 \\
\hline 2. A informação que recebo sobre as mudanças na GNR é a suficiente & 1 & 2 & 3 & 4 & 5 \\
\hline $\begin{array}{l}\text { 3. A informação sobre as orientações de gestão da GNR que recebo é } \\
\text { adequada }\end{array}$ & 1 & 2 & 3 & 4 & 5 \\
\hline $\begin{array}{l}\text { 4. A informação que me é fornecida sobre sucessos ou falhas da } \\
\text { organização é pouca ou nenhuma }\end{array}$ & 1 & 2 & 3 & 4 & 5 \\
\hline
\end{tabular}

Até que ponto concorda com as seguintes afirmações relacio
Informação que Ihe é fornecida no seu local de trabalho?

\begin{tabular}{|c|c|c|c|c|c|}
\hline & 0 & & & & 0 \\
\hline $\begin{array}{l}\text { 5. A informação chega muito tarde porque fica retida nos escalões } \\
\text { superiores }\end{array}$ & 1 & 2 & 3 & 4 & 5 \\
\hline 6. A informação é pouco clara & 1 & 2 & 3 & 4 & 5 \\
\hline 7. A informação escrita é insuficiente ou incompleta & 1 & 2 & 3 & 4 & 5 \\
\hline 8. A informação oral é insuficiente & 1 & 2 & 3 & 4 & 5 \\
\hline 9. A informação escrita é demasiada & 1 & 2 & 3 & 4 & 5 \\
\hline
\end{tabular}

\begin{tabular}{|c|c|c|c|c|c|}
\hline $\begin{array}{l}\text { Até que ponto concorda com as seguintes afirmações relacionadas com o } \\
\text { modo como Comunica com a sua Chefia? }\end{array}$ & 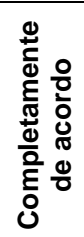 & $\begin{array}{l}\text { 은 } \\
\text { ठํ } \\
\text { ¿ }\end{array}$ & 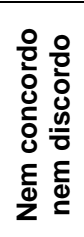 & $\begin{array}{l}\text { 음 } \\
\text { 엄 } \\
\frac{.0}{0}\end{array}$ & 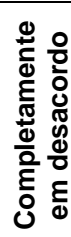 \\
\hline 10. Tendo a evitar dar informações ruins à minha chefia & 1 & 2 & 3 & 4 & 5 \\
\hline $\begin{array}{l}\text { 11. Quando comunico informações ruins à minha chefia tendo a } \\
\text { apresentá-las mais atenuadas }\end{array}$ & 1 & 2 & 3 & 4 & 5 \\
\hline $\begin{array}{l}\text { 12. Não é fundamental que a minha chefia esteja ciente de todos os } \\
\text { problemas relativos à minha unidade de trabalho }\end{array}$ & 1 & 2 & 3 & 4 & 5 \\
\hline $\begin{array}{l}\text { 13. É sempre obrigatória a apresentação de todas as informações, } \\
\text { incluindo informações negativas, à chefia, mesmo quando existe } \\
\text { a probabilidade de consequências adversas ou negativas. }\end{array}$ & 1 & 2 & 3 & 4 & 5 \\
\hline $\begin{array}{l}\text { 14. É permitido lançar uma luz favorável sobre informação negativa a } \\
\text { ser fornecida a uma chefia. }\end{array}$ & 1 & 2 & 3 & 4 & 5 \\
\hline
\end{tabular}

A Comunicação Interna na Guarda Nacional Republicana 


\begin{tabular}{|c|c|c|c|c|c|}
\hline $\begin{array}{l}\text { Até que ponto concorda com as seguintes afirmações relacionadas com o } \\
\text { Clima de Comunicação na GNR? }\end{array}$ & 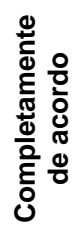 & $\begin{array}{l}\text { 운 } \\
\text { 응 } \\
\text { 은 }\end{array}$ & 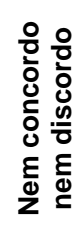 & $\begin{array}{l}\text { 움 } \\
\text { 엉 } \\
\text { 믐 }\end{array}$ & 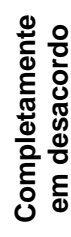 \\
\hline $\begin{array}{l}\text { 15. Gosto pouco do modo como as pessoas nesta instituição } \\
\text { comunicam umas com as outras }\end{array}$ & 1 & 2 & 3 & 4 & 5 \\
\hline $\begin{array}{l}\text { 16. A comunicação nesta instituição incentiva-me a alcançar os meus } \\
\text { objetivos }\end{array}$ & 1 & 2 & 3 & 4 & 5 \\
\hline $\begin{array}{l}\text { 17. A comunicação nesta instituição leva-me a sentir que sou uma } \\
\text { parte importante da mesma }\end{array}$ & 1 & 2 & 3 & 4 & 5 \\
\hline $\begin{array}{l}\text { 18. Nesta instituição as pessoas não se sentem muito à vontade para } \\
\text { expressar livremente a suas opiniões }\end{array}$ & 1 & 2 & 3 & 4 & 5 \\
\hline $\begin{array}{l}\text { 19. Nesta instituição, o modo como as pessoas comunicam umas com } \\
\text { as outras é basicamente saudável }\end{array}$ & 1 & 2 & 3 & 4 & 5 \\
\hline
\end{tabular}

\begin{tabular}{|c|c|c|c|c|c|}
\hline $\begin{array}{l}\text { Até que ponto concorda com as seguintes afirmações relacionadas com a } \\
\text { Comunicação entre Colegas? }\end{array}$ & 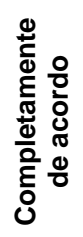 & $\begin{array}{l}\text { 잏 } \\
0 \\
0 \\
0\end{array}$ & 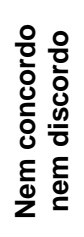 & 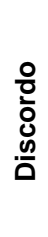 & 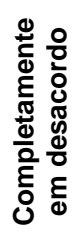 \\
\hline $\begin{array}{l}\text { 20. Agrada-me o modo como a comunicação entre colegas funciona na } \\
\text { instituição }\end{array}$ & 1 & 2 & 3 & 4 & 5 \\
\hline $\begin{array}{l}\text { 21. Sinto que a comunicação entre colegas é pouco precisa e de difícil } \\
\text { circulação }\end{array}$ & 1 & 2 & 3 & 4 & 5 \\
\hline $\begin{array}{l}\text { 22. As práticas de comunicação entre colaboradores são adaptáveis a } \\
\text { situações de emergência }\end{array}$ & 1 & 2 & 3 & 4 & 5 \\
\hline $\begin{array}{l}\text { 23. As pessoas do meu grupo de trabalho são compatíveis umas com } \\
\text { as outras }\end{array}$ & 1 & 2 & 3 & 4 & 5 \\
\hline
\end{tabular}

\begin{tabular}{|c|c|c|c|c|c|}
\hline $\begin{array}{l}\text { Até que ponto concorda com as seguintes afirmações relacionadas com } \\
\text { Boatos e Conflitos existentes na GNR? }\end{array}$ & 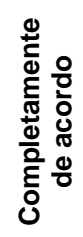 & $\begin{array}{l}\text { 은 } \\
\text { 음 } \\
\text { ㅇ }\end{array}$ & 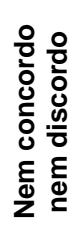 & 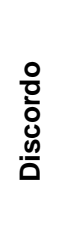 & 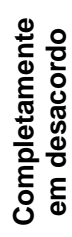 \\
\hline 24. Nesta instituição o "diz que disse" tem muita influência & 1 & 2 & 3 & 4 & 5 \\
\hline 25. Nesta instituição há frequentemente mal-entendidos & 1 & 2 & 3 & 4 & 5 \\
\hline 26. $\mathrm{Na}$ instituição existem bastantes conflitos de interesses & 1 & 2 & 3 & 4 & 5 \\
\hline $\begin{array}{l}\text { 27. Os conflitos são geridos com eficácia através dos canais } \\
\text { adequados }\end{array}$ & 1 & 2 & 3 & 4 & 5 \\
\hline 28. Na GNR os boatos são muito frequentes & 1 & 2 & 3 & 4 & 5 \\
\hline 29. Nesta instituição os boatos são rapidamente desmistificados & 1 & 2 & 3 & 4 & 5 \\
\hline 30. Nesta instituição existem muitos antagonismos entre as pessoas & 1 & 2 & 3 & 4 & 5 \\
\hline $\begin{array}{l}\text { 31. As pessoas do meu grupo de trabalho são compatíveis umas com } \\
\text { as outras }\end{array}$ & 1 & 2 & 3 & 4 & 5 \\
\hline
\end{tabular}


Indique com que frequência usa/consulta os seguintes meios e instrumentos de comunicação interna para a obtenção de informação

\begin{tabular}{|c|c|c|c|}
\hline 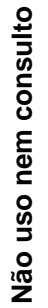 & 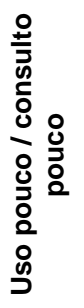 & 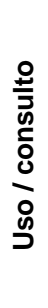 & 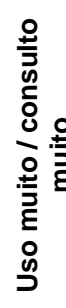 \\
\hline
\end{tabular}

\begin{tabular}{|c|c|c|c|c|c|}
\hline \multirow{5}{*}{$\frac{\overrightarrow{1}}{\mathbf{\alpha}}$} & 32. Conversas informais & 1 & 2 & 3 & 4 \\
\hline & 33. Conversas formais & 1 & 2 & 3 & 4 \\
\hline & 34. Reuniões & 1 & 2 & 3 & 4 \\
\hline & 35. Ações de formação & 1 & 2 & 3 & 4 \\
\hline & 36. Conversas em grupo & 1 & 2 & 3 & 4 \\
\hline \multirow{8}{*}{ 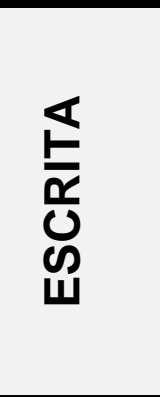 } & 37. Notas internas ou Mensagens & 1 & 2 & 3 & 4 \\
\hline & 38. Ordens de Serviço & 1 & 2 & 3 & 4 \\
\hline & 39. Normas de Execução Permanente (NEP) & 1 & 2 & 3 & 4 \\
\hline & 40. Relatórios de atividades & 1 & 2 & 3 & 4 \\
\hline & 41. Correio Interno & 1 & 2 & 3 & 4 \\
\hline & 42. Folhetos & 1 & 2 & 3 & 4 \\
\hline & 43. Placares & 1 & 2 & 3 & 4 \\
\hline & 44. Revista da GNR & 1 & 2 & 3 & 4 \\
\hline \multirow{8}{*}{ 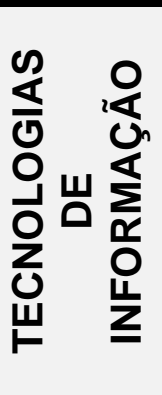 } & 45. Site da GNR & 1 & 2 & 3 & 4 \\
\hline & 46. Intranet GNR & 1 & 2 & 3 & 4 \\
\hline & 47. Correio Eletrónico (E-Mail) & 1 & 2 & 3 & 4 \\
\hline & 48. Telemóvel & 1 & 2 & 3 & 4 \\
\hline & 49. Telefone Fixo & 1 & 2 & 3 & 4 \\
\hline & 50. Audiovisuais (Vídeos, slides, ...) & 1 & 2 & 3 & 4 \\
\hline & 51. Chat & 1 & 2 & 3 & 4 \\
\hline & 52. Videoconferência & 1 & 2 & 3 & 4 \\
\hline
\end{tabular}


Classifique a eficácia dos seguintes meios de comunicação interna quanto à obtenção de informação:

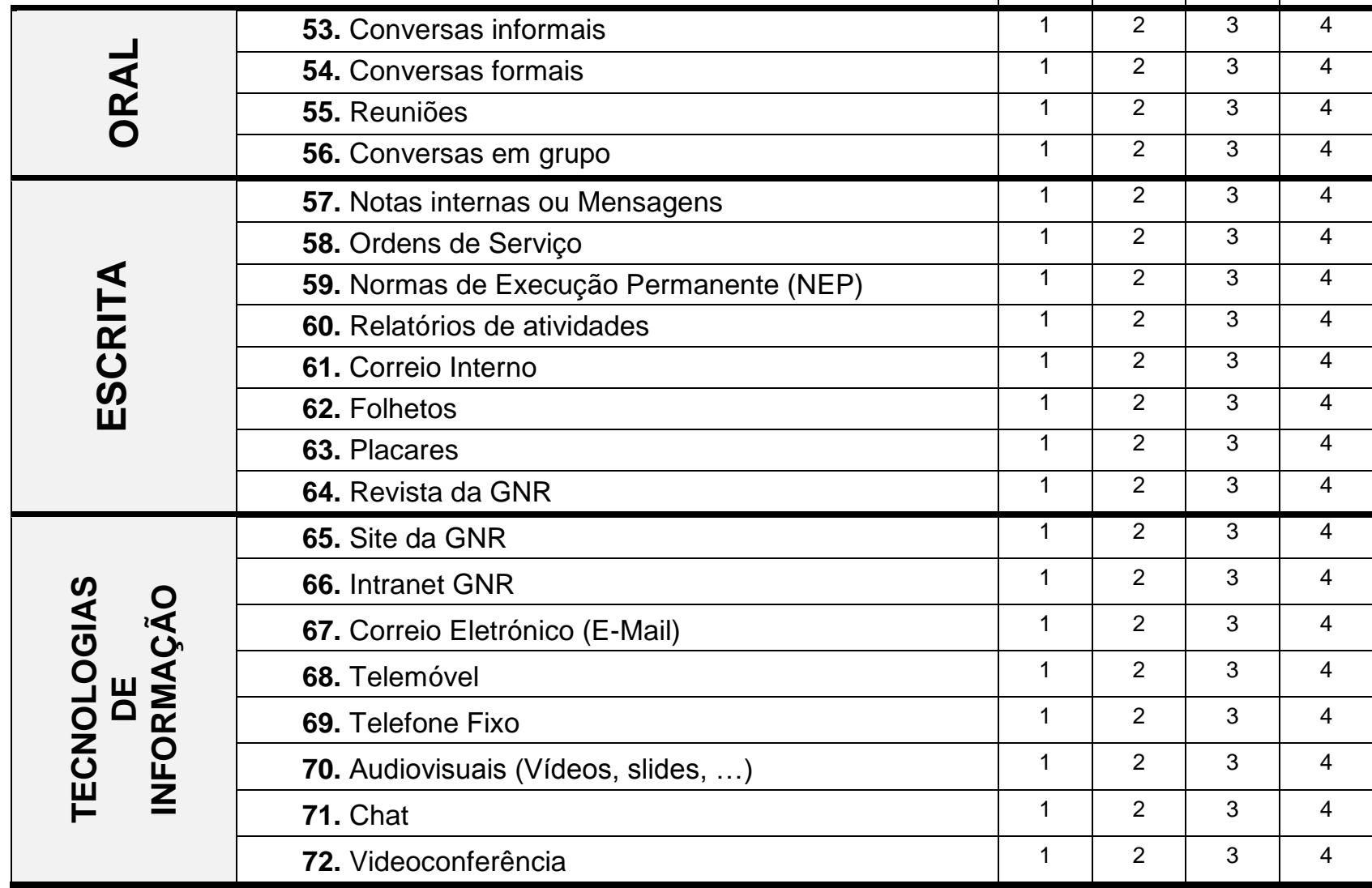

Qual o meio que acha mais adequado para a transmissão da informação, para que esta seja completamente percetível e absorvida? (marque uma das alternativas)

73. Oral

74. Escrita

75. Audiovisuais

76. Tecnologias da Informação e Comunicação (TIC) 


\section{Responda sucintamente à seguinte questão:}

77. Que assuntos gostaria que fossem divulgados para melhorar a comunicação interna na GNR? (Ex: Atividade da GNR, vencimentos, carreiras, formação, objetivos e resultados do seu trabalho, projetos futuros

etc...)

Tem conhecimento da existência de um serviço responsável pela comunicação interna na GNR?

78. Sim .... $\square$

79. Não

\section{A preencher por todos os militares:}

\section{Dados Demográficos}

É importante sabermos alguns dados demográficos sobre si, para podermos comparar as opiniões de diferentes grupos profissionais, de modo a propor eventuais medidas para a melhoria da comunicação no trabalho, nos grupos em que essa necessidade for sentida.

\section{Dados Pessoais/Profissionais}

\section{$\underline{\text { Sexo }}$}

80. Homem

81. Mulher

Idade

82.

\section{Habilitacões Literárias}

83. Ensino primário

84. 3.ำ Ciclo (9ำ Ano)

85. Ensino Secundário

86. Ensino superior

87. Mestrado

88. Doutoramento 
89. Comando Territorial de:

Há quanto tempo trabalha na GNR?

90. Entre 1 e 5 anos

91. Entre 6 e 10 anos

92. Entre 11 e 15 anos

93. Entre 16 e 20 anos

94. Entre 21 e 25 anos

95. Mais de 25 anos

\section{Posto militar de?}

96. Guarda

97. Guarda Principal

98. Cabo

99. Cabo-Chefe

100. Cabo-Mor

Reitero que é garantida, em absoluto, a confidencialidade das suas respostas.

Obrigado pela sua colaboração. 


\section{APÊNDICE B - Definição da Amostra - Caraterização dos inquiridos}

\section{Amostra}

Statistics

\begin{tabular}{|cc|c|}
\hline $\mathrm{N}$ & Valid & 241 \\
& Missing & 0 \\
& & 1,07 \\
\hline
\end{tabular}

Sexo

\begin{tabular}{|cc|c|c|c|c|}
\hline & \multicolumn{5}{|c|}{ Sexo } \\
\hline \multirow{2}{*}{ Valid } & Frequency & Percent & Valid Percent & Cumulative Percent \\
& Homem & 223 & 92,5 & 92,5 & 92,5 \\
& Mulher & 18 & 7,5 & 7,5 & 100,0 \\
& Total & 241 & 100,0 & 100,0 & \\
\hline
\end{tabular}

Idade dos Inquiridos

Statistics

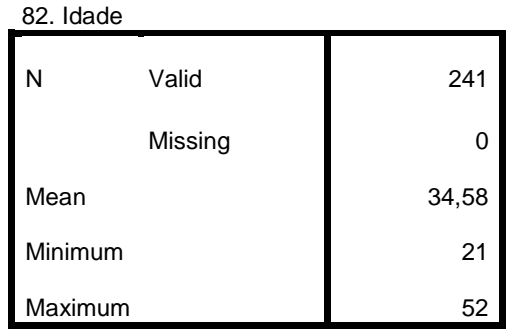

Habilitações Literárias dos Inquiridos

Habilitações Literárias

\begin{tabular}{|c|c|c|c|c|c|}
\hline & & Frequency & Percent & Valid Percent & Cumulative Percent \\
\hline \multirow[t]{6}{*}{ Valid } & Ensino Primário & 16 & 6,6 & 6,6 & 6,6 \\
\hline & $3^{\circ}$ Ciclo (9ano) & 88 & 36,5 & 36,5 & 43,2 \\
\hline & Ensino Secundário & 131 & 54,4 & 54,4 & 97,5 \\
\hline & Ensino Superior & 5 & 2,1 & 2,1 & 99,6 \\
\hline & Mestrado & 1 & ,4 & ,4 & 100,0 \\
\hline & Total & 241 & 100,0 & 100,0 & \\
\hline
\end{tabular}




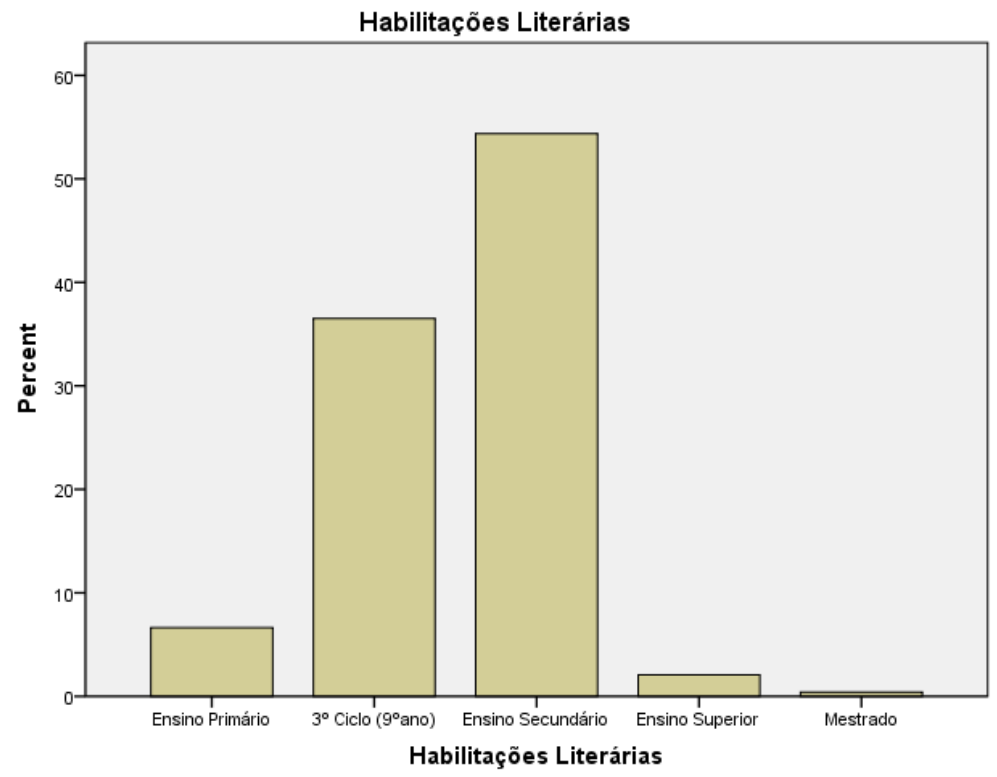

Comando Territorial

89. Comando Territorial de:

\begin{tabular}{|c|c|c|c|c|c|}
\hline & & Frequency & Percent & Valid Percent & Cumulative Percent \\
\hline \multirow[t]{20}{*}{ Valid } & Açores & 8 & 3,3 & 3,3 & 3,3 \\
\hline & Aveiro & 15 & 6,2 & 6,2 & 9,5 \\
\hline & Beja & 1 & ,4 & , 4 & 10,0 \\
\hline & Braga & 19 & 7,9 & 7,9 & 17,8 \\
\hline & Bragança & 9 & 3,7 & 3,7 & 21,6 \\
\hline & Castelo Branco & 9 & 3,7 & 3,7 & 25,3 \\
\hline & Coimbra & 7 & 2,9 & 2,9 & 28,2 \\
\hline & Évora & 20 & 8,3 & 8,3 & 36,5 \\
\hline & Faro & 14 & 5,8 & 5,8 & 42,3 \\
\hline & Guarda & 5 & 2,1 & 2,1 & 44,4 \\
\hline & Leiria & 3 & 1,2 & 1,2 & 45,6 \\
\hline & Lisboa & 10 & 4,1 & 4,1 & 49,8 \\
\hline & Madeira & 19 & 7,9 & 7,9 & 57,7 \\
\hline & Portalegre & 10 & 4,1 & 4,1 & 61,8 \\
\hline & Porto & 13 & 5,4 & 5,4 & 67,2 \\
\hline & Santarém & 1 & ,4 & , 4 & 67,6 \\
\hline & Setúbal & 8 & 3,3 & 3,3 & 71,0 \\
\hline & Viana Castelo & 48 & 19,9 & 19,9 & 90,9 \\
\hline & Viseu & 22 & 9,1 & 9,1 & 100,0 \\
\hline & Total & 241 & 100,0 & 100,0 & \\
\hline
\end{tabular}




\section{Antiguidade dos Militares da GNR}

\begin{tabular}{|c|c|c|c|c|c|}
\hline & & Frequency & Percent & Valid Percent & Cumulative Percent \\
\hline \multirow[t]{7}{*}{ Valid } & $1-5$ & 59 & 24,5 & 24,5 & 24,5 \\
\hline & $6-10$ & 55 & 22,8 & 22,8 & 47,3 \\
\hline & $11-15$ & 57 & 23,7 & 23,7 & 71,0 \\
\hline & $16-20$ & 38 & 15,8 & 15,8 & 86,7 \\
\hline & $21-25$ & 20 & 8,3 & 8,3 & 95,0 \\
\hline & $>25$ & 12 & 5,0 & 5,0 & 100,0 \\
\hline & Total & 241 & 100,0 & 100,0 & \\
\hline
\end{tabular}

\section{Posto Militar (Categorias)}

\begin{tabular}{|l|r|r|r|r|}
\hline & Posto militar & \\
\hline Valid $\quad$ Frequency & Percent & Valid Percent & Cumulative Percent \\
\hline & 155 & 64,3 & 64,3 & 64,3 \\
Guarda & 5 & 2,1 & 2,1 & 66,4 \\
Cabo & 74 & 30,7 & 30,7 & 97,1 \\
Cabo-chefe & 5 & 2,1 & 2,1 & 99,2 \\
Cabo-mor & 2 &, 8 &, 8 & 100,0 \\
Total & 241 & 100,0 & 100,0 & \\
\hline
\end{tabular}

\section{Estatísticas Descritivas do Questionário de CI}

\section{$1^{\text {a }}$ Dimensão - Informação Geral sobre a GNR}

\begin{tabular}{|c|c|c|}
\hline \multicolumn{3}{|c|}{ Reliability Statistics } \\
& $\begin{array}{c}\text { Cronbach's Alpha } \\
\text { Based on }\end{array}$ \\
\hline Cronbach's Alpha & Standardized Items & N of Items \\
\hline, 788 &, 789 & 3 \\
\hline
\end{tabular}

\begin{tabular}{|c|c|c|c|c|c|c|c|}
\hline & \multicolumn{9}{c|}{ Summary Item Statistics } & & \\
& Mean & Minimum & Maximum & Range & Maximum / Minimum & Variance & N of Items \\
\hline Item Means & 2,942 & 2,726 & 3,050 &, 324 & 1,119 &, 035 \\
Item Variances & 1,412 & 1,231 & 1,531 &, 300 & 1,244 & 3 \\
\hline
\end{tabular}




\section{$2^{\text {a }}$ Dimensão - Informação Fornecida no Local de Trabalho}

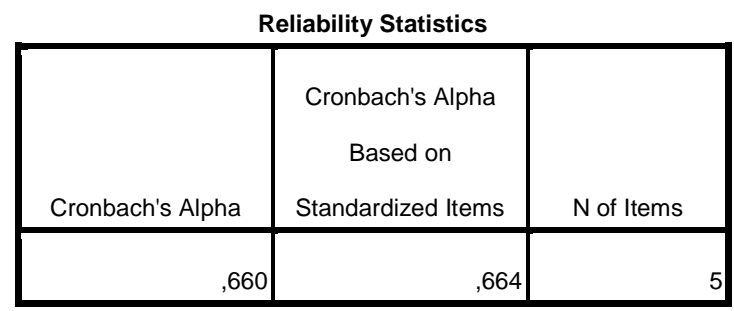

Summary Item Statistics

\begin{tabular}{|c|c|c|c|c|c|c|c|}
\hline & Mean & Minimum & Maximum & Range & Maximum / Minimum & Variance & $\mathrm{N}$ of Items \\
\hline Item Means & 3,827 & 3,523 & 4,071 & ,548 & 1,155 & ,042 & 5 \\
\hline Item Variances & 1,127 & 1,066 & 1,209 & ,143 & 1,134 & ,003 & 5 \\
\hline
\end{tabular}

\section{$3^{\text {a }}$ Dimensão - Comunicação com a Chefia}

Reliability Statistics

\begin{tabular}{|r|r|r|}
\hline \multicolumn{1}{|c|}{$\begin{array}{r}\text { Cronbach's } \\
\text { Alpha }\end{array}$} & $\begin{array}{c}\text { Cronbach's } \\
\text { Alpha Based on } \\
\text { Standardized } \\
\text { Items }\end{array}$ & \\
\hline, 667 & N of Items \\
\hline
\end{tabular}

Summary Item Statistics

\begin{tabular}{|l|r|r|r|r|r|r|r|}
\hline & Mean & Minimum & Maximum & Range & \multicolumn{1}{c|}{$\begin{array}{c}\text { Maximum / } \\
\text { Minimum }\end{array}$} & Variance & N of Items \\
\hline Item Means & 3,124 & 3,108 & 3,141 &, 033 & 1,011 &, 001 & 2 \\
Item Variances & 1,401 & 1,363 & 1,438 &, 075 & 1,055 &, 003 & 2 \\
\hline
\end{tabular}

\section{$4^{\mathrm{a}}$ Dimensão - Clima de Comunicação}

\begin{tabular}{|c|c|c|}
\hline \multicolumn{3}{|c|}{ Reliability Statistics } \\
\hline $\begin{array}{c}\text { Cronbach's } \\
\text { Alpha }\end{array}$ & $\begin{array}{c}\text { Cronbach's } \\
\text { Alpha Based on } \\
\text { Standardized } \\
\text { Items }\end{array}$ & $\mathrm{N}$ of Items \\
\hline, 771 & ,769 & 5 \\
\hline
\end{tabular}


Summary Item Statistics

\begin{tabular}{|l|r|r|r|r|r|r|r|}
\hline & Mean & Minimum & Maximum & Range & \multicolumn{1}{c|}{$\begin{array}{c}\text { Maximum / } \\
\text { Minimum }\end{array}$} & Variance & N of Items \\
\hline Item Means & 3,254 & 2,577 & 4,270 & 1,693 & 1,657 &, 562 & 5 \\
Item Variances & 1,267 & 1,098 & 1,696 &, 598 & 1,545 &, 059 & 5 \\
\hline
\end{tabular}

\section{$5^{\mathrm{a}}$ Dimensão - Comunicação entre Colegas}

\section{Reliability Statistics}

\begin{tabular}{|r|r|r|}
\hline $\begin{array}{c}\text { Cronbach's } \\
\text { Alpha }\end{array}$ & $\begin{array}{c}\text { Cronbach's } \\
\text { Alpha Based on } \\
\text { Standardized } \\
\text { Items }\end{array}$ & \\
\hline, 632 & N of Items \\
\hline
\end{tabular}

Summary Item Statistics

\begin{tabular}{|l|r|r|r|r|r|r|r|}
\hline & Mean & Minimum & Maximum & Range & $\begin{array}{c}\text { Maximum / } \\
\text { Minimum }\end{array}$ & Variance & N of Items \\
\hline Item Means & 2,386 & 1,714 & 3,456 & 1,743 & 2,017 &, 878 & 3 \\
Item Variances & 1,111 &, 941 & 1,237 &, 297 & 1,315 &, 023 & 3 \\
\hline
\end{tabular}

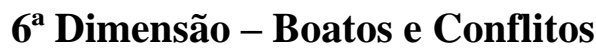

\begin{tabular}{|r|c|c|}
\hline \multicolumn{3}{|c|}{ Reliability Statistics } \\
\multirow{2}{*}{$\begin{array}{c}\text { Cronbach's } \\
\text { Alphach's }\end{array}$} & $\begin{array}{c}\text { Alpha Based on } \\
\text { Standardized } \\
\text { Items }\end{array}$ & \\
\hline, 782 & N of Items \\
\hline
\end{tabular}

Summary Item Statistics

\begin{tabular}{|l|r|r|r|r|r|r|r|}
\hline & Mean & Minimum & Maximum & Range & \multicolumn{1}{c|}{$\begin{array}{c}\text { Maximum / } \\
\text { Minimum }\end{array}$} & Variance & N of Items \\
\hline Item Means & 3,816 & 2,784 & 4,419 & 1,635 & 1,587 &, 502 & 7 \\
Item Variances & 1,024 &, 894 & 1,153 &, 259 & 1,289 &, 009 & 7 \\
\hline
\end{tabular}




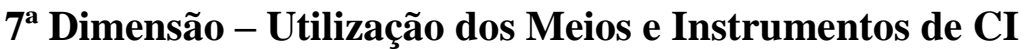

\begin{tabular}{|r|c|l|}
\hline \multicolumn{3}{|c|}{ Reliability Statistics } \\
& Cronbach's & \\
Cronbach's & Alpha Based on \\
Alpha & Standardized & \\
\hline, 821 & Items & N of Items \\
\hline \multicolumn{1}{|c|}{,821 } & 21 \\
\hline
\end{tabular}

Summary Item Statistics

\begin{tabular}{|c|c|c|c|c|c|c|c|}
\hline & Mean & Minimum & Maximum & Range & $\begin{array}{l}\text { Maximum / } \\
\text { Minimum }\end{array}$ & Variance & $\mathrm{N}$ of Items \\
\hline Item Means & 2,148 & 1,166 & 2,817 & 1,651 & 2,416 &, 251 & 21 \\
\hline Item Variances & ,743 & ,306 & 1,000 & 695 & 3,272 &, 051 & 21 \\
\hline
\end{tabular}

\section{$8^{\text {a }}$ Dimensão - Eficácia dos Meios e Instrumentos de CI}

Summary Item Statistics

\begin{tabular}{|l|r|r|r|r|r|r|r|}
\hline & Mean & Minimum & Maximum & Range & \multicolumn{1}{c|}{$\begin{array}{c}\text { Maximum / } \\
\text { Minimum }\end{array}$} & Variance & N of Items \\
\hline Item Means & 2,377 & 1,573 & 2,842 & 1,270 & 1,807 &, 153 & 20 \\
Item Variances &, 716 &, 292 & 1,003 &, 712 & 3,440 &, 045 & 20 \\
\hline
\end{tabular}




\section{APÊNDICE C - RESULTADOS - Médias e Desvios Padrão de cada dimensão}

De salientar que as respostas dadas nos itens que constituem a parte A do questionário apresentam-se com proposições de concordância que variam de 1 ("Completamente de acordo"); a 5 ("Completamente em desacordo") sendo que este facto irá condicionar a análise subjacente na medida em que os valores mais baixos das variáveis correspondem a níveis da escala mais positivos.

Médias e Desvios padrão de todas as dimensões

\begin{tabular}{|c|c|c|c|c|c|c|c|}
\hline \multicolumn{8}{|c|}{ Statistics } \\
\hline & & $\begin{array}{l}\text { Informação } \\
\text { Geral GNR }\end{array}$ & $\begin{array}{c}\text { Informação } \\
\text { Fornecida no } \\
\text { Local de } \\
\text { Trabalho }\end{array}$ & $\begin{array}{l}\text { Comunicação } \\
\text { com a Chefia }\end{array}$ & $\begin{array}{c}\text { Clima de } \\
\text { Comunicação }\end{array}$ & $\begin{array}{l}\text { Comunicação } \\
\text { entre Colegas }\end{array}$ & $\begin{array}{l}\text { Boatos e } \\
\text { Conflitos }\end{array}$ \\
\hline \multirow[t]{2}{*}{$\mathrm{N}$} & Valid & 241 & 241 & 241 & 241 & 241 & 241 \\
\hline & Missing & 0 & 0 & 0 & 0 & 0 & 0 \\
\hline \multicolumn{2}{|c|}{ Mean } & 2,9419 & 3,8266 & 3,124 & 3,2539 & 2,3859 & 3,8156 \\
\hline \multicolumn{2}{|c|}{ Std. Deviation } & ,99552 & ,69135 & 1,0252 & ,81317 & ,79989 & ,66596 \\
\hline \multicolumn{2}{|c|}{ Minimum } & 1,00 & 1,40 & 1,0 & 1,00 & 1,00 & 1,86 \\
\hline \multicolumn{2}{|c|}{ Maximum } & 5,00 & 5,00 & 5,0 & 5,00 & 5,00 & 5,00 \\
\hline
\end{tabular}

Pontuações dos itens - Comunicação entre colegas

Descriptive Statistics

\begin{tabular}{|c|c|c|c|c|c|}
\hline & $\mathrm{N}$ & Minimum & Maximum & Mean & Std. Deviation \\
\hline Item 20 & 241 & 1 & 5 & 1,99 & 1,112 \\
\hline Item 21 & 241 & 1 & 5 & 3,46 & ,970 \\
\hline Item 23 & 241 & 1 & 5 & 1,71 & 1,075 \\
\hline $\begin{array}{ll}\text { Valid } & \mathrm{N} \\
\text { (listwise) } & \end{array}$ & 241 & & & & \\
\hline
\end{tabular}

Item mais pontuado na Dimensão - Comunicação entre colegas

\begin{tabular}{|c|c|c|c|c|c|}
\hline & & Frequency & Percent & Valid Percent & Cumulative Percent \\
\hline \multirow[t]{4}{*}{ Valid } & Completamente em desacordo & 7 & 2,9 & 2,9 & 2,9 \\
\hline & Nem concordo nem discordo & 172 & 71,4 & 71,4 & 74,3 \\
\hline & Completamente de acordo & 62 & 25,7 & 25,7 & 100,0 \\
\hline & Total & 241 & 100,0 & 100,0 & \\
\hline
\end{tabular}


Item menos pontuado na Dimensão - Comunicação entre colegas

\begin{tabular}{|c|c|c|c|c|c|}
\hline \multicolumn{6}{|c|}{ Item 20} \\
\hline & & Frequency & Percent & Valid Percent & Cumulative Percent \\
\hline \multirow[t]{4}{*}{ Valid } & Completamente de acordo & 129 & 53,5 & 53,5 & 53,5 \\
\hline & Nem concordo nem discordo & 105 & 43,6 & 43,6 & 97,1 \\
\hline & Completamente em desacordo & 7 & 2,9 & 2,9 & 100,0 \\
\hline & Total & 241 & 100,0 & 100,0 & \\
\hline
\end{tabular}

Pontuações dos itens - Informação Geral sobre a GNR

\begin{tabular}{|c|c|c|c|c|}
\hline \multicolumn{5}{|c|}{ Statistics } \\
\hline & & Item 1 & Item 2 & Item 3 \\
\hline \multirow[t]{2}{*}{ N } & Valid & 241 & 241 & 241 \\
\hline & Missing & 0 & 0 & 0 \\
\hline \multicolumn{2}{|c|}{ Mean } & 2,73 & 3,05 & 3,05 \\
\hline \multicolumn{2}{|c|}{ Std. Deviation } & 1,214 & 1,237 & 1,109 \\
\hline
\end{tabular}

Pontuação do item mais pontuado - Informação Geral sobre a GNR

\begin{tabular}{|c|c|c|c|c|c|}
\hline & & Frequency & Percent & Valid Percent & Cumulative Percent \\
\hline \multirow[t]{4}{*}{ Valid } & Completamente de acordo & 63 & 26,1 & 26,1 & 26,1 \\
\hline & Nem concordo nem discordo & 148 & 61,4 & 61,4 & 87,6 \\
\hline & Completamente em desacordo & 30 & 12,4 & 12,4 & 100,0 \\
\hline & Total & 241 & 100,0 & 100,0 & \\
\hline
\end{tabular}

Pontuação do item menos pontuado - Informação Geral sobre a GNR

\begin{tabular}{|c|c|c|c|c|c|}
\hline \multicolumn{6}{|c|}{ Item 2} \\
\hline & & Frequency & Percent & Valid Percent & Cumulative Percent \\
\hline \multirow[t]{4}{*}{ Valid } & Completamente de acordo & 43 & 17,8 & 17,8 & 17,8 \\
\hline & Nem concordo nem discordo & 149 & 61,8 & 61,8 & 79,7 \\
\hline & Completamente em desacordo & 49 & 20,3 & 20,3 & 100,0 \\
\hline & Total & 241 & 100,0 & 100,0 & \\
\hline
\end{tabular}


Pontuação do item menos pontuado - Informação Geral sobre a GNR

\begin{tabular}{|c|c|c|c|c|c|}
\hline \multicolumn{6}{|c|}{ Item 3} \\
\hline & & Frequency & Percent & Valid Percent & Cumulative Percent \\
\hline \multirow[t]{4}{*}{ Valid } & Completamente de acordo & 34 & 14,1 & 14,1 & 14,1 \\
\hline & Nem concordo nem discordo & 167 & 69,3 & 69,3 & 83,4 \\
\hline & Completamente em desacordo & 40 & 16,6 & 16,6 & 100,0 \\
\hline & Total & 241 & 100,0 & 100,0 & \\
\hline
\end{tabular}

\section{Pontuações dos itens - Comunicação com a Chefia}

\begin{tabular}{|c|c|c|c|}
\hline \multicolumn{4}{|c|}{ Statistics } \\
\hline & & Item 10 & Item 11 \\
\hline \multirow[t]{2}{*}{ N } & Valid & 241 & 241 \\
\hline & Missing & 0 & 0 \\
\hline \multicolumn{2}{|c|}{ Mean } & 3,11 & 3,14 \\
\hline \multicolumn{2}{|c|}{ Std. Deviation } & 1,199 & 1,168 \\
\hline
\end{tabular}

Pontuação do item mais pontuado - Comunicação sobre a chefia

\begin{tabular}{|ll|r|r|r|r|}
\hline & \multicolumn{2}{|c|}{ Item 11 } & Valid Percent & Cumulative Percent \\
\hline Valid & Frequency & Percent & 13,7 & \\
& Completamente em desacordo & 33 & 13,7 & 65,6 & \\
& Nem concordo nem discordo & 158 & 65,6 & 20,7 & \\
& Completamente de acordo & 50 & 20,7 & 100,0 \\
& 241 & 100,0 & 100,0 & \\
\hline
\end{tabular}

Pontuação do item menos pontuado - Comunicação sobre a chefia

\begin{tabular}{|ll|r|r|r|r|}
\hline & \multicolumn{2}{|c|}{ Item 10 } & \\
\hline Valid & Frequency & Percent & Valid Percent & Cumulative Percent \\
\cline { 2 - 5 } & 37 & 15,4 & 15,4 & 15,4 \\
& Completamente em desacordo & 154 & 63,9 & 63,9 & 79,3 \\
& Nem concordo nem discordo & 50 & 20,7 & 20,7 & 100,0 \\
Completamente de acordo & 241 & 100,0 & 100,0 & \\
Total & & &
\end{tabular}




\section{Pontuações dos itens - Clima de Comunicação}

\begin{tabular}{|c|c|c|c|c|c|c|}
\hline \multicolumn{7}{|c|}{ Statistics } \\
\hline & & Item 15 & Item 16 & Item 17 & Item 18 & Item 19 \\
\hline \multirow[t]{2}{*}{$\mathrm{N}$} & Valid & 241 & 241 & 241 & 241 & 241 \\
\hline & Missing & 0 & 0 & 0 & 0 & 0 \\
\hline \multicolumn{2}{|c|}{ Mean } & 3,83 & 2,86 & 2,73 & 4,27 & 2,58 \\
\hline \multicolumn{2}{|c|}{ Std. Deviation } & 1,069 & 1,094 & 1,302 & 1,048 & 1,097 \\
\hline
\end{tabular}

\section{Pontuação do item mais pontuado - Clima de Comunicação}

\begin{tabular}{|c|c|c|c|c|c|}
\hline \multicolumn{6}{|c|}{ Item 18} \\
\hline & & Frequency & Percent & Valid Percent & Cumulative Percent \\
\hline \multirow[t]{4}{*}{ Valid } & Completamente em desacordo & 5 & 2,1 & 2,1 & 2,1 \\
\hline & Nem concordo nem discordo & 78 & 32,4 & 32,4 & 34,4 \\
\hline & Completamente de acordo & 158 & 65,6 & 65,6 & 100,0 \\
\hline & Total & 241 & 100,0 & 100,0 & \\
\hline
\end{tabular}

Pontuação do item menos pontuado - Clima de Comunicação

\begin{tabular}{|c|c|c|c|c|c|}
\hline & & Frequency & Percent & Valid Percent & Cumulative Percent \\
\hline \multirow[t]{4}{*}{ Valid } & Completamente de acordo & 45 & 18,7 & 18,7 & 18,7 \\
\hline & Nem concordo nem discordo & 168 & 69,7 & 69,7 & 88,4 \\
\hline & Completamente em desacordo & 28 & 11,6 & 11,6 & 100,0 \\
\hline & Total & 241 & 100,0 & 100,0 & \\
\hline
\end{tabular}

\section{Pontuações dos itens - Boatos e Conflitos}

\begin{tabular}{|c|c|c|c|c|c|c|c|c|}
\hline \multicolumn{9}{|c|}{ Statistics } \\
\hline & & Item 24 & Item 25 & Item 26 & Item 27 & Item 28 & Item 29 & Item 30 \\
\hline \multirow[t]{2}{*}{$\mathrm{N}$} & Valid & 241 & 241 & 241 & 241 & 241 & 241 & 241 \\
\hline & Missing & 0 & 0 & 0 & 0 & 0 & 0 & 0 \\
\hline \multicolumn{2}{|c|}{ Mean } & 4,24 & 4,29 & 4,32 & 2,78 & 4,42 & 2,85 & 3,81 \\
\hline \multicolumn{2}{|c|}{ Std. Deviation } & 1,007 & ,977 & 1,001 & 1,074 & ,946 & 1,070 & 1,001 \\
\hline
\end{tabular}


Pontuação do item mais pontuado - Boatos e Conflitos

\begin{tabular}{|c|c|c|c|c|c|}
\hline \multicolumn{6}{|c|}{ Item 28} \\
\hline & & Frequency & Percent & Valid Percent & Cumulative Percent \\
\hline \multirow[t]{4}{*}{ Valid } & Completamente em desacordo & 2 & ,8 & 8 & ,8 \\
\hline & Nem concordo nem discordo & 66 & 27,4 & 27,4 & 28,2 \\
\hline & Completamente de acordo & 173 & 71,8 & 71,8 & 100,0 \\
\hline & Total & 241 & 100,0 & 100,0 & \\
\hline
\end{tabular}

Pontuação do item menos pontuado - Boatos e Conflitos

\begin{tabular}{|ll|r|r|r|r|}
\hline & \multicolumn{2}{|c|}{ Item 29 } & & \\
\hline \multirow{2}{*}{ Valid } & Frequency & Percent & Valid Percent & Cumulative Percent \\
\cline { 2 - 4 } & 44 & 18,3 & 18,3 & 18,3 \\
& Completamente de acordo & 171 & 71,0 & 71,0 & 89,2 \\
& 26 & 10,8 & 10,8 & 100,0 \\
Com concordo nem discordo & 241 & 100,0 & 100,0 & \\
Total & & &
\end{tabular}

\section{Pontuações dos itens - Informação Fornecida no Local de Trabalho}

\begin{tabular}{|c|c|c|c|c|c|c|}
\hline \multicolumn{7}{|c|}{ Statistics } \\
\hline & & Item 5 & Item 6 & Item 7 & Item 8 & Item 9 \\
\hline \multirow[t]{2}{*}{$\mathrm{N}$} & Valid & 241 & 241 & 241 & 241 & 241 \\
\hline & Missing & 0 & 0 & 0 & 0 & 0 \\
\hline \multicolumn{2}{|c|}{ Mean } & 3,87 & 3,91 & 3,76 & 4,07 & 3,52 \\
\hline \multicolumn{2}{|c|}{ Std. Deviation } & 1,059 & 1,047 & 1,070 & 1,032 & 1,099 \\
\hline
\end{tabular}

Pontuação do item mais pontuado - Informação Fornecida no Local de Trabalho

\begin{tabular}{|ll|r|r|r|r|}
\hline \multicolumn{2}{|c|}{ Item 8 } \\
\hline Valid & Frequency & Percent & Valid Percent & Cumulative Percent \\
& Completamente em desacordo & 2 &, 8 &, 8 &, 8 \\
& Nem concordo nem discordo & 108 & 44,8 & 44,8 & 45,6 \\
Completamente de acordo & 131 & 54,4 & 54,4 & 100,0 \\
Total & 241 & 100,0 & 100,0 & \\
\hline
\end{tabular}


Pontuação do item menos pontuado - Informação Fornecida no Local de Trabalho

\begin{tabular}{|ll|r|r|r|r|}
\hline & \multicolumn{2}{|c|}{ Item 9 } & \multicolumn{1}{|c|}{ Cumulative Percent } \\
\hline Valid & Frequency & Percent & Valid Percent & 5,4 \\
& Completamente em desacordo & 13 & 5,4 & 5,4 & 68,5 \\
& Nem concordo nem discordo & 152 & 63,1 & 63,1 & 100,0 \\
Completamente de acordo & 76 & 31,5 & 31,5 & 100,0 & \\
Total & 241 & 100,0 & 1 & \\
\end{tabular}




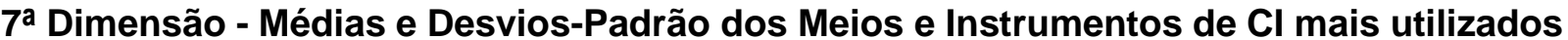

\begin{tabular}{|c|c|c|c|c|c|c|c|c|c|c|c|c|c|c|c|c|c|c|c|c|c|}
\hline & $\begin{array}{c}\text { Convers } \\
\text { as } \\
\text { Informai } \\
\text { s }\end{array}$ & $\begin{array}{l}\text { Convers } \\
\text { as } \\
\text { Formais }\end{array}$ & $\begin{array}{c}\text { Reuniõ } \\
\text { es }\end{array}$ & $\begin{array}{l}\text { Ações } \\
\text { de } \\
\text { Formaç } \\
\text { ão }\end{array}$ & $\begin{array}{l}\text { Convers } \\
\text { as em } \\
\text { Grupo }\end{array}$ & $\begin{array}{c}\text { Notas } \\
\text { internas } \\
\text { ou } \\
\text { Mensage } \\
\text { ns }\end{array}$ & $\begin{array}{c}\text { Orden } \\
\mathrm{s} \text { de } \\
\text { Serviç } \\
0\end{array}$ & NEP & $\begin{array}{l}\text { Relatóri } \\
\text { os de } \\
\text { Atividad } \\
\text { es }\end{array}$ & $\begin{array}{c}\text { Correi } \\
0 \\
\text { Intern } \\
0\end{array}$ & $\begin{array}{c}\text { Folhet } \\
\text { os }\end{array}$ & $\begin{array}{l}\text { Placar } \\
\text { es }\end{array}$ & $\begin{array}{c}\text { Revist } \\
\text { a da } \\
\text { GNR }\end{array}$ & $\begin{array}{c}\text { Site } \\
\text { da } \\
\text { GN } \\
\text { R }\end{array}$ & $\begin{array}{l}\text { Intran } \\
\text { et } \\
\text { GNR }\end{array}$ & $\begin{array}{l}\text { Correio } \\
\text { Eletróni } \\
\text { co }\end{array}$ & $\begin{array}{c}\text { Telemóv } \\
\text { el }\end{array}$ & $\begin{array}{c}\text { Telefo } \\
\text { ne Fixo }\end{array}$ & $\begin{array}{l}\text { Audio } \\
\text { visuai } \\
\mathrm{s}\end{array}$ & Chat & $\begin{array}{c}\text { Video } \\
\text { conferênc } \\
\text { ia }\end{array}$ \\
\hline $\mathrm{N}$ Valid & 241 & 241 & 241 & 241 & 241 & 241 & 241 & 241 & 241 & 241 & 241 & 241 & 241 & 241 & 241 & 241 & 241 & 241 & 241 & 241 & 241 \\
\hline Missin & 0 & 0 & 0 & 0 & 0 & 0 & 0 & 0 & 0 & 0 & 0 & 0 & 0 & 0 & 0 & 0 & 0 & 0 & 0 & 0 & 0 \\
\hline Mean & 2,23 & 2,49 & 1,61 & 1,75 & 2,29 & 2,64 & 2,59 & 2,58 & 2,24 & 2,46 & 1,91 & 2,06 & 1,76 & 2,53 & 2,74 & 2,817 & 2,43 & 2,21 & 1,37 & 1,22 & 1,17 \\
\hline $\begin{array}{l}\text { Std. } \\
\text { Deviation }\end{array}$ & 0,976 & 0,871 & 0,921 & 0,969 & 0,958 & 0,767 & 0,807 & $\begin{array}{r}0,81 \\
9\end{array}$ & 0,972 & 0,889 & 0,998 & 1 & 0,972 & $\begin{array}{r}0,85 \\
2\end{array}$ & 0,671 & 0,577 & 0,906 & 0,979 & 0,781 & $\begin{array}{r}0,62 \\
2\end{array}$ & 0,553 \\
\hline Minimum & 1 & 1 & 1 & 1 & 1 & 1 & 1 & 1 & 1 & 1 & 1 & 1 & 1 & 1 & 1 & 1 & 1 & 1 & 1 & 1 & 1 \\
\hline Maximum & 3 & 3 & 3 & 3 & 3 & 3 & 3 & 3 & 3 & 3 & 3 & 3 & 3 & 3 & 3 & 3 & 3 & 3 & 3 & 3 & 3 \\
\hline
\end{tabular}


Utilização dos Meios e Instrumentos de CI - por ordem do mais utilizado para o $\underline{\text { menos utilizado }}$

\begin{tabular}{|c|c|c|c|c|c|}
\hline \multicolumn{6}{|c|}{ Correio Eletrónico } \\
\hline & & Frequency & Percent & Valid Percent & $\begin{array}{c}\text { Cumulative } \\
\text { Percent }\end{array}$ \\
\hline \multirow[t]{3}{*}{ Valid } & Não uso nem consulto & 22 & 9,1 & 9,1 & 9,1 \\
\hline & Uso / consulto & 219 & 90,9 & 90,9 & 100,0 \\
\hline & Total & 241 & 100,0 & 100,0 & \\
\hline
\end{tabular}

\begin{tabular}{|c|c|c|c|c|c|}
\hline \multicolumn{6}{|c|}{ Intranet GNR } \\
\hline & & Frequency & Percent & Valid Percent & $\begin{array}{c}\text { Cumulative } \\
\text { Percent }\end{array}$ \\
\hline \multirow[t]{3}{*}{ Valid } & Não uso nem consulto & 31 & 12,9 & 12,9 & 12,9 \\
\hline & Uso / consulto & 210 & 87,1 & 87,1 & 100,0 \\
\hline & Total & 241 & 100,0 & 100,0 & \\
\hline
\end{tabular}

Notas internas ou Mensagens

\begin{tabular}{|ll|r|r|r|r|}
\hline & & & & \multicolumn{2}{c|}{$\begin{array}{c}\text { Cumulative } \\
\text { Percent }\end{array}$} \\
\hline \multirow{2}{*}{ Valid } & Frequency & Percent & Valid Percent & 17,8 \\
& Não uso nem consulto & 43 & 17,8 & 17,8 & 100,0 \\
& Uso / consulto & 198 & 82,2 & 82,2 & \\
Total & 241 & 100,0 & 100,0 & \\
\hline
\end{tabular}

\begin{tabular}{|c|c|c|c|c|c|}
\hline \multicolumn{6}{|c|}{ Ordens de Serviço } \\
\hline & & Frequency & Percent & Valid Percent & $\begin{array}{c}\text { Cumulative } \\
\text { Percent }\end{array}$ \\
\hline \multirow[t]{3}{*}{ Valid } & Não uso nem consulto & 49 & 20,3 & 20,3 & 20,3 \\
\hline & Uso / consulto & 192 & 79,7 & 79,7 & 100,0 \\
\hline & Total & 241 & 100,0 & 100,0 & \\
\hline
\end{tabular}

\begin{tabular}{|c|c|c|c|c|c|}
\hline \multicolumn{6}{|c|}{ NEP } \\
\hline & & Frequency & Percent & Valid Percent & $\begin{array}{c}\text { Cumulative } \\
\text { Percent }\end{array}$ \\
\hline \multirow[t]{3}{*}{ Valid } & Não uso nem consulto & 51 & 21,2 & 21,2 & 21,2 \\
\hline & Uso / consulto & 190 & 78,8 & 78,8 & 100,0 \\
\hline & Total & 241 & 100,0 & 100,0 & \\
\hline
\end{tabular}


Site da GNR

\begin{tabular}{|ll|r|r|r|r|}
\hline & & & & \multicolumn{2}{c|}{$\begin{array}{c}\text { Cumulative } \\
\text { Percent }\end{array}$} \\
\hline \multirow{2}{*}{ Valid } & Frequency & Percent & Valid Percent & 23,7 \\
& Não uso nem consulto & 57 & 23,7 & 23,7 & 100,0 \\
& Uso / consulto & 184 & 76,3 & 76,3 & 100,0 \\
Total & 241 & 100,0 & \\
\hline
\end{tabular}

Conversas Formais

\begin{tabular}{|ll|r|r|r|r|}
\hline & & & & Cumulative \\
& Frequency & Percent & Valid Percent & Percent \\
\hline Valid Não uso nem consulto & 61 & 25,3 & 25,3 & 25,3 \\
& Uso / consulto & 180 & 74,7 & 74,7 & 100,0 \\
Total & 241 & 100,0 & 100,0 & \\
\hline
\end{tabular}

\section{Correio Interno}

\begin{tabular}{|ll|r|r|r|r|}
\hline & & & & Cumulative \\
& Frequency & Percent & Valid Percent & Percent \\
\hline Valid Não uso nem consulto & 65 & 27,0 & 27,0 & 27,0 \\
& Uso / consulto & 176 & 73,0 & 73,0 & 100,0 \\
Total & 241 & 100,0 & 100,0 & \\
\hline
\end{tabular}

\section{Telemóvel}

\begin{tabular}{|ll|r|r|r|r|}
\hline & & & & $\begin{array}{c}\text { Cumulative } \\
\text { Percent }\end{array}$ \\
\hline \multirow{2}{*}{ Valid } & Frequency & Percent & Valid Percent & 28,6 \\
& Não uso nem consulto & 69 & 28,6 & 28,6 & 71,4 \\
\\
Uso / consulto & 172 & 71,4 & 100,0 \\
Total & 241 & 100,0 & 100,0 & \\
\hline
\end{tabular}

\begin{tabular}{|c|c|c|c|c|c|}
\hline \multicolumn{6}{|c|}{ Conversas em Grupo } \\
\hline & & Frequency & Percent & Valid Percent & $\begin{array}{c}\text { Cumulative } \\
\text { Percent }\end{array}$ \\
\hline \multirow[t]{3}{*}{ Valid } & Não uso nem consulto & 85 & 35,3 & 35,3 & 35,3 \\
\hline & Uso / consulto & 156 & 64,7 & 64,7 & 100,0 \\
\hline & Total & 241 & 100,0 & 100,0 & \\
\hline
\end{tabular}


Relatórios de Atividades

\begin{tabular}{|ll|r|r|r|r|}
\hline & & & & $\begin{array}{c}\text { Cumulative } \\
\text { Percent }\end{array}$ \\
\hline Valid Não uso nem consulto & Frequency & Percent & Valid Percent & 37,8 \\
& Uso / consulto & 150 & 37,8 & 37,8 & 62,2 \\
& 150 & 62,2 & 100,0 \\
Total & 241 & 100,0 & 100,0 & \\
\hline
\end{tabular}

\begin{tabular}{|c|c|c|c|c|c|}
\hline \multicolumn{6}{|c|}{ Conversas Informais } \\
\hline & & Frequency & Percent & Valid Percent & $\begin{array}{c}\text { Cumulative } \\
\text { Percent }\end{array}$ \\
\hline \multirow[t]{3}{*}{ Valid } & Não uso nem consulto & 93 & 38,6 & 38,6 & 38,6 \\
\hline & Uso / consulto & 148 & 61,4 & 61,4 & 100,0 \\
\hline & Total & 241 & 100,0 & 100,0 & \\
\hline
\end{tabular}

\section{Telefone Fixo}

\begin{tabular}{|ll|r|r|r|r|}
\hline & & & & Cumulative \\
& Frequency & Percent & Valid Percent & Percent \\
\hline Valid Não uso nem consulto & 95 & 39,4 & 39,4 & 39,4 \\
& Uso / consulto & 146 & 60,6 & 60,6 & 100,0 \\
Total & 241 & 100,0 & 100,0 & \\
\hline
\end{tabular}

\section{Placares}

\begin{tabular}{|ll|r|r|r|r|}
\hline & & & & \multicolumn{2}{c|}{$\begin{array}{c}\text { Cumulative } \\
\text { Percent }\end{array}$} \\
\hline Valid Não uso nem consulto & Frequency & Percent & Valid Percent & 46,9 \\
& 113 & 46,9 & 46,9 & 100,0 \\
& Uso / consulto & 128 & 53,1 & 53,1 & 100,0 \\
& 241 & 100,0 & \\
\hline
\end{tabular}

\section{Folhetos}

\begin{tabular}{|ll|r|r|r|r|}
\hline & & & & Cumulative \\
& Frequency & Percent & Valid Percent & Percent \\
\hline Valid Não uso nem consulto & 131 & 54,4 & 54,4 & 54,4 \\
& Uso / consulto & 110 & 45,6 & 45,6 & 100,0 \\
Total & 241 & 100,0 & 100,0 & \\
\hline
\end{tabular}




\begin{tabular}{|c|c|c|c|c|c|}
\hline \multicolumn{6}{|c|}{ Revista da GNR } \\
\hline & & Frequency & Percent & Valid Percent & $\begin{array}{c}\text { Cumulative } \\
\text { Percent }\end{array}$ \\
\hline \multirow[t]{3}{*}{ Valid } & Não uso nem consulto & 150 & 62,2 & 62,2 & 62,2 \\
\hline & Uso / consulto & 91 & 37,8 & 37,8 & 100,0 \\
\hline & Total & 241 & 100,0 & 100,0 & \\
\hline
\end{tabular}

\begin{tabular}{|c|c|c|c|c|c|}
\hline \multicolumn{6}{|c|}{ Ações de Formação } \\
\hline & & Frequency & Percent & Valid Percent & $\begin{array}{c}\text { Cumulative } \\
\text { Percent }\end{array}$ \\
\hline \multirow[t]{3}{*}{ Valid } & Não uso nem consulto & 151 & 62,7 & 62,7 & 62,7 \\
\hline & Uso / consulto & 90 & 37,3 & 37,3 & 100,0 \\
\hline & Total & 241 & 100,0 & 100,0 & \\
\hline
\end{tabular}

\begin{tabular}{|ll|r|r|r|r|}
\hline & & & & \multicolumn{2}{|c|}{ Reuniões } \\
& Frequency & Percent & Valid Percent & Percent \\
\hline \multirow{2}{*}{ Valid Não uso nem consulto } & 168 & 69,7 & 69,7 & 69,7 \\
& Uso / consulto & 73 & 30,3 & 30,3 & 100,0 \\
Total & 241 & 100,0 & 100,0 & \\
\hline
\end{tabular}

\begin{tabular}{|ll|r|r|r|r|}
\hline & & & & \\
& & Cumulative \\
& Frequency & Percent & Valid Percent & Percent \\
\hline \multirow{2}{*}{ Valid Não uso nem consulto } & 196 & 81,3 & 81,3 & 81,3 \\
& Uso / consulto & 45 & 18,7 & 18,7 & 100,0 \\
Total & 241 & 100,0 & 100,0 & \\
\hline
\end{tabular}

\begin{tabular}{|c|c|c|c|c|c|}
\hline \multicolumn{6}{|c|}{ Chat } \\
\hline & & Frequency & Percent & Valid Percent & $\begin{array}{c}\text { Cumulative } \\
\text { Percent }\end{array}$ \\
\hline \multirow[t]{3}{*}{ Valid } & Não uso nem consulto & 215 & 89,2 & 89,2 & 89,2 \\
\hline & Uso / consulto & 26 & 10,8 & 10,8 & 100,0 \\
\hline & Total & 241 & 100,0 & 100,0 & \\
\hline
\end{tabular}


Videoconferência

\begin{tabular}{|l|r|r|r|r|}
\hline & & & & Cumulative \\
& Frequency & Percent & Valid Percent & Percent \\
\hline Valid Não uso nem consulto & 221 & 91,7 & 91,7 & 91,7 \\
& 20 & 8,3 & 8,3 & 100,0 \\
Uso / consulto & 241 & 100,0 & 100,0 & \\
Total & & \\
\hline
\end{tabular}




\section{Dimensão - Médias e Desvios-Padrão dos Meios e Instrumentos de Cl mais eficazes}

\begin{tabular}{|c|c|c|c|c|c|c|c|c|c|c|c|c|c|c|c|c|c|c|c|c|}
\hline \multicolumn{21}{|c|}{ Statistics } \\
\hline & $\begin{array}{c}\text { Conversa } \\
\mathrm{s} \\
\text { Informais }\end{array}$ & $\begin{array}{c}\text { Conversa } \\
\text { s } \\
\text { Formais }\end{array}$ & $\begin{array}{c}\text { Reuniõe } \\
\mathrm{s}\end{array}$ & $\begin{array}{c}\text { Conversa } \\
\text { s em } \\
\text { Grupo }\end{array}$ & $\begin{array}{c}\text { Notas } \\
\text { internas } \\
\text { ou } \\
\text { Mensagen } \\
\text { s }\end{array}$ & $\begin{array}{l}\text { Orden } \\
\text { s de } \\
\text { Serviç } \\
0\end{array}$ & $\begin{array}{c}\mathrm{NE} \\
\mathrm{P}\end{array}$ & $\begin{array}{c}\text { Relatório } \\
\text { s de } \\
\text { Atividade } \\
\mathrm{s}\end{array}$ & $\begin{array}{c}\text { Correi } \\
0 \\
\text { Intern } \\
0 \\
\end{array}$ & $\begin{array}{c}\text { Folheto } \\
\mathrm{s} \\
\end{array}$ & $\begin{array}{c}\text { Placare } \\
\mathrm{s}\end{array}$ & $\begin{array}{c}\text { Revist } \\
\text { a da } \\
\text { GNR }\end{array}$ & $\begin{array}{l}\text { Site } \\
\text { da } \\
\text { GN } \\
\text { R }\end{array}$ & $\begin{array}{c}\text { Intran } \\
\text { et } \\
\text { GNR }\end{array}$ & $\begin{array}{c}\text { Correio } \\
\text { Eletrónic } \\
0\end{array}$ & $\begin{array}{c}\text { Telemóv } \\
\text { el }\end{array}$ & $\begin{array}{l}\text { Telefon } \\
\text { e Fixo }\end{array}$ & $\begin{array}{c}\text { Audiovisua } \\
\text { is }\end{array}$ & $\begin{array}{c}\text { Cha } \\
\mathrm{t}\end{array}$ & $\begin{array}{c}\text { Videoconferênc } \\
\text { ia }\end{array}$ \\
\hline N Valid & 241 & 241 & 241 & 241 & 241 & 241 & 241 & 241 & 241 & 241 & 241 & 241 & 241 & 241 & 241 & 241 & 241 & 241 & 241 & 241 \\
\hline $\begin{array}{l}\text { Missin } \\
\mathrm{g}\end{array}$ & 0 & 0 & 0 & 0 & 0 & 0 & 0 & 0 & 0 & 0 & 0 & 0 & 0 & 0 & 0 & 0 & 0 & 0 & 0 & 0 \\
\hline Mean & 2,21 & 2,63 & 2,47 & 2,57 & 2,66 & 2,64 & $\begin{array}{r}2,7 \\
3\end{array}$ & 2,49 & 2,65 & 2,03 & 2,11 & 1,91 & 2,62 & 2,80 & 2,84 & 2,59 & 2,49 & 1,91 & $\begin{array}{r}1,5 \\
7\end{array}$ & 1,59 \\
\hline $\begin{array}{l}\text { Std. } \\
\text { Deviation }\end{array}$ & ,979 & ,781 & ,885 & ,824 & ,753 & ,767 & $\begin{array}{r}, 68 \\
0\end{array}$ & ,871 & ,760 & 1,002 & ,996 & ,998 & (788 & ,600 &, 540 & ,807 & ,871 & ,998 & $\begin{array}{r}, 90 \\
6\end{array}$ & ,914 \\
\hline Minimum & 1 & 1 & 1 & 1 & 1 & 1 & 1 & 1 & 1 & 1 & 1 & 1 & 1 & 1 & 1 & 1 & 1 & 1 & 1 & 1 \\
\hline Maximum & 3 & 3 & 3 & 3 & 3 & 3 & 3 & 3 & 3 & 3 & 3 & 3 & 3 & 3 & 3 & 3 & 3 & 3 & 3 & 3 \\
\hline
\end{tabular}


Utilizacão dos Meios e Instrumentos de CI - por ordem do mais utilizado para o menos utilizado

\begin{tabular}{|c|c|c|c|c|c|}
\hline \multicolumn{6}{|c|}{ Correio Eletrónico } \\
\hline & & Frequency & Percent & Valid Percent & $\begin{array}{c}\text { Cumulative } \\
\text { Percent }\end{array}$ \\
\hline \multirow[t]{3}{*}{ Valid } & Ineficaz & 19 & 7,9 & 7,9 & 7,9 \\
\hline & Eficaz & 222 & 92,1 & 92,1 & 100,0 \\
\hline & Total & 241 & 100,0 & 100,0 & \\
\hline
\end{tabular}

Intranet GNR

\begin{tabular}{|rl|r|r|r|r|}
\hline & Frequency & Percent & Valid Percent & Cumulative Percent \\
\hline \multirow{2}{*}{ Valid } & Ineficaz & 24 & 10,0 & 10,0 & 10,0 \\
& Eficaz & 217 & 90,0 & 90,0 & 100,0 \\
& Total & 241 & 100,0 & 100,0 & \\
\hline
\end{tabular}

\begin{tabular}{|c|c|c|c|c|c|}
\hline \multicolumn{6}{|c|}{ NEP } \\
\hline & & Frequency & Percent & Valid Percent & Cumulative Percent \\
\hline \multirow[t]{3}{*}{ Valid } & Ineficaz & 32 & 13,3 & 13,3 & 13,3 \\
\hline & Eficaz & 209 & 86,7 & 86,7 & 100,0 \\
\hline & Total & 241 & 100,0 & 100,0 & \\
\hline
\end{tabular}

Notas internas ou Mensagens

\begin{tabular}{|c|c|c|c|c|c|}
\hline & & Frequency & Percent & Valid Percent & Cumulative Percent \\
\hline \multirow[t]{3}{*}{ Valid } & Ineficaz & 41 & 17,0 & 17,0 & 17,0 \\
\hline & Eficaz & 200 & 83,0 & 83,0 & 100,0 \\
\hline & Total & 241 & 100,0 & 100,0 & \\
\hline
\end{tabular}

Correio Interno

\begin{tabular}{|rl|r|r|r|r|}
\hline & Frequency & Percent & Valid Percent & Cumulative Percent \\
\hline \multirow{2}{*}{ Valid } & Ineficaz & 42 & 17,4 & 17,4 & 17,4 \\
& Eficaz & 199 & 82,6 & 82,6 & 100,0 \\
& Total & 241 & 100,0 & 100,0 & \\
\hline
\end{tabular}

Ordens de Serviço

\begin{tabular}{|ll|r|r|r|r|}
\hline & Frequency & Percent & Valid Percent & Cumulative Percent \\
\hline \multirow{2}{*}{ Valid } & Ineficaz & 43 & 17,8 & 17,8 & 17,8 \\
& Eficaz & 198 & 82,2 & 82,2 & 100,0 \\
& Total & 241 & 100,0 & 100,0 & \\
\hline
\end{tabular}

A Comunicação Interna na Guarda Nacional Republicana 
Conversas Formais

\begin{tabular}{|rl|r|r|r|r|}
\hline & \multicolumn{2}{|c|}{ Frequency } & Percent & Valid Percent & Cumulative Percent \\
\hline Valid & Ineficaz & 45 & 18,7 & 18,7 & 18,7 \\
& Eficaz & 196 & 81,3 & 81,3 & 100,0 \\
& Total & 241 & 100,0 & 100,0 & \\
\hline
\end{tabular}

Site da GNR

\begin{tabular}{|rl|r|r|r|r|}
\hline & \multicolumn{1}{|c|}{ Frequency } & Percent & Valid Percent & Cumulative Percent \\
\hline \multirow{2}{*}{ Valid } & Ineficaz & 46 & 19,1 & 19,1 & 19,1 \\
& Eficaz & 195 & 80,9 & 80,9 & 100,0 \\
& Total & 100,0 & 100,0 & \\
\hline
\end{tabular}

Telemóvel

\begin{tabular}{|ll|r|r|r|r|}
\hline & & \multicolumn{1}{|c|}{ Frequency } & Percent & Valid Percent & Cumulative Percent \\
\hline \multirow{2}{*}{ Valid } & Ineficaz & 49 & 20,3 & 20,3 & 20,3 \\
& Eficaz & 192 & 79,7 & 79,7 & 100,0 \\
& Total & 241 & 100,0 & 100,0 & \\
\hline
\end{tabular}

Conversas em Grupo

\begin{tabular}{|rl|r|r|r|r|}
\hline & \multicolumn{2}{|c|}{ Frequency } & Percent & Valid Percent & Cumulative Percent \\
\hline \multirow{2}{*}{ Valid } & Ineficaz & 52 & 21,6 & 21,6 & 21,6 \\
& Eficaz & 189 & 78,4 & 78,4 & 100,0 \\
& Total & 241 & 100,0 & 100,0 & \\
\hline
\end{tabular}

Relatórios de Atividades

\begin{tabular}{|rl|r|r|r|r|}
\hline & & Frequency & Percent & Valid Percent & Cumulative Percent \\
\hline \multirow{2}{*}{ Valid } & Ineficaz & 61 & 25,3 & 25,3 & 25,3 \\
& Eficaz & 180 & 74,7 & 74,7 & 100,0 \\
& Total & 241 & 100,0 & 100,0 & \\
\hline
\end{tabular}

Telefone Fixo

\begin{tabular}{|rl|r|r|r|r|}
\hline & & Frequency & Percent & Valid Percent & Cumulative Percent \\
\hline \multirow{2}{*}{ Valid } & Ineficaz & 61 & 25,3 & 25,3 & 25,3 \\
& Eficaz & 180 & 74,7 & 74,7 & 100,0 \\
& Total & 241 & 100,0 & 100,0 & \\
\hline
\end{tabular}




\section{Reuniões}

\begin{tabular}{|rl|r|r|r|r|}
\hline & Frequency & Percent & Valid Percent & Cumulative Percent \\
\hline \multirow{2}{*}{ Valid } & Ineficaz & 64 & 26,6 & 26,6 & 26,6 \\
& Eficaz & 177 & 73,4 & 73,4 & 100,0 \\
& Total & 241 & 100,0 & 100,0 & \\
\hline
\end{tabular}

Conversas Informais

\begin{tabular}{|rl|r|r|r|r|}
\hline & \multicolumn{2}{|c|}{ Frequency } & Percent & Valid Percent & Cumulative Percent \\
\hline \multirow{2}{*}{ Valid } & Ineficaz & 95 & 39,4 & 39,4 & 39,4 \\
& Eficaz & 146 & 60,6 & 60,6 & 100,0 \\
& Total & 241 & 100,0 & 100,0 & \\
\hline
\end{tabular}

Placares

\begin{tabular}{|rl|r|r|r|r|}
\hline & Frequency & Percent & Valid Percent & Cumulative Percent \\
\hline \multirow{2}{*}{ Valid } & Ineficaz & 107 & 44,4 & 44,4 & 44,4 \\
& Eficaz & 134 & 55,6 & 55,6 & 100,0 \\
& Total & 100,0 & 100,0 & \\
\hline
\end{tabular}

Folhetos

\begin{tabular}{|rl|r|r|r|r|}
\hline & \multicolumn{1}{|c|}{ Frequency } & Percent & Valid Percent & Cumulative Percent \\
\hline \multirow{2}{*}{ Valid } & Ineficaz & 117 & 48,5 & 48,5 & 48,5 \\
& Eficaz & 124 & 51,5 & 51,5 & 100,0 \\
& Total & 100,0 & 100,0 & \\
\hline
\end{tabular}

Revista da GNR

\begin{tabular}{|rl|r|r|r|r|}
\hline & \multicolumn{1}{|c|}{ Frequency } & Percent & Valid Percent & Cumulative Percent \\
\hline \multirow{2}{*}{ Valid } & Ineficaz & 131 & 54,4 & 54,4 & 54,4 \\
& Eficaz & 110 & 45,6 & 45,6 & 100,0 \\
& Total & 241 & 100,0 & 100,0 & \\
\hline
\end{tabular}

Audiovisuais

\begin{tabular}{|ll|r|r|r|r|}
\hline & & & & \multicolumn{2}{|c|}{$\begin{array}{c}\text { Cumulative } \\
\text { Percent }\end{array}$} \\
\hline Valid & Ineficaz & Frequency & Percent & Valid Percent & \multicolumn{2}{|c|}{54,4} \\
& Eficaz & 131 & 54,4 & 54,4 & 100,0 \\
& Total & 110 & 45,6 & 45,6 & \\
\hline
\end{tabular}


Videoconferência

\begin{tabular}{|rl|r|r|r|r|}
\hline & & Frequency & Percent & Valid Percent & Cumulative Percent \\
\hline \multirow{2}{*}{ Valid } & Ineficaz & 170 & 70,5 & 70,5 & 70,5 \\
& Eficaz & 71 & 29,5 & 29,5 & 100,0 \\
& Total & 241 & 100,0 & 100,0 & \\
\hline
\end{tabular}

Chat

\begin{tabular}{|c|c|c|c|c|c|}
\hline & & Frequency & Percent & Valid Percent & $\begin{array}{c}\text { Cumulative } \\
\text { Percent }\end{array}$ \\
\hline \multirow[t]{3}{*}{ Valid } & Ineficaz & 172 & 71,4 & 71,4 & 71,4 \\
\hline & Eficaz & 69 & 28,6 & 28,6 & 100,0 \\
\hline & Total & 241 & 100,0 & 100,0 & \\
\hline
\end{tabular}

Qual o meio que acha mais adequado para a transmissão da informação, para que esta seja completamente percetível e absorvida? (marque uma das alternativas)

\begin{tabular}{|l|r|r|r|r|}
\hline & Frequency & Percent & Valid Percent & $\begin{array}{c}\text { Cumulative } \\
\text { Percent }\end{array}$ \\
\hline Valid Oral & 96 & 39,8 & 39,8 & 39,8 \\
& 84 & 34,9 & 34,9 & 74,7 \\
& Escrita & 78 & 7,5 & 82,2 \\
Audiovisuais & 43 & 17,8 & 17,8 & 100,0 \\
TIC & 241 & 100,0 & 100,0 & \\
Total & & & & \\
\hline
\end{tabular}

\section{Assuntos a serem divulgados pela CI na GNR}

Statistics

Responda sucintamente à seguinte questão:

\begin{tabular}{|c|c|c|}
\hline \multirow[t]{2}{*}{$\mathrm{N}$} & Valid & 112 \\
\hline & Missing & 129 \\
\hline \multicolumn{2}{|c|}{ Mean } & 3,38 \\
\hline \multicolumn{2}{|c|}{ Std. Deviation } & 1,720 \\
\hline \multicolumn{2}{|c|}{ Minimum } & 1 \\
\hline \multicolumn{2}{|c|}{ Maximum } & 7 \\
\hline
\end{tabular}


Responda sucintamente à seguinte questão:

\begin{tabular}{|ll|r|r|r|r|}
\hline & & & & \multicolumn{2}{c|}{$\begin{array}{c}\text { Cumulative } \\
\text { Percent }\end{array}$} \\
\hline Valid & Frequency & Percent & Valid Percent & 14,3 \\
& Vencimentos & 16 & 6,6 & 14,3 & 35,7 \\
& Carreiras & 24 & 10,0 & 21,4 & 52,7 \\
& Formação & 19 & 7,9 & 17,0 & 81,3 \\
& Resultados & 32 & 13,3 & 28,6 & 84,8 \\
& Objetivos & 4 & 1,7 & 3,6 & 92,9 \\
& Projetos Futuros & 9 & 3,7 & 8,0 & 100,0 \\
& Total & 8 & 3,3 & 7,1 & 100,0 \\
Missing & System & 112 & 46,5 & & \\
Total & & 129 & 53,5 & & \\
\hline
\end{tabular}

Conhecimento da existência de um serviço de CI

Tem conhecimento da existência de um serviço responsável pela comunicação interna na GNR?

\begin{tabular}{|c|c|c|c|c|c|}
\hline & & Frequency & Percent & Valid Percent & Cumulative Percent \\
\hline \multirow[t]{3}{*}{ Valid } & Não & 103 & 42,7 & 42,7 & 42,7 \\
\hline & Sim & 138 & 57,3 & 57,3 & 100,0 \\
\hline & Total & 241 & 100,0 & 100,0 & \\
\hline
\end{tabular}




\section{APÊNDICE D - Resultados - Influência das Variáveis Sócio- demográficas nas Dimensões do Questionário}

De salientar que as respostas dadas nos itens que constituem a parte A do questionário apresentam-se com proposições de concordância que variam de 1 ("Completamente de acordo"); a 5 ("Completamente em desacordo") sendo que este facto irá condicionar a análise subjacente na medida em que os valores mais baixos das variáveis correspondem a níveis da escala mais positivos.

Existência de diferenças significativas entre Idade e as Dimensões da Parte A

Descriptives

\begin{tabular}{|c|c|c|c|c|c|}
\hline & & $\mathrm{N}$ & Mean & Std. Deviation & Std. Error \\
\hline \multirow[t]{5}{*}{ Informação Geral GNR } & $20-30$ & 79 & 2,9409 & ,88797 & 09990 \\
\hline & $31-40$ & 98 & 3,1020 & 1,10545 & ,11167 \\
\hline & $41-50$ & 62 & 2,7312 & ,89897 &, 11417 \\
\hline & $51-60$ & 2 & 1,6667 &, 00000 &, 00000 \\
\hline & Total & 241 & 2,9419 & ,99552 & ,06413 \\
\hline \multirow{5}{*}{$\begin{array}{l}\text { Informação Fornecida no Local } \\
\text { Trabalho }\end{array}$} & de $20-30$ & 79 & 3,8608 & 67509 &, 07595 \\
\hline & $31-40$ & 98 & 3,7592 & ,67836 &, 06852 \\
\hline & $41-50$ & 62 & 3,8710 & ,73694 & ,09359 \\
\hline & $51-60$ & 2 & 4,4000 &, 28284 & ,20000 \\
\hline & Total & 241 & 3,8266 & ,69135 & 04453 \\
\hline \multirow[t]{5}{*}{ Comunicação com a Chefia } & $20-30$ & 79 & 3,177 & ,9576 & , 1077 \\
\hline & $31-40$ & 98 & 3,010 & 1,1260 &, 1137 \\
\hline & $41-50$ & 62 & 3,194 & ,9204 &, 1169 \\
\hline & $51-60$ & 2 & 4,500 &, 7071 &, 5000 \\
\hline & Total & 241 & 3,124 & 1,0252 & 0660 \\
\hline \multirow[t]{3}{*}{ Clima de Comunicação } & $20-30$ & 79 & 3,4506 &, 83111 & ,09351 \\
\hline & $31-40$ & 98 & 3,2204 & ,88072 & ,08897 \\
\hline & $41-50$ & 62 & 3,0710 & ,62526 &, 07941 \\
\hline
\end{tabular}




\begin{tabular}{|lr|r|r|r|r|}
\hline & $51-60$ & 2 & 2,8000 &, 28284 &, 20000 \\
& Total & 241 & 3,2539 &, 81317 &, 05238 \\
\hline Comunicação entre Colegas & $20-30$ & 79 & 2,3333 &, 77717 &, 08744 \\
& $31-40$ & 98 & 2,3605 &, 86642 &, 08752 \\
& $41-50$ & 62 & 2,4839 &, 72849 &, 09252 \\
& $51-60$ & 2 & 2,6667 &, 47140 &, 33333 \\
& Total & 241 & 2,3859 &, 79989 &, 05153 \\
\hline Boatos e Conflitos & $20-30$ & 79 & 3,9042 &, 62132 &, 06990 \\
& $31-40$ & 98 & 3,7784 &, 71623 &, 07235 \\
& $41-50$ & 62 & 3,7512 &, 64458 &, 08186 \\
& $51-60$ & 4,1429 &, 00000 &, 00000 \\
& Total & 241 & 3,8156 &, 66596 &, 04290 \\
\hline
\end{tabular}

Existência de diferenças significativas entre o Comando Territorial e as Dimensões da Parte A

\begin{tabular}{|c|c|c|c|c|c|c|c|c|c|}
\hline \multicolumn{10}{|c|}{ Descriptives } \\
\hline & & \multirow[b]{2}{*}{$\mathrm{N}$} & \multirow[b]{2}{*}{ Mean } & \multirow[b]{2}{*}{ Std. Deviation } & \multirow[b]{2}{*}{ Std. Error } & \multicolumn{2}{|c|}{$\begin{array}{l}\text { 95\% Confidence Interval for } \\
\text { Mean }\end{array}$} & \multirow[b]{2}{*}{ Minimum } & \multirow[b]{2}{*}{ Maximum } \\
\hline & & & & & & Lower Bound & Upper Bound & & \\
\hline \multirow[t]{12}{*}{ Informação Geral GNR } & Açores & 8 & 3,1667 & 1,22150 & ,43187 & 2,1455 & 4,1879 & 1,00 & 5,00 \\
\hline & Aveiro & 15 & 2,9111 & 1,03484 & ,26720 & 2,3380 & 3,4842 & 1,67 & 4,33 \\
\hline & Beja & 1 & 3,6667 & & & . & . & 3,67 & 3,67 \\
\hline & Braga & 19 & 2,9649 & 1,18579 & ,27204 & 2,3934 & 3,5364 & 1,00 & 5,00 \\
\hline & Bragança & 9 & 2,3333 & ,88192 & ,29397 & 1,6554 & 3,0112 & 1,00 & 3,00 \\
\hline & Castelo Branco & 9 & 3,6667 & ,74536 & ,24845 & 3,0937 & 4,2396 & 3,00 & 5,00 \\
\hline & Coimbra & 7 & 3,1905 & ,83571 & ,31587 & 2,4176 & 3,9634 & 2,33 & 5,00 \\
\hline & Évora & 20 & 2,5333 & ,86788 & ,19406 & 2,1272 & 2,9395 & 1,00 & 3,67 \\
\hline & Faro & 14 & 2,7143 & ,96836 & ,25881 & 2,1552 & 3,2734 & 1,00 & 5,00 \\
\hline & Guarda & 5 & 3,6667 & ,94281 & ,42164 & 2,4960 & 4,8373 & 3,00 & 5,00 \\
\hline & Leiria & 3 & 3,0000 & 2,00000 & 1,15470 & $-1,9683$ & 7,9683 & 1,00 & 5,00 \\
\hline & Lisboa & 10 & 3,9333 & 1,00370 &, 31740 & 3,2153 & 4,6513 & 3,00 & 5,00 \\
\hline
\end{tabular}




\begin{tabular}{|c|c|c|c|c|c|c|c|c|c|}
\hline & Madeira & 19 & 2,7895 & ,99511 & 22829 & 2,3098 & 3,2691 & 1,00 & 433 \\
\hline & Portalegre & 10 & 3,0000 & ,44444 & 14055 & 2,6821 & 3,3179 & 2,33 & 3,67 \\
\hline & Porto & 13 & 3,4615 & 1,06752 & 29608 & 2,8164 & 4,1066 & 1,67 & 5,00 \\
\hline & Santarém & 1 & 3,0000 & & & & & 3,00 & 3,00 \\
\hline & Setúbal & 8 & 3,0833 & 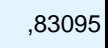 & 29378 & 2,3886 & 3,7780 & 2,33 & 5,00 \\
\hline & Viana Castelo & 48 & 2,6389 & ,83605 - - 1 & 12067 & 2,3961 & 2,8817 & 1,00 & 5,00 \\
\hline & Viseu & 22 & 3,0000 & ,96500 & ,20574 & 2,5721 & 3,4279 & 1,00 & 5,00 \\
\hline & Total & 241 & 2,9419 & 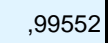 & ,06413 & 2,8156 & 3,0682 & 1,00 & 5,00 \\
\hline Informação Fornecida & no Açores & 8 & 3,7500 & ,58310 & ,20616 & 3,2625 & 4,2375 & 3,00 & 4,60 \\
\hline Local de Trabalho & Aveiro & 15 & 3,8533 & 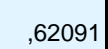 & 16032 - - & 3,5095 & 4,1972 & 3,00 & 4,60 \\
\hline & Beja & 1 & 2,6000 & & & & & 2,60 & 2,60 \\
\hline & Braga & 19 & 4,0526 & ,68262 & , 15660 & 3,7236 & 4,3816 & 3,00 & 5,00 \\
\hline & Bragança & 9 & 3,5333 & 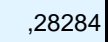 & 09428 & 3,3159 & 3,7507 & 3,00 & 3,80 \\
\hline & Castelo Branco & 9 & 3,5333 & ,87178 & 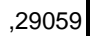 & 2,8632 & 4,2034 & 2,20 & 4,60 \\
\hline & Coimbra & 7 & 4,2000 & ,56569 & 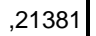 & 3,6768 & 4,7232 & 3,40 & 5,00 \\
\hline & Évora & 20 & 3,8400 & ,66046 & ,14768 & 3,5309 & 4,1491 & 3,00 & 5,00 \\
\hline & Faro & 14 & 3,7143 & ,65027 & ,17379 & 3,3388 & 4,0897 & 3,00 & 5,00 \\
\hline & Guarda & 5 & 3,7200 & ,71554 & ,32000 & 2,8315 & 4,6085 & 3,40 & 5,00 \\
\hline & Leiria & 3 & 3,6667 & ,61101 & 35277 & 2,1488 & 5,1845 & 3,00 & 4,20 \\
\hline & Lisboa & 10 & 4,2400 & ,66533 & ,21040 & 3,7641 & 4,7159 & 3,00 & 5,00 \\
\hline & Madeira & 19 & 3,6947 & ,54719 & ,12553 & 3,4310 & 3,9585 & 3,00 & 5,00 \\
\hline & Portalegre & 10 & 3,4400 & 1,00576 & ,31805 & 2,7205 & 4,1595 & 1,40 & 4,60 \\
\hline & Porto & 13 & 4,1692 & ,77393 - - l & 21465 & 3,7015 & 4,6369 & 3,00 & 5,00 \\
\hline & Santarém & 1 & 3,8000 & & & & & 3,80 & 3,80 \\
\hline & Setúbal & 8 & 3,8000 & ,64143 & 22678 & 3,2638 & 4,3362 & 3,00 & 4,60 \\
\hline & Viana Castelo & 48 & 3,7583 & ,67156 & ,09693 & 3,5633 & 3,9533 & 2,60 & 5,00 \\
\hline & Viseu & 22 & 3,9818 & ,76820 & ,16378 & 3,6412 & 4,3224 & 3,00 & 5,00 \\
\hline & Total & 241 & 3,8266 & ,69135 &, 04453 & 3,7388 & 3,9143 & 1,40 & 5,00 \\
\hline Comunicação com & a Açores & 8 & 2,750 & 1,3887 & 4910 & 1,589 & 3,911 & 1,0 & 5,0 \\
\hline Chefia & Aveiro & 15 & 3,133 &, 5164 & 1333 & 2,847 & 3,419 & 2,0 & 4,0 \\
\hline & Beja & 1 & 3,000 & & & & & 3,0 & 3,0 \\
\hline & Braga & 19 & 3,316 & 1,3355 & | & 2,672 & 3,959 & 1,0 & 5,0 \\
\hline & Bragança & 9 & 3,000 & 1,7321 & ,5774 & 1,669 & 4,331 & 1,0 & 5,0 \\
\hline
\end{tabular}




\begin{tabular}{|c|c|c|c|c|c|c|c|c|c|}
\hline & Castelo Branco & 9 & 3,000 & 1,0000 & ,3333 & 2.231 & 3.769 & 2.0 & 50 \\
\hline & Coimbra & 7 & 3,286 & ,7559 & 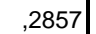 & 2,587 & 3,985 & 3,0 & 5,0 \\
\hline & Évora & 20 & 3,450 & ,7592 & 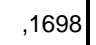 & 3,095 & 3,805 & 2,0 & 5,0 \\
\hline & Faro & 14 & 3,357 & ,4972 & 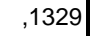 & 3,070 & 3,644 & 3,0 & 4,0 \\
\hline & Guarda & 5 & 2,400 & 1,3416 & 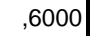 & ,734 & 4,066 & 1,0 & 4,0 \\
\hline & Leiria & 3 & 3,333 & ,5774 & ,3333 & 1,899 & 4,768 & 3,0 & 4,0 \\
\hline & Lisboa & 10 & 2,700 & 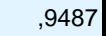 & 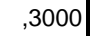 & 2,021 & 3,379 & 1,0 & 4,0 \\
\hline & Madeira & 19 & 3,368 & 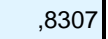 & 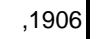 & 2,968 & 3,769 & 2,0 & 5,0 \\
\hline & Portalegre & 10 & 2,900 & 1,5951 & | & 1,759 & 4,041 & 1,0 & 5,0 \\
\hline & Porto & 13 & 3,154 & (9871 & 2738 & 2,557 & 3,750 & 1,0 & 5,0 \\
\hline & Santarém & 1 & 3,000 & & & & & 3,0 & 3,0 \\
\hline & Setúbal & 8 & 3,250 & ,8864 & |3134 & 2,509 & 3,991 & 2,0 & 5,0 \\
\hline & Viana Castelo & 48 & 2,896 & ,9048 & 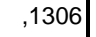 & 2,633 & 3,159 & 1,0 & 5,0 \\
\hline & Viseu & 22 & 3,364 & 1,2168 & 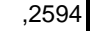 & 2,824 & 3,903 & 1,0 & 5,0 \\
\hline & Total & 241 & 3,124 & 1,0252 & ,0660 & 2,994 & 3,255 & 1,0 & 5,0 \\
\hline Clima de Comunicação & Açores & 8 & 2,9000 & 1,08496 & - 38359 & 1,9929 & 3,8071 & 1,40 & 4,20 \\
\hline & Aveiro & 15 & 3,1867 & , 85345 & - 22036 & 2,7140 & 3,6593 & 2,20 & 4,60 \\
\hline & Beja & 1 & 3,4000 & & & & & 3,40 & 3,40 \\
\hline & Braga & 19 & 3,8211 & -94726 & 21732 & 3,3645 & 4,2776 & 2,20 & 5,00 \\
\hline & Bragança & 9 & 2,9556 & , 85894 & 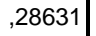 & 2,2953 & 3,6158 & 1,80 & 4,20 \\
\hline & Castelo Branco & 9 & 3,7111 & ,68638 & 22879 & 3,1835 & 4,2387 & 2,60 & 4,60 \\
\hline & Coimbra & 7 & 3,4000 & ,83267 & , 31472 & 2,6299 & 4,1701 & 2,60 & 5,00 \\
\hline & Évora & 20 & 3,2400 & ,50928 & - 11388 & 3,0016 & 3,4784 & 1,80 & 3,80 \\
\hline & Faro & 14 & 3,1429 & , 80929 & , 21629 & 2,6756 & 3,6101 & 1,80 & 4,60 \\
\hline & Guarda & 5 & 3,0000 & ,63246 & 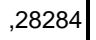 & 2,2147 & 3,7853 & 2,20 & 3,80 \\
\hline & Leiria & 3 & 3,2667 & 1,28582 & (74237 & , 0725 & 6,4608 & 1,80 & 4,20 \\
\hline & Lisboa & 10 & 3,5200 & 1,11634 & 35302 & 2,7214 & 4,3186 & 1,00 & 5,00 \\
\hline & Madeira & 19 & 2,8947 & ,71606 & 16428 & 2,5496 & 3,2399 & 1,80 & 4,20 \\
\hline & Portalegre & 10 & 3,3600 & , 47889 & | 15144, & 3,0174 & 3,7026 & 2,60 & 4,20 \\
\hline & Porto & 13 & 3,5846 & , 75922 & | 21057, & 3,1258 & 4,0434 & 2,60 & 5,00 \\
\hline & Santarém & 1 & 2,6000 & & & & & 2,60 & 2,60 \\
\hline & Setúbal & 8 & 3,3500 & , 39641 & -14015 & 3,0186 & 3,6814 & 2,60 & 3,80 \\
\hline & Viana Castelo & 48 & 3,0250 & ,77583 & 11198 & 2,7997 & 3,2503 & 1,40 & 4,60 \\
\hline
\end{tabular}




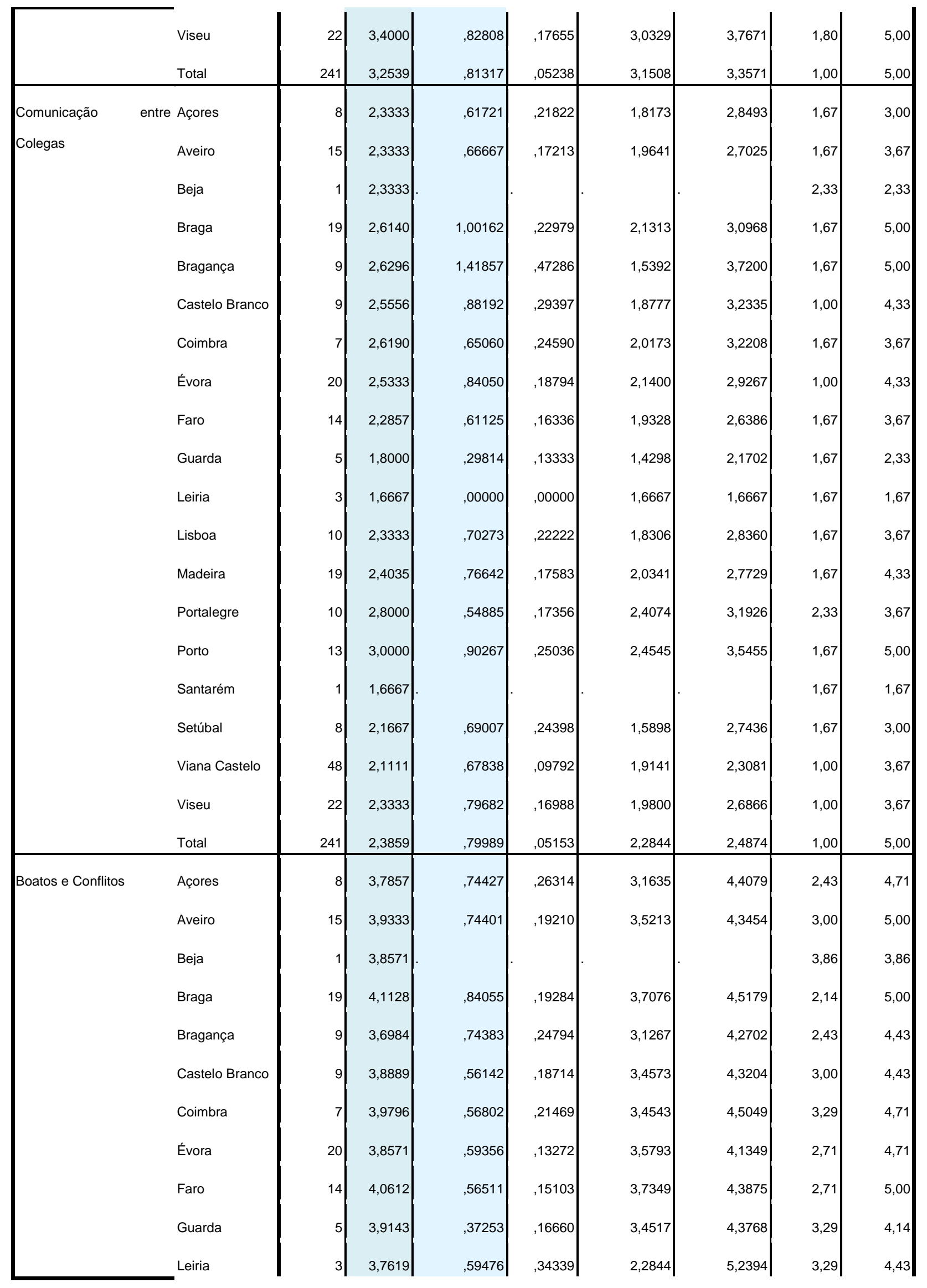




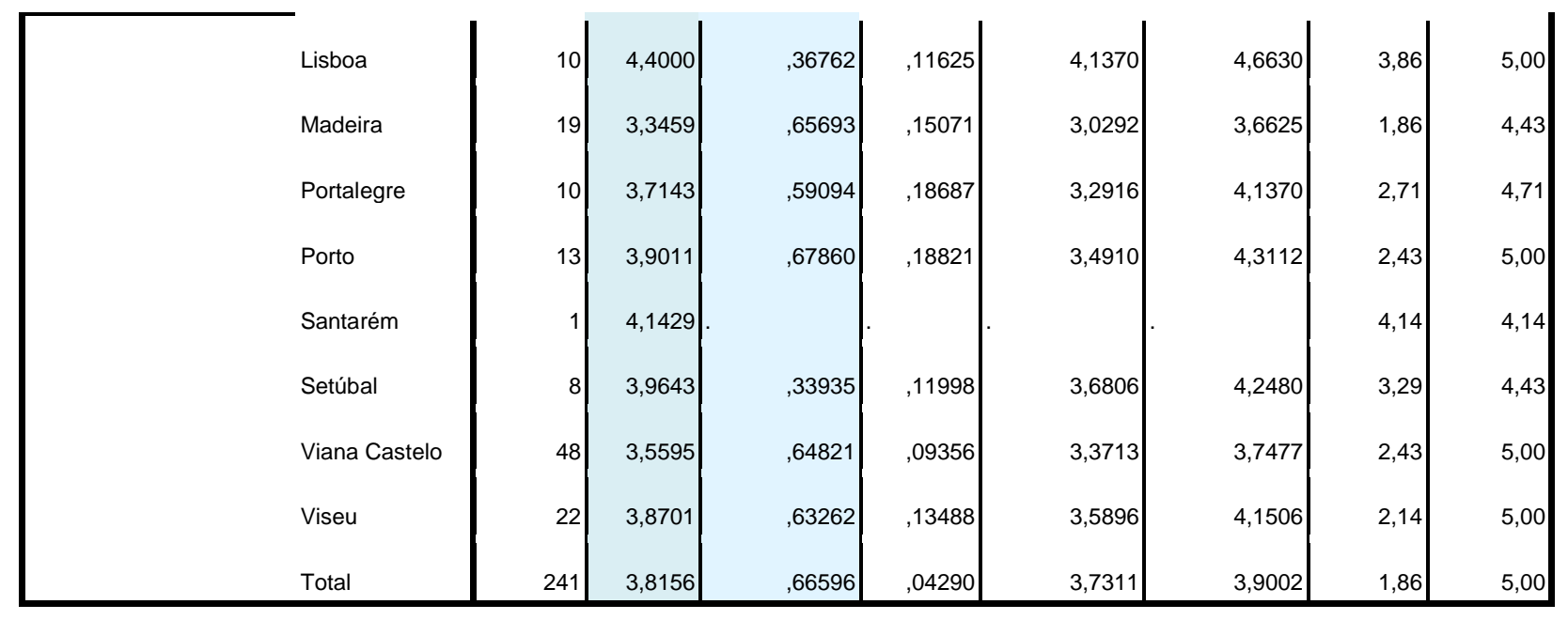

Existência de diferenças significativas entre a Antiguidade e as Dimensões da Parte A

\begin{tabular}{|c|c|c|c|c|c|c|c|c|c|}
\hline \multicolumn{10}{|c|}{ Descriptives } \\
\hline & & \multirow[b]{2}{*}{$\mathrm{N}$} & \multirow[b]{2}{*}{ Mean } & \multirow{2}{*}{$\begin{array}{c}\text { Std. } \\
\text { Deviation }\end{array}$} & \multirow{2}{*}{$\begin{array}{l}\text { Std. } \\
\text { Error }\end{array}$} & \multicolumn{2}{|c|}{$\begin{array}{l}\text { 95\% Confidence Interval for } \\
\text { Mean }\end{array}$} & \multirow[b]{2}{*}{ Minimum } & \multirow[b]{2}{*}{ Maximum } \\
\hline & & & & & & Lower Bound & Upper Bound & & \\
\hline \multirow[t]{7}{*}{ Informação Geral GNR } & $1-5$ & 59 & 3,0113 & ,94680 & ,12326 & 2,7646 & 3,2580 & 1,00 & 5,00 \\
\hline & $6-10$ & 55 & 3,0606 & 1,13509 & , 15306 & 2,7537 & 3,3675 & 1,00 & 5,00 \\
\hline & $11-15$ & 57 & 3,0936 & ,92099 & 12199 & 2,8492 & 3,3379 & 1,00 & 5,00 \\
\hline & $16-20$ & 38 & 2,7368 & ,93692 & 15199 & 2,4289 & 3,0448 & 1,00 & 5,00 \\
\hline & $21-25$ & 20 & 2,5333 & ,92021 & 20576 & 2,1027 & 2,9640 & 1,00 & 4,33 \\
\hline & $>25$ & 12 & 2,6667 & 1,04447 & 30151 & 2,0030 & 3,3303 & 1,67 & 5,00 \\
\hline & Total & 241 & 2,9419 & ,99552 & ,06413 & 2,8156 & 3,0682 & 1,00 & 5,00 \\
\hline \multirow{7}{*}{$\begin{array}{l}\text { Informação Fornecida } \\
\text { no Local de Trabalho }\end{array}$} & $1-5$ & 59 & 3,8881 & ,68105 & ,08866 & 3,7107 & 4,0656 & 2,20 & 5,00 \\
\hline & $6-10$ & 55 & 3,7855 & ,70117 & ,09455 & 3,5959 & 3,9750 & 3,00 & 5,00 \\
\hline & $11-15$ & 57 & 3,8351 & ,67731 & ,08971 & 3,6554 & 4,0148 & 2,20 & 5,00 \\
\hline & $16-20$ & 38 & 3,8105 & ,64086 & 10396 & 3,5999 & 4,0212 & 2,60 & 5,00 \\
\hline & $21-25$ & 20 & 3,5800 & 84579 & 18913 & 3,1842 & 3,9758 & 1,40 & 5,00 \\
\hline & $>25$ & 12 & 4,1333 & ,61101 & ,17638 & 3,7451 & 4,5216 & 3,00 & 4,60 \\
\hline & Total & 241 & 3,8266 & ,69135 & ,04453 & 3,7388 & 3,9143 & 1,40 & 5,00 \\
\hline \multirow{6}{*}{$\begin{array}{l}\text { Comunicação com a } \\
\text { Chefia }\end{array}$} & $1-5$ & 59 & 3,034 & 1,0662 & 1388 & 2,756 & 3,312 & 1,0 & 5,0 \\
\hline & $6-10$ & 55 & 3,145 & 1,0438 & 1407 & 2,863 & 3,428 & 1,0 & 5,0 \\
\hline & $11-15$ & 57 & 3,070 & ,9794 & ,1297 & 2,810 & 3,330 & 1,0 & 5,0 \\
\hline & $16-20$ & 38 & 3,263 & 1,0826 &, 1756 & 2,907 & 3,619 & 1,0 & 5,0 \\
\hline & $21-25$ & 20 & 3,000 & ,9733 & ,2176 & 2,544 & 3,456 & 1,0 & 5,0 \\
\hline & $>25$ & 12 & 3,500 & ,9045 & ,2611 & 2,925 & 4,075 & 2,0 & 5,0 \\
\hline
\end{tabular}




\begin{tabular}{|c|c|c|c|c|c|c|c|c|c|}
\hline & Total & 241 & 3,124 & 1,0252 & ,0660 & 2,994 & 3,255 & 1,0 & 5,0 \\
\hline \multirow[t]{7}{*}{ Clima de Comunicação } & $1-5$ & 59 & 3,4746 & 80849 & , 10526 & 3,2639 & 3,6853 & 1,80 & 5,00 \\
\hline & $6-10$ & 55 & 3,3491 & 92714 & 12502 & 3,0985 & 3,5997 & 1,40 & 5,00 \\
\hline & $11-15$ & 57 & 3,1825 & ,86212 & 11419 & 2,9537 & 3,4112 & 1,00 & 5,00 \\
\hline & $16-20$ & 38 & 3,0947 & ,59862 - r & 09711 - - & 2,8980 & 3,2915 & 1,80 & 4,20 \\
\hline & $21-25$ & 20 & 2,9000 & ,72111 & 16125 & 2,5625 & 3,2375 & 1,40 & 4,20 \\
\hline & $>25$ & 12 & 3,1667 & 46580 & 13446 & 2,8707 & 3,4626 & 2,20 & 3,80 \\
\hline & Total & 241 & 3,2539 & ,81317 & ,05238 & 3,1508 & 3,3571 & 1,00 & 5,00 \\
\hline \multirow{7}{*}{$\begin{array}{l}\text { Comunicação } \\
\text { Colegas }\end{array}$} & $1-5$ & 59 & 2,3446 & ,79742 & 10382 - r l & 2,1368 & 2,5524 & 1,00 & 5,00 \\
\hline & $6-10$ & 55 & 2,3091 & ,86983 & 11729 & 2,0739 & 2,5442 & 1,00 & 5,00 \\
\hline & $11-15$ & 57 & 2,4152 & ,85514 & 11327 - - & 2,1883 & 2,6421 & 1,00 & 5,00 \\
\hline & $16-20$ & 38 & 2,3860 & ,74948 & 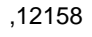 & 2,1396 & 2,6323 & 1,00 & 3,67 \\
\hline & $21-25$ & 20 & 2,5000 & ,71328 & 15949 & 2,1662 & 2,8338 & 1,00 & 3,67 \\
\hline & $>25$ & 12 & 2,6111 & ,52864 & 15261 & 2,2752 & 2,9470 & 1,67 & 3,67 \\
\hline & Total & 241 & 2,3859 & ,79989 & ,05153 & 2,2844 & 2,4874 & 1,00 & 5,00 \\
\hline \multirow[t]{7}{*}{ Boatos e Conflitos } & $1-5$ & 59 & 3,8862 & 66626 & ,08674 & 3,7126 & 4,0598 & 2,14 & 5,00 \\
\hline & $6-10$ & 55 & 3,8623 & ,69005 & ,09305 & 3,6758 & 4,0489 & 2,14 & 5,00 \\
\hline & $11-15$ & 57 & 3,7669 & , 70846 & , 09384 & 3,5789 & 3,9549 & 1,86 & 5,00 \\
\hline & $16-20$ & 38 & 3,8496 & ,57714 & , 09362 - l & 3,6599 & 4,0393 & 2,71 & 5,00 \\
\hline & $21-25$ & 20 & 3,5000 & 64139 & 14342 & 3,1998 & 3,8002 & 2,43 & 4,43 \\
\hline & $>25$ & 12 & 3,9048 & 60711 & 17526 & 3,5190 & 4,2905 & 2,43 & 4,43 \\
\hline & Total & 241 & 3,8156 & ,66596 & , 04290 & 3,7311 & 3,9002 & 1,86 & 5,00 \\
\hline
\end{tabular}

Existência de diferenças significativas entre o e as Dimensões da Parte A

Descriptives

\begin{tabular}{|c|c|c|c|c|c|c|c|c|c|}
\hline & & \multirow[b]{2}{*}{$\mathrm{N}$} & \multirow[b]{2}{*}{ Mean } & \multirow[b]{2}{*}{$\begin{array}{c}\text { Std. } \\
\text { Deviation }\end{array}$} & \multirow[b]{2}{*}{$\begin{array}{l}\text { Std. } \\
\text { Error }\end{array}$} & \multicolumn{2}{|c|}{$\begin{array}{l}95 \% \text { Confidence } \\
\text { Interval for Mean }\end{array}$} & \multirow[b]{2}{*}{ Minimum } & \multirow[b]{2}{*}{ Maximum } \\
\hline & & & & & & $\begin{array}{l}\text { Lower } \\
\text { Bound }\end{array}$ & $\begin{array}{l}\text { Upper } \\
\text { Bound } \\
\end{array}$ & & \\
\hline \multirow{6}{*}{$\begin{array}{l}\text { Informação Geral } \\
\text { GNR }\end{array}$} & Guarda & 155 & 3,0473 & 1,00822 & ,08098 & 2,8873 & 3,2073 & 1,00 & 5,00 \\
\hline & Guarda Principal & 5 & 3,5333 & 1,44530 & ,64636 & 1,7388 & 5,3279 & 1,67 & 5,00 \\
\hline & Cabo & 74 & 2,7207 & ,87590 & , 10182 & 2,5178 & 2,9237 & 1,00 & 5,00 \\
\hline & Cabo-chefe & 5 & 3,0000 & 1,05409 & , 47140 & 1,6912 & 4,3088 & 1,67 & 4,33 \\
\hline & Cabo-mor & 2 & 1,3333 &, 47140 & ,33333 & $-2,9021$ & 5,5687 & 1,00 & 1,67 \\
\hline & Total & 241 & 2,9419 &, 99552 &, 06413 & 2,8156 & 3,0682 & 1,00 & 5,00 \\
\hline Informação & Guarda & 155 & 3,8206 & ,67887 & ,05453 & 3,7129 & 3,9284 & 2,20 & 5,00 \\
\hline
\end{tabular}




\begin{tabular}{|c|c|c|c|c|c|c|c|c|c|}
\hline Fornecida & o Guarda Principal & 5 & 4,1200 & ,81976 &, 36661 & 3,1021 & 5,1379 & 3,40 & 5,00 \\
\hline Local & e Cabo & 74 & 3,8000 & ,71615 & 08325 & 3,6341 & 3,9659 & 1,40 & 5,00 \\
\hline \multirow[t]{3}{*}{ Trabalho } & Cabo-chefe & 5 & 4,2000 & ,74833 & ,33466 & 3,2708 & 5,1292 & 3,40 & 5,00 \\
\hline & Cabo-mor & 2 & 3,6000 & ,28284 & ,20000 & 1,0588 & 6,1412 & 3,40 & 3,80 \\
\hline & Total & 241 & 3,8266 & ,69135 &, 04453 & 3,7388 & 3,9143 & 1,40 & 5,00 \\
\hline \multirow{6}{*}{$\begin{array}{l}\text { Comunicação } \\
\text { com a Chefia }\end{array}$} & Guarda & 155 & 3,058 & 1,0583 &, 0850 & 2,890 & 3,226 & 1,0 & 5,0 \\
\hline & Guarda Principal & 5 & 4,200 & ,8367 &, 3742 & 3,161 & 5,239 & 3,0 & 5,0 \\
\hline & Cabo & 74 & 3,189 & ,9316 & , 1083 & 2,973 & 3,405 & 1,0 & 5,0 \\
\hline & Cabo-chefe & 5 & 3,000 & 1,2247 & ,5477 & 1,479 & 4,521 & 1,0 & 4,0 \\
\hline & Cabo-mor & 2 & 3,500 &, 7071 &, 5000 & $-2,853$ & 9,853 & 3,0 & 4,0 \\
\hline & Total & 241 & 3,124 & 1,0252 &, 0660 & 2,994 & 3,255 & 1,0 & 5,0 \\
\hline \multirow{6}{*}{$\begin{array}{l}\text { Clima de } \\
\text { Comunicação }\end{array}$} & e Guarda & 155 & 3,3406 & 84398 & ,06779 & 3,2067 & 3,4746 & 1,40 & 5,00 \\
\hline & Guarda Principal & 5 & 3,4000 & 1,49666 & ,66933 & 1,5416 & 5,2584 & 1,80 & 5,00 \\
\hline & Cabo & 74 & 3,0865 & ,64624 & ,07512 & 2,9368 & 3,2362 & 1,00 & 5,00 \\
\hline & Cabo-chefe & 5 & 3,2400 & 1,08074 & ,48332 & 1,8981 & 4,5819 & 1,40 & 4,20 \\
\hline & Cabo-mor & 2 & 2,4000 & ,28284 & ,20000 &,- 1412 & 4,9412 & 2,20 & 2,60 \\
\hline & Total & 241 & 3,2539 &, 81317 &, 05238 & 3,1508 & 3,3571 & 1,00 & 5,00 \\
\hline \multirow{7}{*}{$\begin{array}{l}\text { Comunicação } \\
\text { entre Colegas }\end{array}$} & Guarda & 155 & 2,3462 & ,84761 & ,06808 & 2,2117 & 2,4807 & 1,00 & 5,00 \\
\hline & Guarda Principal & 5 & 1,8000 & ,29814 &, 13333 & 1,4298 & 2,1702 & 1,67 & 2,33 \\
\hline & Cabo & 74 & 2,4775 & ,70025 & , 08140 & 2,3152 & 2,6397 & 1,00 & 3,67 \\
\hline & Cabo-chefe & 5 & 2,7333 & ,59628 & ,26667 & 1,9929 & 3,4737 & 1,67 & 3,00 \\
\hline & Cabo-mor & 2 & 2,6667 & 1,41421 & 1,0000 & & 15,3729 & 1,67 & 3,67 \\
\hline & & & & & 0 & 10,0395 & & & \\
\hline & Total & 241 & 2,3859 & ,79989 &, 05153 & 2,2844 & 2,4874 & 1,00 & 5,00 \\
\hline \multirow{6}{*}{$\begin{array}{l}\text { Boatos } \\
\text { Conflitos }\end{array}$} & e Guarda & 155 & 3,8221 & 68325 &, 05488 & 3,7137 & 3,9305 & 1,86 & 5,00 \\
\hline & Guarda Principal & 5 & 4,0857 & ,93460 & ,41796 & 2,9253 & 5,2462 & 3,00 & 5,00 \\
\hline & Cabo & 74 & 3,8031 & ,60688 & 07055 & 3,6625 & 3,9437 & 2,43 & 5,00 \\
\hline & Cabo-chefe & 5 & 3,9143 & 61941 & ,27701 & 3,1452 & 4,6834 & 3,00 & 4,43 \\
\hline & Cabo-mor & 2 & 2,8571 & 60609 & ,42857 & $-2,5884$ & 8,3027 & 2,43 & 3,29 \\
\hline & Total & 241 & 3,8156 & 66596 & 04290 & 3,7311 & 3,9002 & 1,86 & 5,00 \\
\hline
\end{tabular}




\section{ANEXOS}




\section{ANEXO A - Intranet}

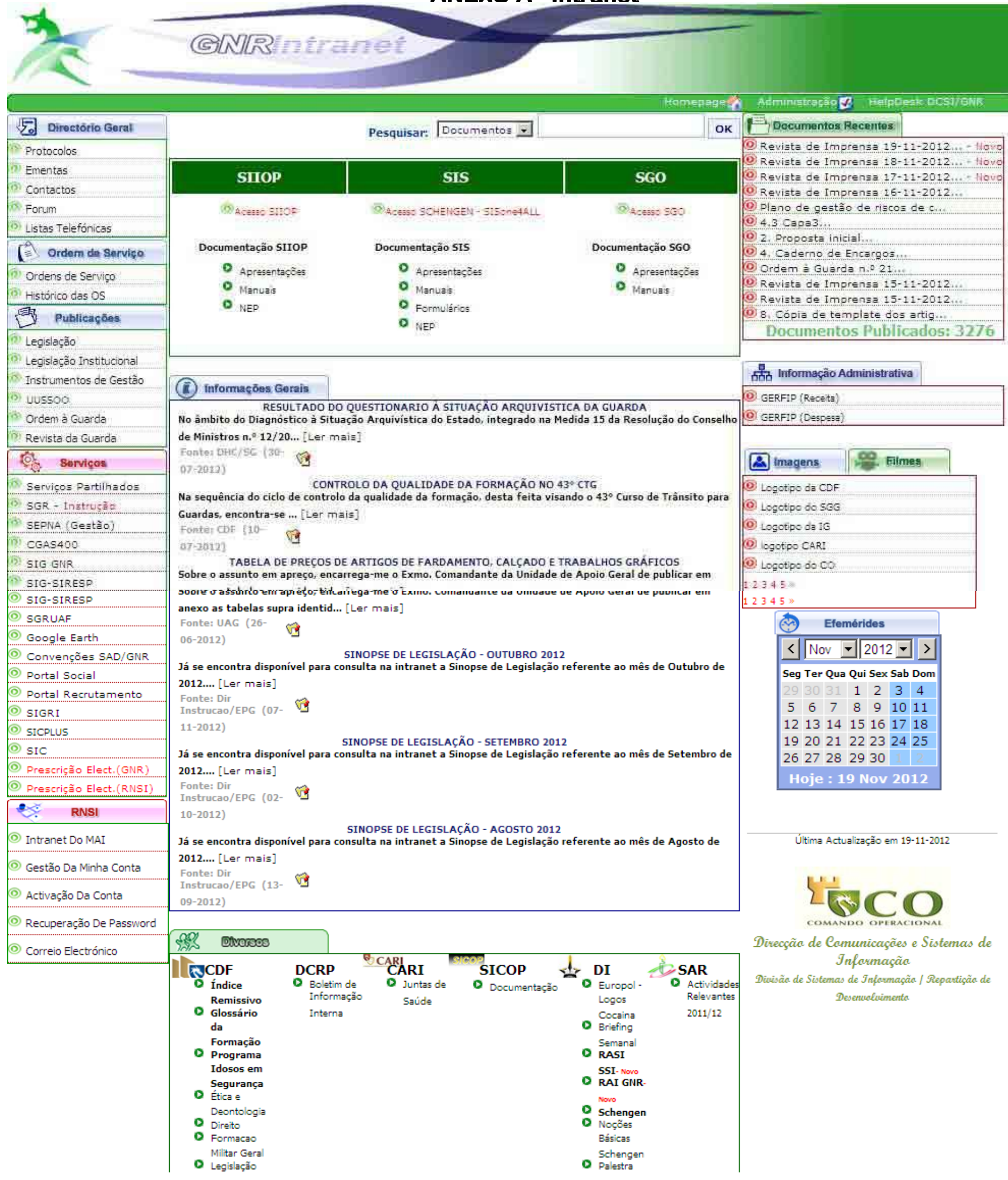




\section{ANEXO B - Extratos da Lei Orgânica da Guarda Nacional Republicana}

\section{ASSEMBLEIA DA REPÚBLICA}

\author{
Lei n. ${ }^{\circ} 63 / 2007$
}

de 6 de Novembro

\section{Aprova a orgânica da Guarda Nacional Republicana}

A Assembleia da República decreta, nos termos da alínea $c$ ) do artigo $1611^{\circ}$ da Constituiçào, o seguinte:

\section{TÍTULO I}

Disposições gerais

\section{CAPITULO I}

\section{Natureza, atribuições e símbolos}

\section{Artigo $1 .^{\circ}$ \\ Definiçăo}

1 - A Guarda Nacional Republicana, adiante designada por Guarda, é uma força de segurança de natureza militar, constituida por militares organizados num corpo especial de tropas e dotada de autonomia administrativa.

2 - A Guarda tem por missâo, no âmbito dos sistemas nacionais de segurança e protecção, assegurar a legalidade democrática, garantir a segurança interna e os direitos dos cidadãos, bem como colaborar na execução da política de defesa nacional, nos termos da Constituição e da lei.

\section{Artigo 2.}

\section{Dependência}

1 - A Guarda depende do membro do Governo responsável pela área da administração interna.

2 - As forças da Guarda são colocadas na dependência operacional do Chefe do Estado-Maior-General das Forças Armadas, através do seu comandante-geral, nos casos e termos previstos nas Leis de Defesa Nacional e das Forças Armadas e do regime do estado de sítio e do estado de emergência, dependendo, nesta medida, do membro do Governo responsável pela área da defesa nacional no que respeita ả uniformização, normalização da doutrina militar. do armamento e do equipamento.

\section{Artigo 3," \\ Atribuiçôes}

1 - Constituem atribuiçōes da Guarda:

a) Garantir as condições de segurança que permitam o exercicio dos direitos e liberdades e o respeito pelas garantias dos cidadãos, bem como o pleno funcionamento das instituições democráticas, no respeito pela legalidade e pelos principios do Estado de direito;

b) Garantir a ordem e a tranquilidade públicas e a segurança e a protecção das pessoas e dos bens;

c) Prevenir a criminalidade em geral, em coordenação com as demais forças e serviços de segurança;

d) Prevenir a prática dos demais actos contrários à lei e aos regulamentos;

e) Desenvolver as acções de investigação criminal $\mathrm{e}$ contra-ordenacional que Ihe sejam atribuidas por lei, dele- gadas pelas autoridades judiciárias ou solicitadas pelas autoridades administrativas;

$f)$ Velar pelo cumprimento das leis e regulamentos relativos à viaçào terrestre e aos transportes rodoviários, e promover e garantir a segurança rodoviária, designadamente, através da fiscalização, do ordenamento e da disciplina do trânsito:

g) Garantir a execução dos actos administrativos emanados da autoridade competente que visem impedir o incumprimento da lei ou a sua violaçâo continuada;

h) Participar no controlo da entrada e saida de pessoas e bens no território nacional:

i) Proteger, socorrer e auxiliar os cidadãos e defender e preservar os bens que se encontrem em situações de perigo, por causas provenientes da acção humana ou da natureza;

j) Manter a vigilância e a protecção de pontos sensiveis, nomeadamente infra-estruturas rodoviárias, ferroviárias, aeroportuárias e portuárias, edifícios públicos e outras instalaçôes criticas:

l) Garantir a segurança nos espectáculos, incluindo os desportivos, e noutras actividades de recreação e lazer, nos termos da lei:

m) Prevenir e detectar situações de tráfico e consumo de estupefacientes ou outras substâncias proibidas, através da vigilância e do patrulhamento das zonas referenciadas como locais de tráfico ou de consumo:

n) Participar na fiscalização do uso e transporte de armas, munições e substâncias explosivas e equiparadas que não pertençam às demais forças e serviços de segurança ou às Forças Armadas, sem prejuizo das competências atribuidas a outras entidades:

o) Participar, nos termos da lei e dos compromissos decorrentes de acordos, designadamente em operaçôes internacionais de gestão civil de crises, de paz e humanitárias, no âmbito policial e de protecçâo civil, bem como em missões de cooperação policial internacional e no âmbito da União Europeia e na representação do Pais em organismos e instituições internacionais;

p) Contribuir para a formação e informação em matéria de segurança dos cidadãos;

q) Prosseguir as demais atribuiçôes que lhe forem cometidas por lei.

\section{2 - Constituem, ainda, atribuições da Guarda:}

a) Assegurar o cumprimento das disposições legais e regulamentares referentes à protecçào e conservação da natureza e do ambiente, bem como prevenir e investigar os respectivos ilicitos;

b) Garantir a fiscalização, o ordenamento e a disciplina do trânsito em todas as infra-estruturas constitutivas dos eixos da Rede Nacional Fundamental e da Rede Nacional Complementar, em toda a sua extensão, fora das áreas metropolitanas de Lisboa e Porto:

c) Assegurar, no âmbito da sua missão própria, a vigilância, patrulhamento e intercepção terrestre e maritima, $\mathrm{em}$ toda a costa e mar territorial do continente e das Regiỏes Autónomas:

d) Prevenir e investigar as infracções tributárias, fiscais e aduaneiras, bem como fiscalizar e controlar a circulação de mercadorias sujeitas à acção tributária, fiscal ou aduaneira;

e) Controlar e fiscalizar as embarcaçôes, seus passageiros e carga, para os efeitos previstos na alinea anterior $\mathrm{e}$, 


\section{TÍTULO II \\ Organização geral}

\section{CAPÍTULO I}

\section{Disposições gerais}

Artigo 19.

Categorias profissionais e postos

1 - A Guarda está organizada hierarquicamente e os militares dos seus quadros permanentes estão sujeitos à condição militar, nos termos da lei de bases gerais do Estatuto da Condição Militar.

2 - Os militares da Guarda agrupam-se hierarquicamente nas seguintes categorias profissionais, subcategorias e postos:

a) Categoria profissional de oficiais:

i) Oficiais generais, que compreende os postos de tenente-general e major-general;

ii) Oficiais superiores, que compreende os postos de coronel, tenente-coronel e major;

iii) Capitães, que compreende o posto de capitão;

iv) Oficiais subalternos, que compreende os postos de tenente e alferes;

b) Categoria profissional de sargentos, que compreende os postos de sargento-mor, sargento-chefe, sargento-ajudante, primeiro-sargento, segundo-sargento e furriel;

c) Categoria profissional de guardas, que compreende os postos de cabo-mor, cabo-chefe, cabo, guarda principal e guarda.

3 - As promoções a oficial general realizam-se por escolha de entre os oficiais com formação de nível superior e qualificaçōes complementares idênticas às exigidas para acesso aos postos de contra-almirante ou de major-general das Forças Armadas.

4 - As promoções a oficial general, bem como as promoções de oficiais generais, do quadro de pessoal da Guarda, são sujeitas a aprovação pelo Ministro da Administração Interna e a confirmação pelo Presidente da República, sem o que não produzem efeitos.

5 - Os postos da subcategoria de oficiais generais são constituídos pelo número máximo de 11 efectivos.

\section{Artigo $200^{\circ}$}

\section{Estrutura geral}

A Guarda compreende:

a) A estrutura de comando;

b) As unidades;

c) O estabelecimento de ensino.

\section{Artigo 21.}

Estrutura de comando

1 - A estrutura de comando compreende:

a) O Comando da Guarda;

b) Os órgãos superiores de comando e direcção.

2 - O Comando da Guarda compreende:

a) O comandante-geral;

b) $\mathrm{O} 2 .^{\circ}$ comandante-geral; c) $\mathrm{O}$ órgão de inspecção;

d) Os órgãos de conselho;

e) A Secretaria-Geral.

3 - São órgãos superiores de comando e direcção:

a) O Comando Operacional (CO);

b) O Comando da Administração dos Recursos Internos (CARI);

c) O Comando da Doutrina e Formação (CDF).

\section{Artigo 22.}

Unidades e estabelecimento de ensino

1 - Na Guarda existem as seguintes unidades:

a) O Comando-Geral;

b) Territoriais, os comandos territoriais;

c) Especializadas, a Unidade de Controlo Costeiro (UCC), a Unidade de Acção Fiscal (UAF) e a Unidade Nacional de Trânsito (UNT);

d) De representação, a Unidade de Segurança e Honras de Estado (USHE);

e) De intervenção e reserva, a Unidade de Intervenção (UI).

2 - Podem ser constituídas unidades para actuar fora do território nacional, nos termos da lei.

3 - O estabelecimento de ensino da Guarda é a Escola da Guarda (EG).

\section{CAPÍTULO II}

\section{Estrutura de comando}

\section{SECĊ̃̃O 1 \\ Comando da Guarda}

Artigo $23 .^{\circ}$

Comandante-geral

1 - O comandante-geral é um tenente-general nomeado por despacho conjunto do Primeiro-Ministro, do ministro da tutela e do membro do Governo responsável pela área da defesa nacional, ouvido o Conselho de Chefes de Estado-Maior se a nomeação recair em oficial general das Forças Armadas.

2 - O comandante-geral é o responsável pelo cumprimento das missões gerais da Guarda, bem como de outras que the sejam cometidas por lei.

3 - Além das competências próprias dos cargos de direcção superior de $10^{\circ}$ grau, compete ao comandante-geral:

a) Exercer o comando completo sobre todas as forças e elementos da Guarda;

b) Representar a Guarda;

c) Exercer o poder disciplinar;

d) Atribuir a condecoração prevista no artigo $8 .^{\circ}$;

e) Propor ao ministro da tutela a requisição ao membro do Governo responsável pela área da defesa nacional do pessoal dos ramos das Forças Armadas necessários à Guarda;

f) Mandar executar as operações de recrutamento do pessoal necessário aos quadros da Guarda; 
ii) Apreciação das promoções a oficial general;

iii) Outras questões de elevada sensibilidade e importância para a Guarda que sejam submetidas à sua apreciação pelo comandante-geral;

c) Exercer as competências previstas no Estatuto dos Juizes Militares e dos Assessores Militares do Ministério Público e as demais que lhe forem legalmente cometidas.

6 - Compete ao CSG em composição alargada aprovar o seu regimento e emitir parecer sobre:

a) O plano e relatório de actividades da Guarda;

b) Questões relevantes para a Guarda, designadamente em matéria de organização e estatuto do pessoal;

c) Listas de promoção por escolha e outros assuntos relativos a promoções, nos termos do Estatuto dos Militares da Guarda;

d) Quaisquer outros assuntos que sejam submetidos à sua apreciação pelo comandante-geral.

7 - Em matéria de promoções, só pode participar na discussão e votação o pessoal de graduação igual ou superior à do posto para o qual a promoção se deva efectuar.

Artigo 29.

Conselho de Ética, Deontologia e Disciplina

1 - O CEDD é o órgão de consulta do comandante-geral em matéria de justiça e disciplina.

2 - O CEDD tem a seguinte composição:

a) $\mathrm{O}$ comandante-geral;

b) $\mathrm{O} 2 .^{\circ}$ comandante-geral;

c) $\mathrm{O}$ inspector da Guarda;

d) Os comandantes dos órgãos superiores de comando e direcção;

e) Os comandantes das unidades especializadas, de representação, de intervenção e reserva e do estabelecimento de ensino;

f) Os comandantes de cinco unidades territoriais;

g) O director do serviço responsável pela área de recursos humanos;

h) Representantes das categorias profissionais de oficiais, sargentos e guardas, eleitos nos termos a definir por portaria do ministro da tutela.

\section{3 - Compete ao CEDD emitir parecer sobre:}

a) A aplicação das penas disciplinares de reforma compulsiva e de separação de serviço e da medida estatutária de dispensa de serviço;

b) Recursos disciplinares de revisão;

c) Quaisquer outros assuntos do âmbito da ética ou disciplina que sejam submetidos à sua apreciação pelo comandante-geral.

4-O regulamento de funcionamento do CEDD é aprovado por despacho do ministro da tutela.

\section{Artigo 30.}

\section{Junta Superior de Saúde}

1 - A JSS é o órgão a que compete julgar o grau de capacidade para o serviço de oficiais, sargentos e guardas aue. bor ordem do comandante-geral. lhe forem presentes. bem como emitir parecer sobre os recursos relativos a decisões baseadas em pareceres formulados pelas juntas médicas da Guarda.

2 - A JSS é constituída por três médicos nomeados pelo comandante-geral, que designa, de entre eles, o presidente.

3 - Quando funcionar como junta de recurso, a JSS é composta por dois médicos designados pelo comandante-geral, que não tenham intervindo anteriormente no processo, e por um médico escolhido pelo requerente, o qual, não sendo indicado no prazo que para o efeito for fixado pelo comandante-geral, é substituido pelo médico que este designar.

\section{Artigo $31 .^{\circ}$}

\section{Secretaria-Geral da Guarda}

1 - A SGG é responsável pela elaboração e publicação da Ordem à Guarda e da Ordem de Serviço do Comando-Geral, competindo-lhe, ainda, assegurar o apoio e o enquadramento administrativo de todo o pessoal, a recepção, expedição e arquivo de toda a correspondência, a administração e o controlo das instalações, dos equipamentos e demais material e o normal funcionamento da unidade Comando-Geral.

2 - A SGG pode, ainda, prestar apoio administrativo a outras unidades da Guarda.

3 - Compete, ainda, à SGG assegurar o funcionamento da Biblioteca, do Museu e Arquivo Histórico e da Revista da Guarda.

\section{SECCC̃̃O II}

\section{Órgãos superiores de comando e direcçāo}

Artigo $32{ }^{\circ}$

Comando Operacional

1 - O CO assegura o comando de toda a actividade operacional da Guarda.

2 - O comandante do $\mathrm{CO}$ é um tenente-general, nomeado pelo ministro da tutela, sob proposta do comandante-geral da Guarda.

3 - O CO compreende as áreas de operações, informações, investigação criminal, protecção da natureza e do ambiente e missões internacionais.

4 - O comandante do $\mathrm{CO}$ tem sob o seu comando directo, para efeitos operacionais, as unidades territoriais, especializadas, de representação e de intervenção e reserva.

5 - O comandante do $\mathrm{CO}$ pode constituir comandos eventuais para operações de âmbito nacional ou regional, quando tal se justificar.

6 - O comandante do $\mathrm{CO}$ é coadjuvado por um major-general, nomeado pelo comandante-geral.

\section{Artigo $330^{\circ}$}

\section{Comando da Administração dos Recursos Internos}

1 - O CARI assegura o comando e direcção de toda a actividade da Guarda nos domínios da administração dos recursos humanos, materiais e financeiros.

2 - O comandante do CARI é um major-general, nomeado pelo comandante-geral. 
especialmente beneficiem com aquela actividade, nos termos a regular em diploma próprio.

\section{TÍTULO IV}

\section{Disposições complementares, transitórias e finais}

\section{Artigo 51.}

\section{Estruturas portuárias}

As atribuições cometidas à Guarda em matéria de vigilância e protecção de estruturas portuárias não prejudicam o exercício das atribuições legalmente previstas de outras entidades, designadamente a Autoridade Maritima Nacional, em matéria de protecção do transporte marítimo e dos portos.

\section{Artigo 52.}

\section{Disposiçôes transitórias}

1 - As atribuições cometidas à Guarda pela presente lei em matéria de vigilância, protecção e segurança de infra-estruturas aeroportuárias não prejudicam a competência atribuída à Polícia de Segurança Pública nos aeroportos internacionais actualmente existentes.

2 - A organização e funcionamento dos serviços sociais são regulados por diploma próprio.

3 - Para efeitos dos quadros anexos A e B do Regulamento de Disciplina da Guarda Nacional Republicana, aprovado pela Lei n. ${ }^{\circ} 145 / 99$, de 1 de Setembro, são estabelecidas as seguintes equiparações:

a) Comandante do Comando Operacional, comandante do Comando de Administração de Recursos Internos e comandante do Comando de Doutrina e Formação a chefe de estado-maior;

b) Comandante de estabelecimento de ensino a comandante de unidade;

c) $2 .^{\circ}$ comandante e director de instrução de estabelecimento de ensino a comandante de agrupamento ou de grupo destacados.

\section{Artigo 53, \\ Regulamentação}

1 - São regulados por diploma próprio:

a) A aplicação de taxas e a cobrança de despesas a cargo de entidades que especialmente beneficiem com a actividade da Guarda;

b) $\mathrm{O}$ estatuto remuneratório do comandante-geral

2 - É regulada por decreto regulamentar a prossecução pela Guarda na zona contigua da atribuição prevista na alinea $d$ ) do n. $^{\circ} 2$ do artigo $3 .^{\circ}$ bem como a articulação entre a Guarda e a Autoridade Marítima Nacional, no tocante às atribuições previstas nas alíneas $c$ ), e) e $f$ ) do mesmo número.

3 - São regulados por portaria conjunta do ministro da tutela e do membro do Governo responsável pela área das finanças os termos da ligação funcional entre a Unidade de Acção Fiscal e o Ministério das Finanças prevista no n. ${ }^{\circ} 2$ do artigo $13 .^{\circ}$

4 - A prestação e o pagamento dos serviços requisitados à Guarda nos termos dos artigos $17 .^{\circ} \mathrm{e} 18^{\circ}$ da presente lei são objecto de portaria conjunta do ministro da tutela, do membro do Governo responsável pela área das finanças e, quando aplicável, do membro do Governo com a tutela da entidade requisitante.

5 - $\mathrm{O}$ número, as competências, a estrutura interna e 0 posto correspondente à chefia dos serviços de apoio directamente dependentes do comandante-geral e dos serviços dos órgãos superiores de comando e direcção são definidos por decreto regulamentar.

6 - São determinados por portaria do ministro da tutela:

a) A área de responsabilidade da Guarda, no caso de atribuições simultaneamente cometidas à Polícia de Segurança Pública, bem como das unidades territoriais e respectivas subunidades;

b) Os símbolos e condecoração previstos no artigo $8 .^{\circ}$, bem como o regulamento de atribuição desta;

c) As condições em que o pessoal militar da Guarda pode ser afecto a organismos de interesse público;

d) Os termos a que obedece a eleição dos representantes dos oficiais, sargentos e guardas no CSG e no CEDD;

e) A criação e extinção de subunidades das unidades territoriais, especializadas, de representação e de intervenção e reserva;

f) A criação e extinção e o funcionamento dos serviços das unidades territoriais, bem como do estabelecimento de ensino;

g) Os termos em que se processa o apoio administrativo das unidades, especializadas, de representação e de intervenção e reserva pelos serviços do CARI e da SGG.

7 - São regulados por despacho do ministro da tutela:

a) Os tipos de armas em uso pela Guarda, bem como as regras do respectivo emprego;

b) $\mathrm{O}$ regulamento da $\mathrm{IG}$;

c) O regulamento de funcionamento do CEDD.

\section{Artigo $54 .^{\circ}$ \\ Norma revogatória}

É revogado o Decreto-Lei n. ${ }^{\circ} 231 / 93$, de 26 de Junho, com excepção:

a) Dos artigos $29 .^{\circ}$ e $30 .^{\circ}$, cuja revogação produz efeitos com a entrada em vigor de uma nova lei de segurança interna;

b) Dos artigos $33 .^{\circ}, 92 .^{\circ}$ e $94 .^{\circ}$, cuja revogação produz efeitos com a entrada em vigor de um novo Estatuto dos Militares da Guarda.

\section{Artigo 55. \\ Entrada em vigor}

A presente lei entra em vigor no prazo de 30 dias, com excepção do artigo $53 .^{\circ}$, que entra em vigor no dia seguinte ao da publicação.

Aprovada em 19 de Setembro de 2007. Gama.

O Presidente da Assembleia da República, Jaime

Promulgada em 19 de Outubro de 2007.

Publique-se.

O Presidente da República, Anibal Cavaco Silva.

Referendada em 25 de Outubro de 2007.

O Primeiro-Ministro, José Sócrates Carvalho Pinto de Sousa. 


\section{ANEXO C-Posição da Guarda Nacional Republicana no Sistema}

Nacional de Forças

FORÇAS MILITARES

FORÇAS DE SEGURANÇA

SERVIÇOS DE SEGURANÇA

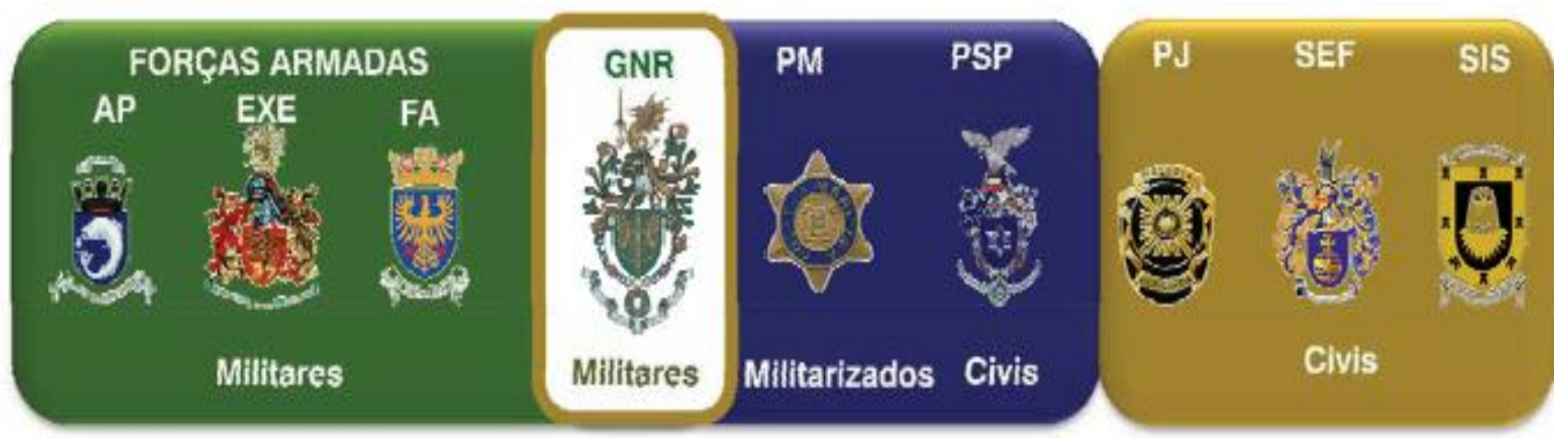

Fonte: GNR - Plano de Atividades da GNR de 2011. 
ANEXO D Estrutura do Comando

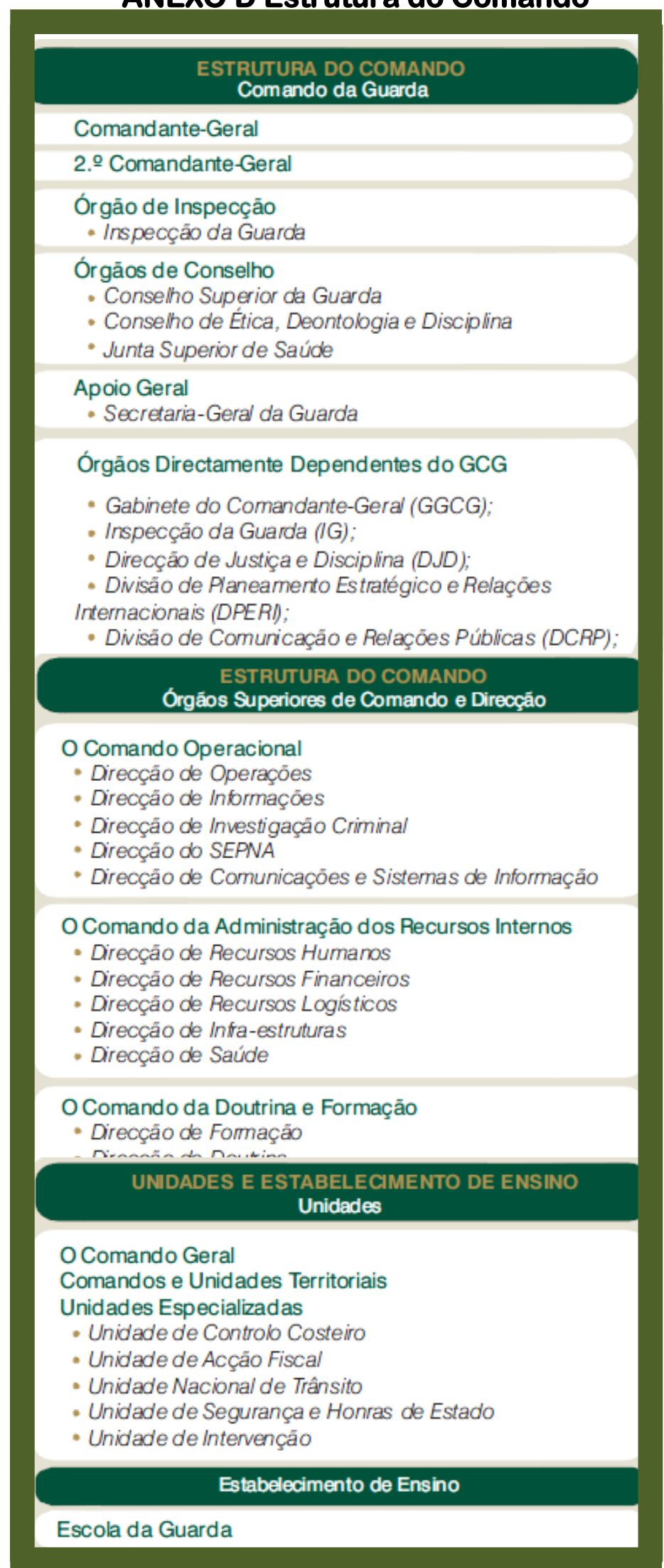

Fonte: GNR - Plano de Atividades da GNR de 2011 


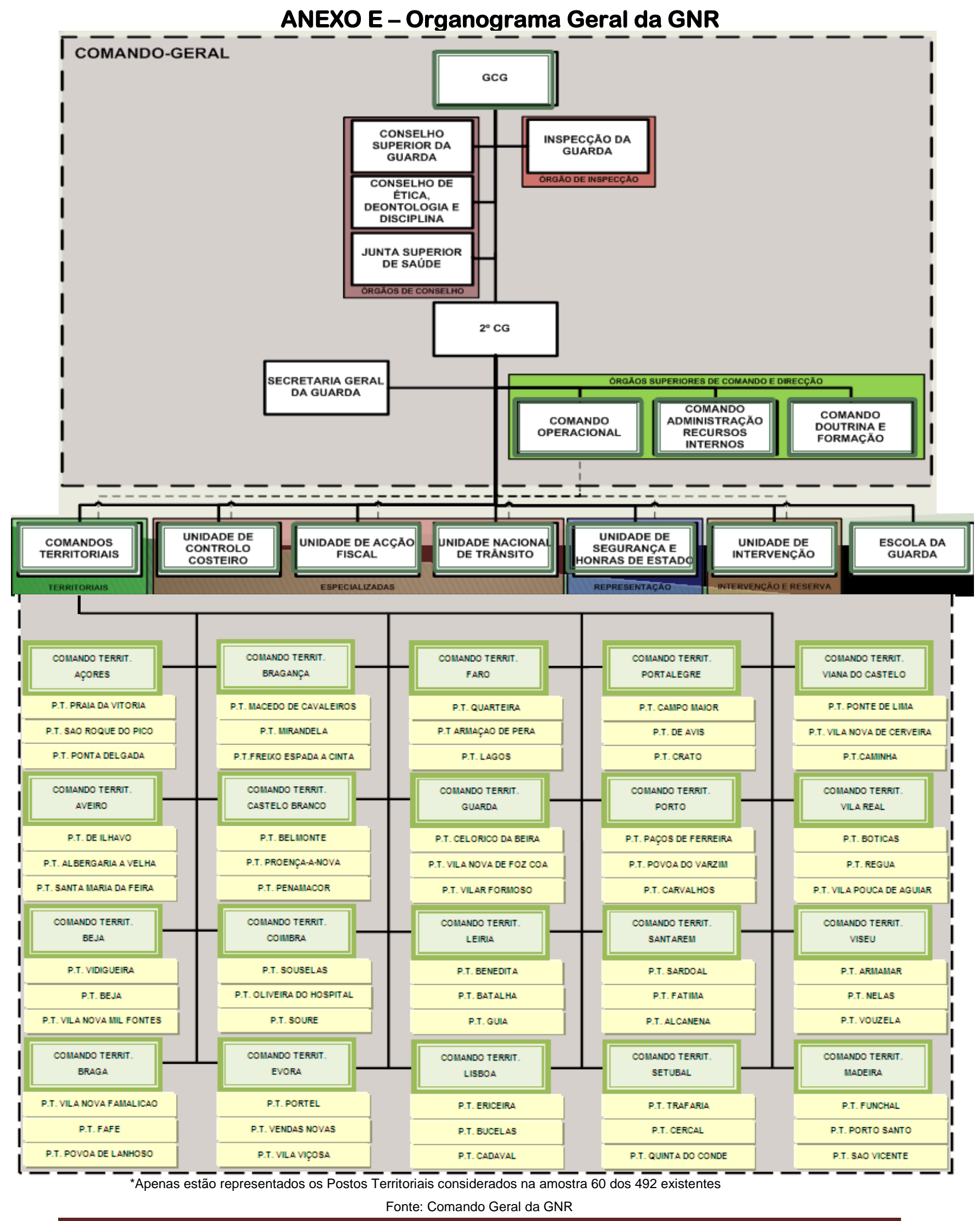

A Comunicação Interna na Guarda Nacional Republicana

Página 121 


\title{
Anexo F - Folheto de Informação Interna de 1974
}

Folheto de informação Interna de 29/05/1974 dirigido aos militares da GNR.

\author{
QUEM NOS ATACA, ATACA O DOVO
}

\section{OS HOMENS DA GNR AJUDAM A CONSTRUIR 0 PORTUGAL NOVO}

\section{AOS MILITARES DA GNR}

Algumas atitudes hostis para com a GNR têm levantado dúvidas entre o Pessoal. Importa lembrar que não é possível a GNR deixar de ter inimigos quando ela procura fazer cumprir as Leis àqueles para quem as Leis são obstáculos.

QUE A PRESENÇA DA GNR SEJA EM TODA A PARTE UMA PRESENÇA AMIGA, ÚTIL E VIGILANTE

DA ORDEM E DA TRANQUILIDADE DE TODOS OS PORTUGUESES

Quando Portugal procura construir uma Ordem Nova, em que haja mais liberdade, mais igualdade, mais prosperidade e mais justiça, a GNR é mais precisa do que nunca.

O Povo Português, cuja sabedoria é grande, não precisa de jornais, rádio e TV para conhecer os serviços da GNR e saber quanto deles necessita. O Povo quer a GNR.

Só uma minoria, muito barulhenta mas que daí não passa, ataca a GNR. Mil pessoas a fazer barulho parecem mais do que um milhão delas caladas. Mas estas são mil vezes mais do que aquelas. Oito milhões de portugueses sensatos estimam a GNR.

Mas nunca esqueça de que na GNR de que Portugal precisa e que o Povo quer só podem estar Homens, amigos dos outros Homens, educados e competen. tes seja em que circunstâncias fôr.

QUEM NOS ATACA, ATACA O POVO

SÓ OS ANARQUISTAS NOS ATACAM

A GNR ORGULHA-SE DO 25 de ABRIL

PORTUGAL PRECISA DA GNR

O POVO QUER A GNR

OS HOMENS DA GNR MANTÊM-SE SERENOS E FIRMES

ONRICOR. REP $-29 \mathrm{MNH} 4-\Lambda_{\mathrm{p}} \mathrm{s}$

Fonte: ANDRADE Nuno (2011), 100 anos Guarda Nacional Republicana (1911-2011), Editora Guerra \& Paz S.A. 
ANEXO G - Dispersão e ocupação territorial dos postos da Guarda

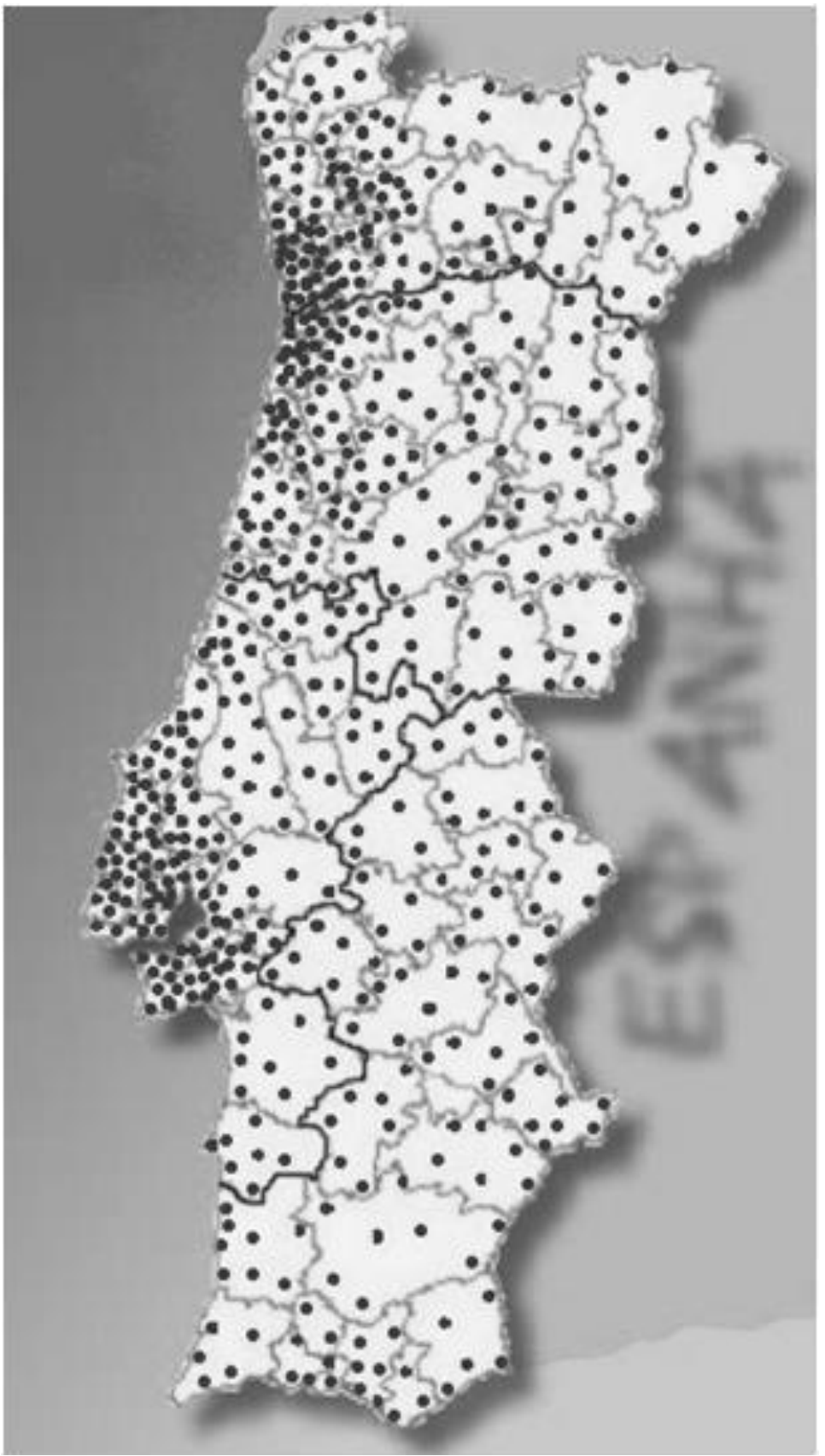




\section{Anexo H - Relação dos Comandos Territoriais e Postos da GNR}

estudados:

\section{COMANDO TERRITORIAL DE AVEIRO}

1. POSTO TERRITORIAL DE ILHAVO

2. POSTO TERRITORIAL DE ALBERGARIA-A-VELHA

3. POSTO TERRITORIAL DE SANTA MARIA DA FEIRA

\section{COMANIDO TERRITORIAL DE BEJA}

4. POSTO TERRITORIAL DE VIDIGUEIRA

5. POSTO TERRITORIAL DE BEJA

6. POSTO TERRITORIAL DE VILA NOVA DE MILFONTES

\section{COMANIDO TERRITORIAL DE BRAGA}

7. POSTO TERRITORIAL DE VILA NOVA FAMALICÃO

8. POSTO TERRITORIAL DE FAFE

9. POSTO TERRITORIAL DE PÓVOA DE LANHOSO

COMANDO TERHITORIAL DE BRAGANÇA

10. POSTO TERRITORIAL DE MACEDO DE CAVALEIROS

11. POSTO TERRITORIAL DE MIRANDELA

12. POSTO TERRITORIAL DE FREIXO DE ESPADA À CINTA

COMANDO TERRITORIAL DE CASTELO BRANCO

13. POSTO TERRITORIAL DE BELMONTE

14. POSTO TERRITORIAL DE PROENÇA-A-NOVA

15. POSTO TERRITORIAL DE PENAMACOR

\section{COMANDO TERRITORIAL DE COIMBRA}

16. POSTO TERRITORIAL DE SOUSELAS

17. POSTO TERRITORIAL DE OLIVEIRA DO HOSPITAL

18. POSTO TERRITORIAL DE SOURE

\section{COMANDO TERRITORIAL DE ÉVORA}

19. POSTO TERRITORIAL DE PORTEL

20. POSTO TERRITORIAL DE VENDAS NOVAS

21. POSTO TERRITORIAL DE VILA VIÇOSA 


\section{COMANIDO TERRITORIAL DE FARO}

22. POSTO TERRITORIAL DE QUARTEIRA

23. POSTO TERRITORIAL DE ARMAÇÃO DE PÊRA

24. POSTO TERRITORIAL DE LAGOS

COMANDO TERRITORIAL DA GUARIA

25. POSTO TERRITORIAL DE CELORICO DA BEIRA

26. POSTO TERRITORIAL DE VILA NOVA DE FOZ CÔA

27. POSTO TERRITORIAL DE VILAR FORMOSO

\section{COMANDO TERRITORIAL DE LEIRIA}

28. POSTO TERRITORIAL DE BENEDITA

29. POSTO TERRITORIAL DE BATALHA

30. POSTO TERRITORIAL DE GUIA

COMANDO TERRITORIAL DE LISBA

31. POSTO TERRITORIAL DE ERICEIRA

32. POSTO TERRITORIAL DE BUCELAS

33. POSTO TERRITORIAL DE CADAVAL

COMANDO TERRITORIAL DE PORTALEGRE

34. POSTO TERRITORIAL DE CAMPO MAIOR

35. POSTO TERRITORIAL DE AVIS

36. POSTO TERRITORIAL DE CRATO

COMANDO TERRITORIAL DE PORTO

37. POSTO TERRITORIAL DE PAÇOS DE FERREIRA

38. POSTO TERRITORIAL DE PÓVOA DO VARZIM

39. POSTO TERRITORIAL DE CARVALHOS

\section{COMANDO TERRITORIAL DE SANTARÉM}

40. POSTO TERRITORIAL DE SARDOAL

41. POSTO TERRITORIAL DE FÁTIMA

42. POSTO TERRITORIAL DE ALCANENA

\section{COMANIDO TERRITORIAL DE SETÚBAL}

43. POSTO TERRITORIAL DE TRAFARIA

44. POSTO TERRITORIAL DE CERCAL

45. POSTO TERRITORIAL DE QUINTA DO CONDE 
COMANDO TERRITORIAL DE VIANA DO CASTELO

46. POSTO TERRITORIAL DE PONTE DE LIMA

47. POSTO TERRITORIAL DE VILA NOVA DE CERVEIRA

48. POSTO TERRITORIAL DE CAMINHA

\section{COMANDO TERRITORIAL DE VILA REAL}

49. POSTO TERRITORIAL DE BOTICAS

50. POSTO TERRITORIAL DE RÉGUA

51. POSTO TERRITORIAL DE VILA POUCA DE AGUIAR

\section{COMANIDO TERRITORIAL IDE VISEU}

52. POSTO TERRITORIAL DE ARMAMAR

53. POSTO TERRITORIAL DE NELAS

54. POSTO TERRITORIAL DE VOUZELA

\section{COMANDO TERRITORIAL DE AÇORES}

55. POSTO TERRITORIAL DA PRAIA DA VITÓRIA (TERCEIRA)

56. POSTO TERRITORIAL DE SÃO ROQUE DO PICO

57. POSTO TERRITORIAL DE PONTA DELGADA (SÃO MIGUEL)

\section{COMANIDO TERRITORIAL IE MADEIRA}

58. POSTO TERRITORIAL DO FUNCHAL

59. POSTO TERRITORIAL DE PORTO SANTO

60. POSTO TERRITORIAL DE SÃO VICENTE 